\title{
Conceptual Design Report for the Irradiated Materials Characterization Laboratory (IMCL)
}

\author{
S. L. Austad \\ R. C. Bohachek \\ L. A. Bumb \\ L. L. Burke \\ D. W. Craig \\ B. A. Hilton \\ D. H. James \\ K. T. Kennedy \\ C. J. Knight \\ S. Marschman \\ C. W. McKnight \\ D. E. Nishioka \\ M. T. Owens \\ K. B. Phillips \\ R. D. Seifert \\ M. D. Varvel Zolynski
}

June 2010

The INL is a U.S. Department of Energy National Laboratory operated by Battelle Energy Alliance 


\section{DISCLAIMER}

This information was prepared as an account of work sponsored by an agency of the U.S. Government. Neither the U.S. Government nor any agency thereof, nor any of their employees, makes any warranty, expressed or implied, or assumes any legal liability or responsibility for the accuracy, completeness, or usefulness, of any information, apparatus, product, or process disclosed, or represents that its use would not infringe privately owned rights. References herein to any specific commercial product, process, or service by trade name, trade mark, manufacturer, or otherwise, does not necessarily constitute or imply its endorsement, recommendation, or favoring by the U.S. Government or any agency thereof. The views and opinions of authors expressed herein do not necessarily state or reflect those of the U.S. Government or any agency thereof. 


\section{Conceptual Design Report for the Irradiated Materials Characterization Laboratory (IMCL)}

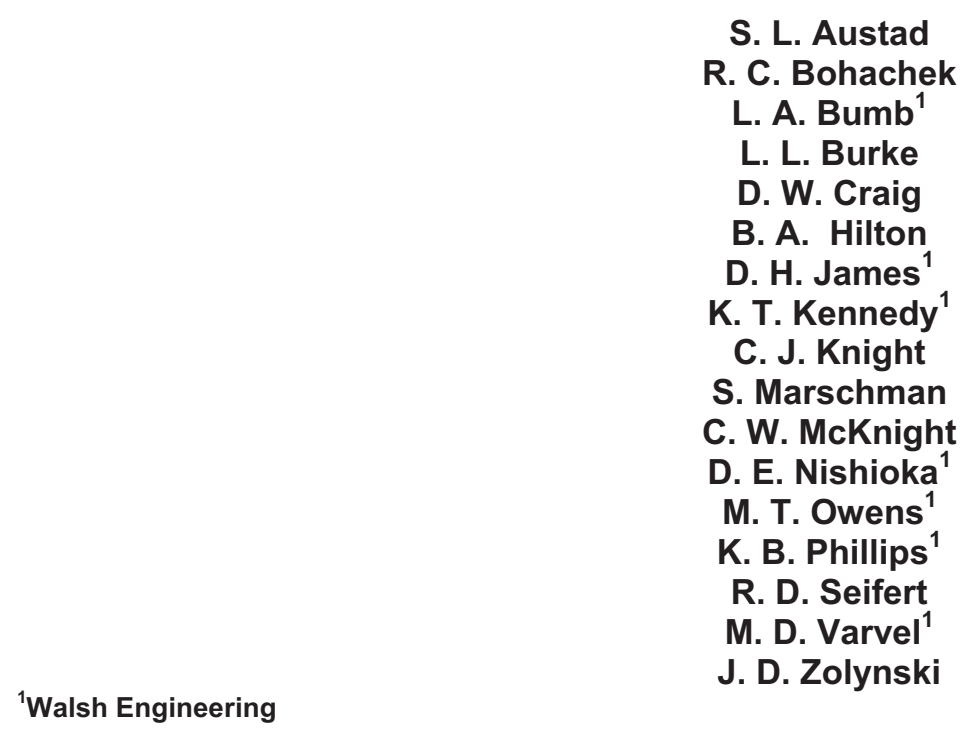

June 2010

\section{Idaho National Laboratory \\ Next Generation Nuclear Plant Project Idaho Falls, Idaho 83415}

http://www.inl.gov

Prepared for the

U.S. Department of Energy

Office of Nuclear Energy

Under DOE Idaho Operations Office

Contract DE-AC07-05ID14517 



\section{Conceptual Design Report for the Irradiated Materials Characterization Laboratory (IMCL)}

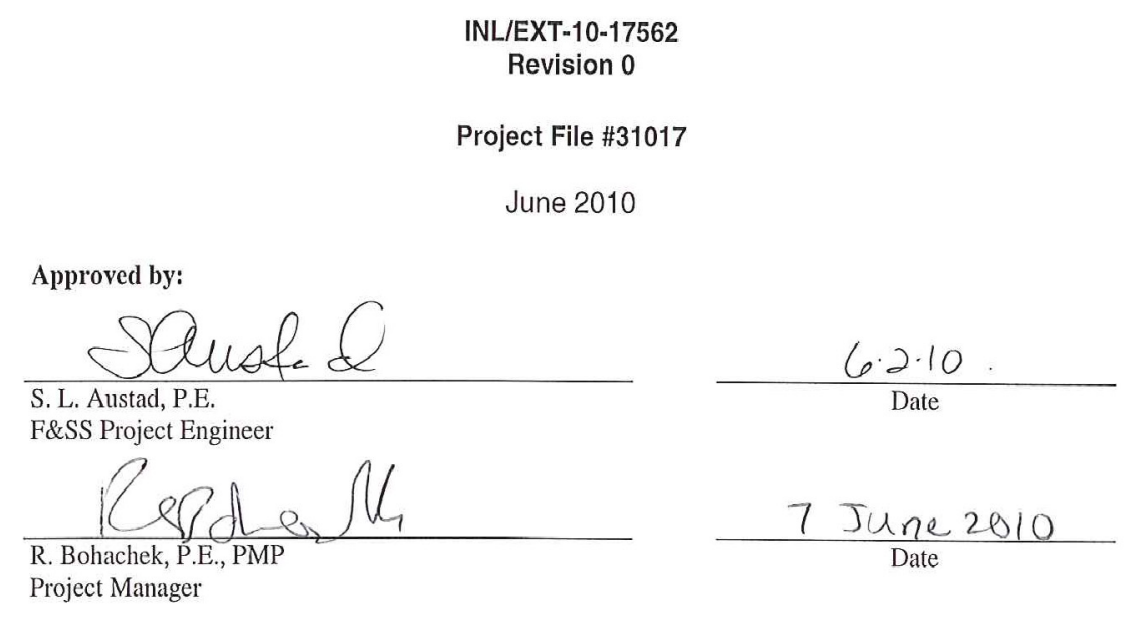


The following Conceptual Design was prepared under the responsible charge of the Professional Engineers as indicated by the seals and signatures provided on this page.
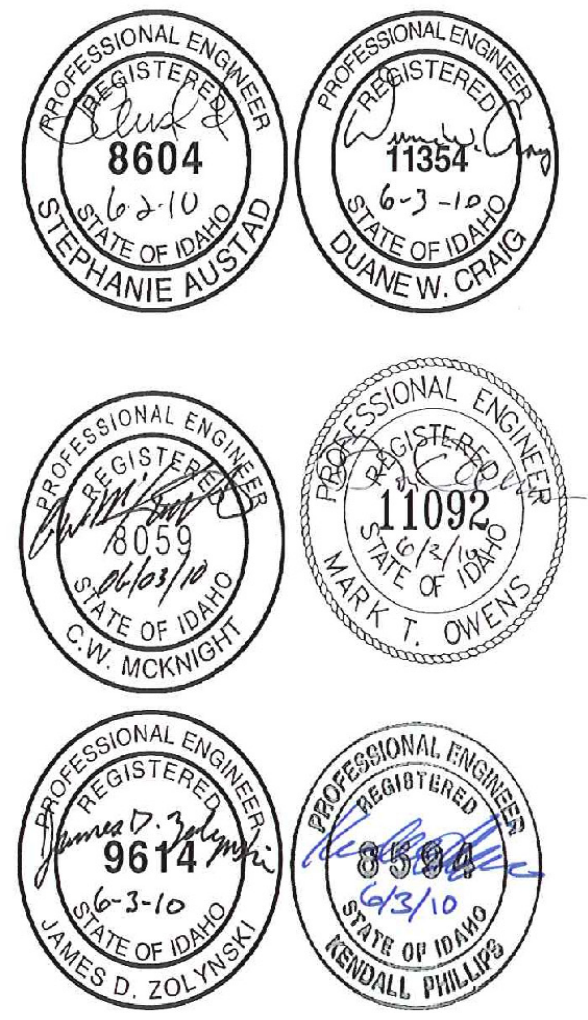


\section{CONTENTS}

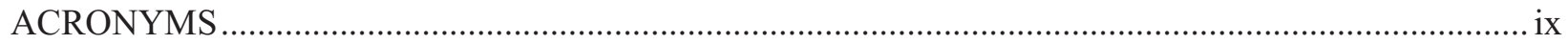

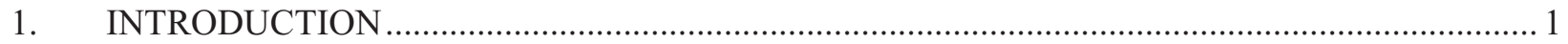

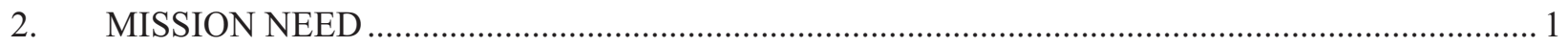

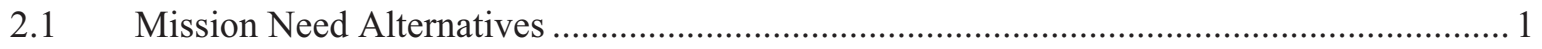

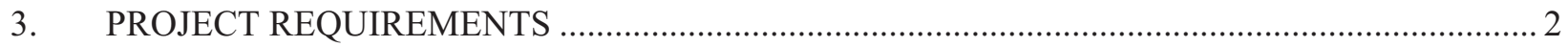

3.1 Technical and Functional Requirements .................................................................... 2

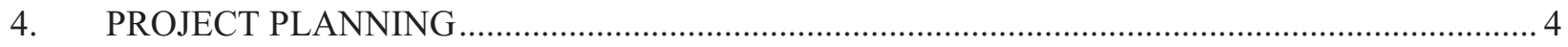

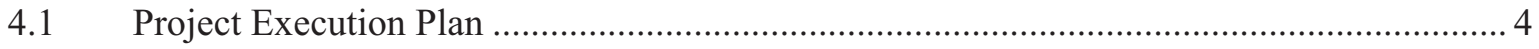

4.2 Work/Organizational Breakdown Structure .................................................................. 4

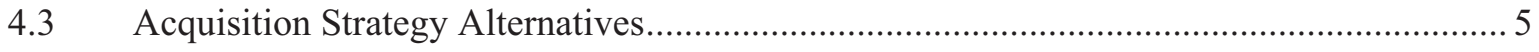

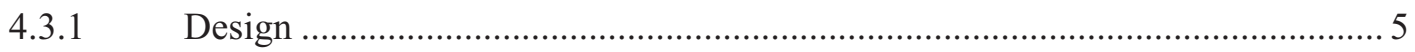

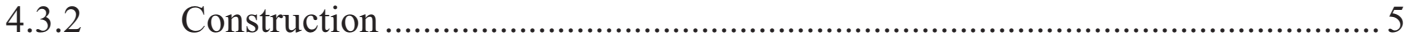

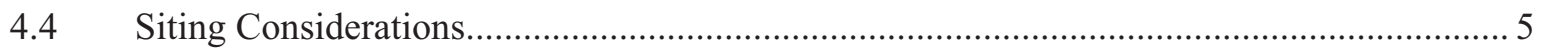

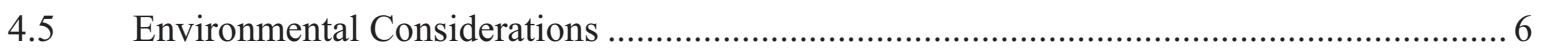

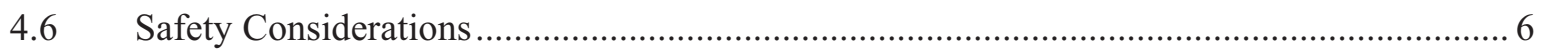

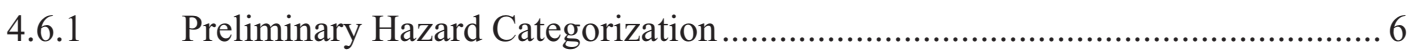

4.6.2 Safety Analysis Approach and Plan ........................................................... 7

4.6.3 Seismic and Other Natural Phenomena Design Category ................................... 7

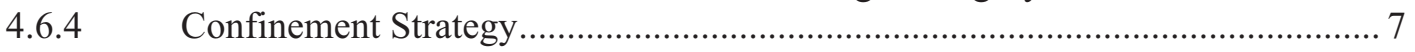

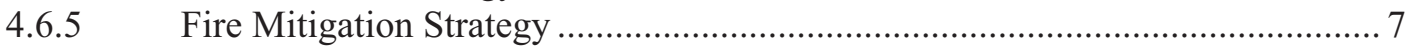

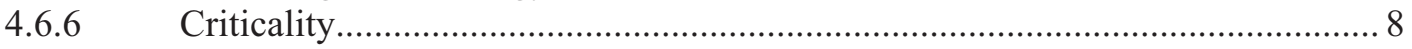

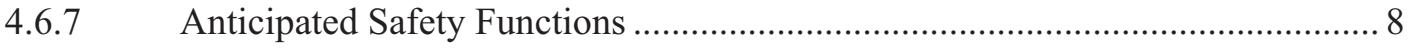

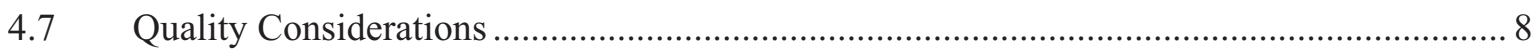

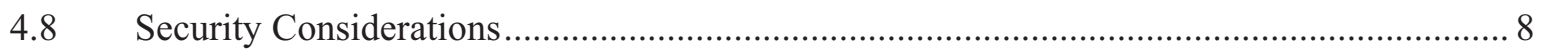

$4.9 \quad$ High-Performance Sustainable Building Considerations ............................................ 8

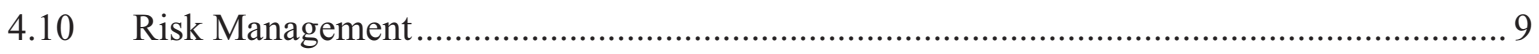

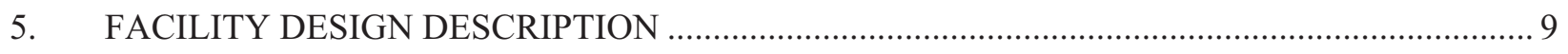

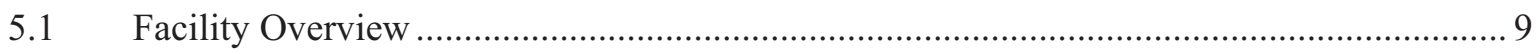

5.1.1 General Personnel and Equipment Traffic Flow .......................................... 10 


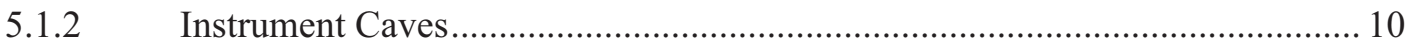

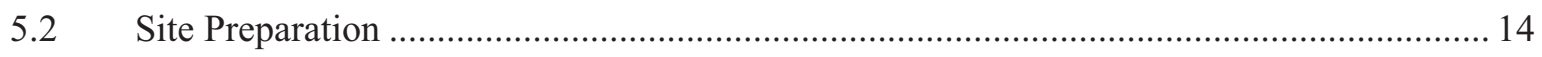

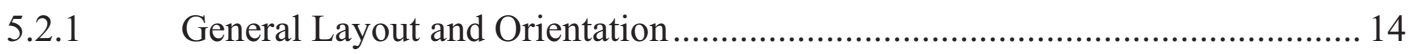

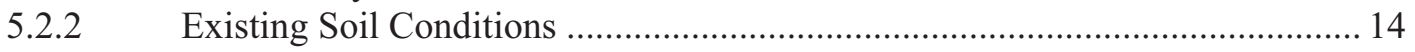

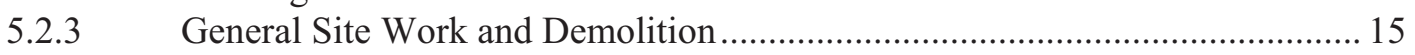

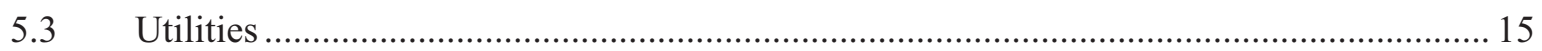

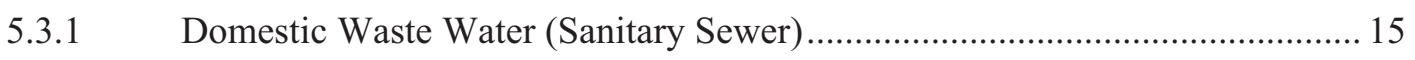

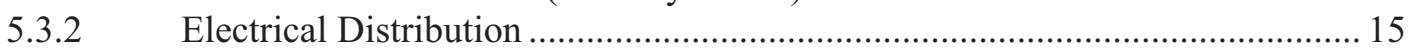

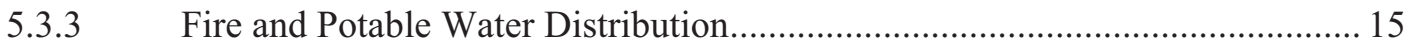

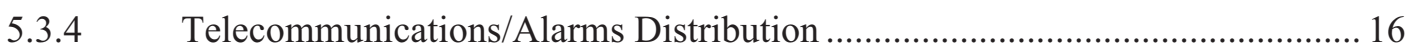

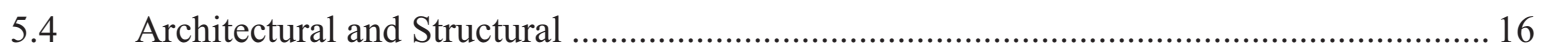

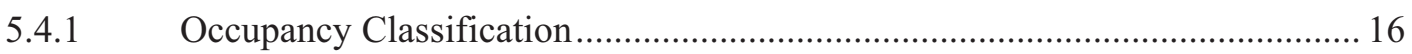

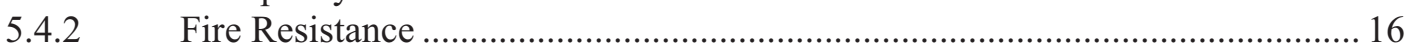

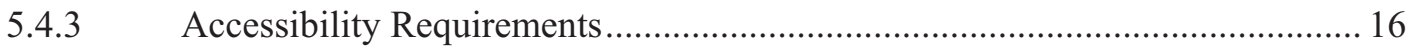

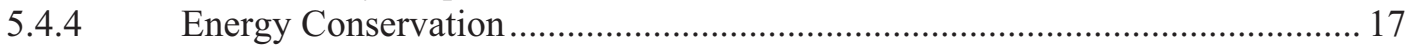

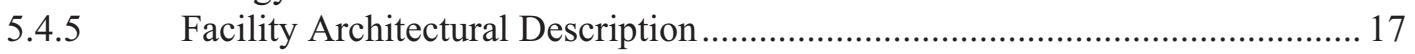

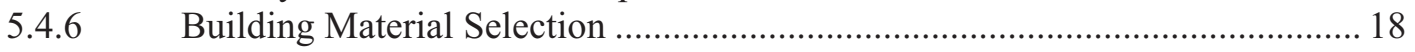

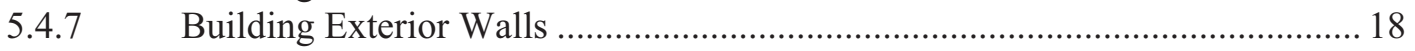

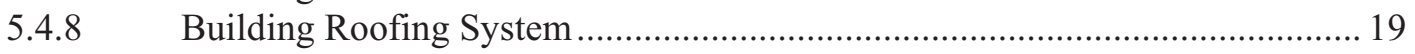

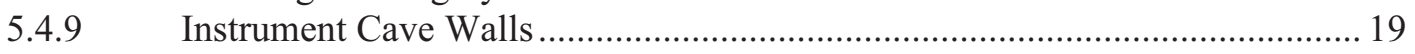

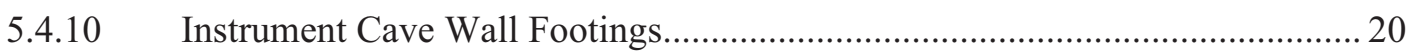

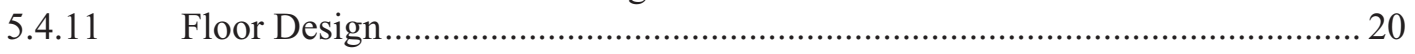

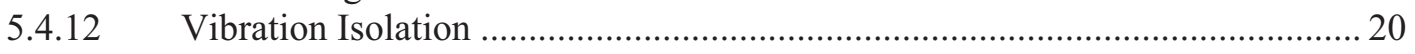

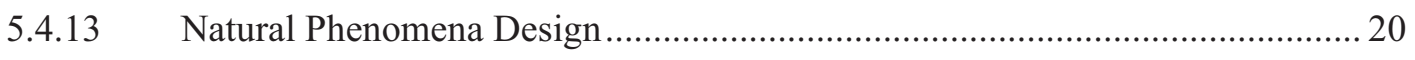

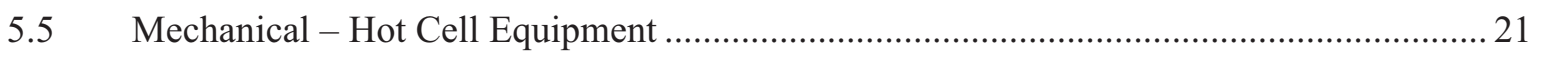

5.5.1 Inter-building Pneumatic Transfer System ............................................... 21

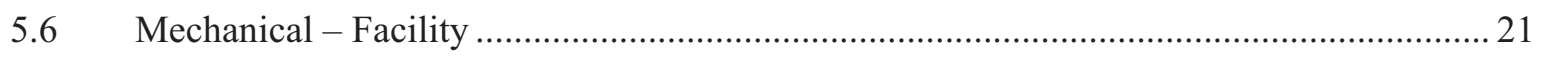

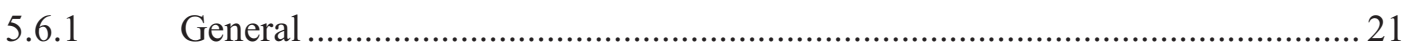

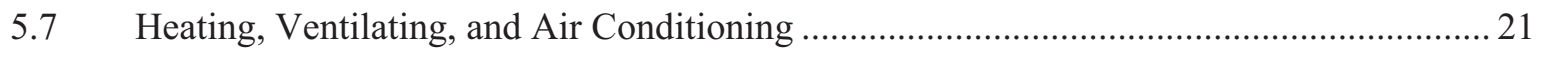

5.7.1 Laboratory Heating, Ventilating, and Air Conditioning ................................. 21

5.7.2 Office Area Heating, Ventilating, and Air Conditioning ................................. 22

5.7.3 Heating, Ventilating, and Air Conditioning System (Telecommunications/

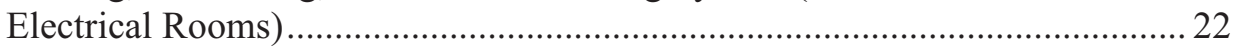

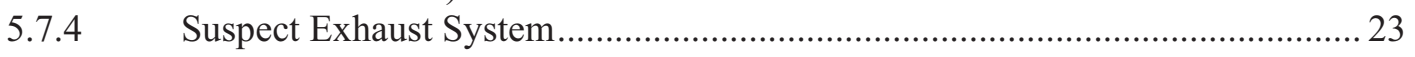

5.7.5 Exhaust Stack and Emissions Monitoring Capability ................................... 23

5.7.6 Heating, Ventilating, and Air Conditioning Controls ..................................... 24

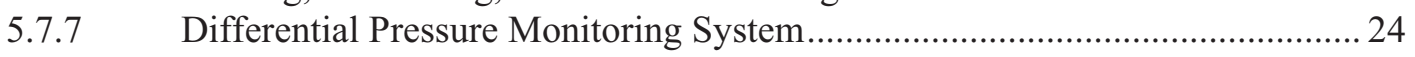

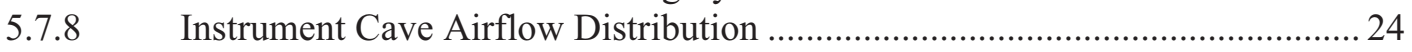

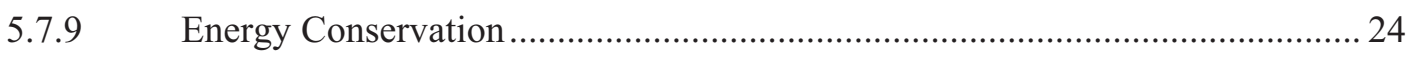




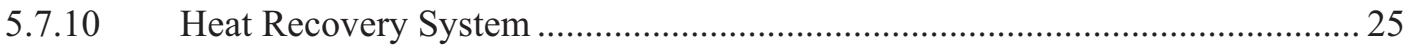

5.7.11 Water Use Reduction and Energy Efficiency............................................... 25

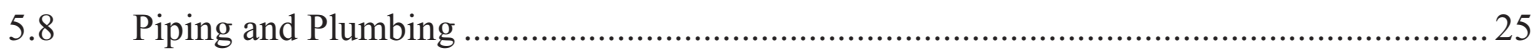

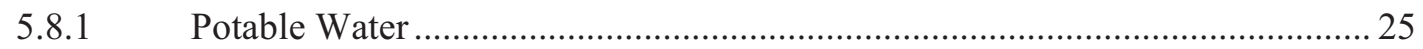

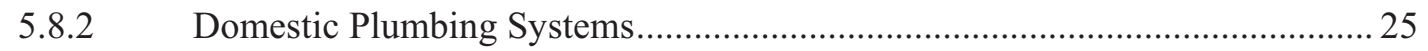

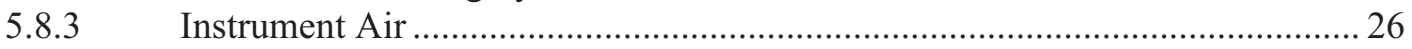

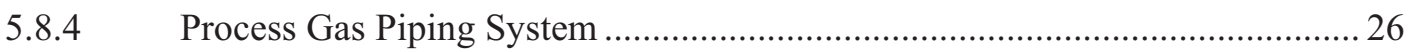

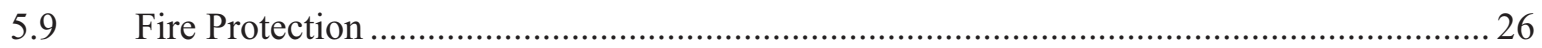

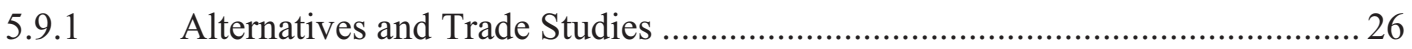

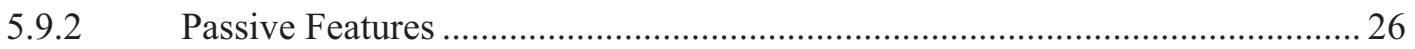

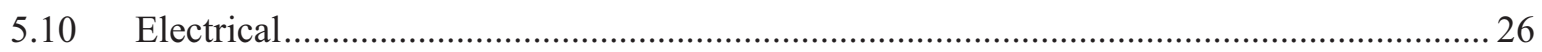

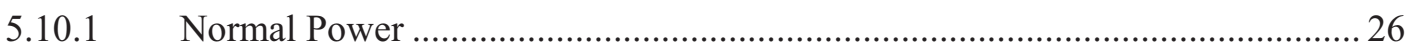

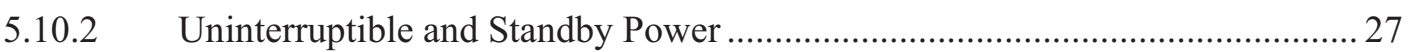

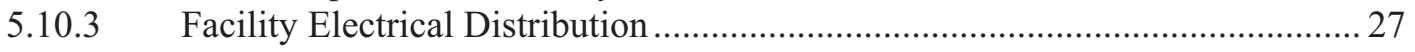

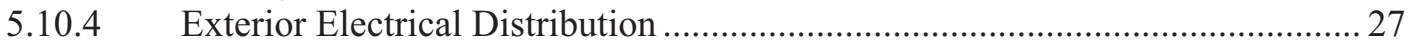

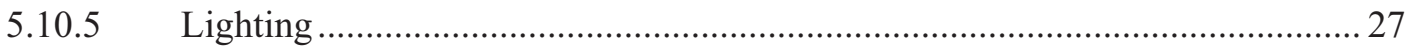

5.10.6 Construction Methods for Mitigating Alternating Current Extremely Low Frequency Magnetic Fields ..................................................................... 28

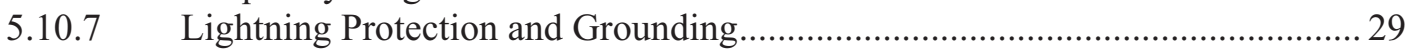

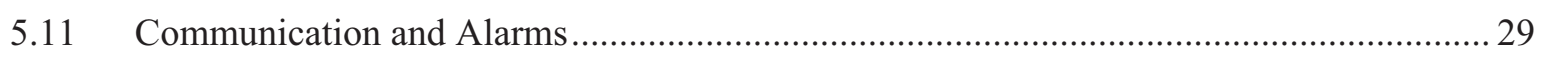

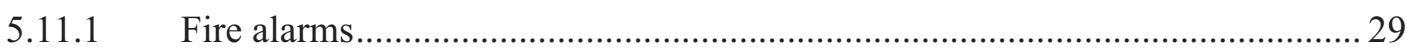

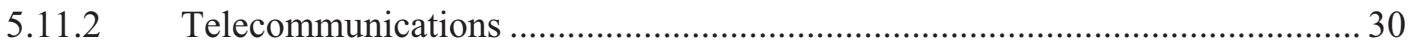

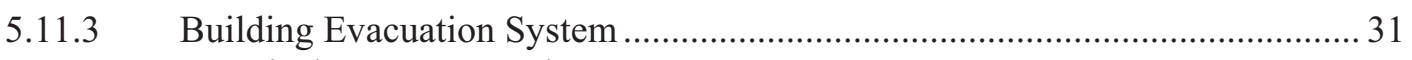

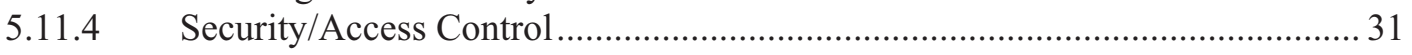

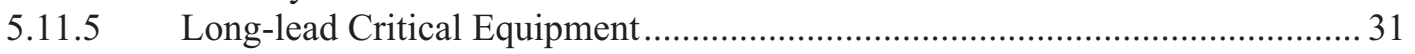

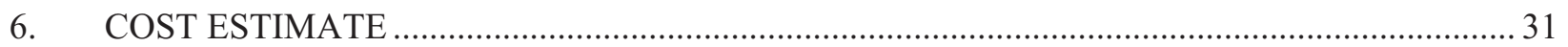

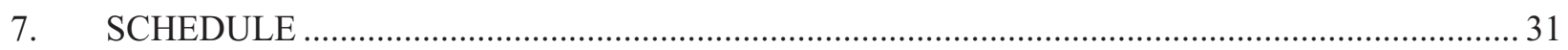

\section{FIGURES}

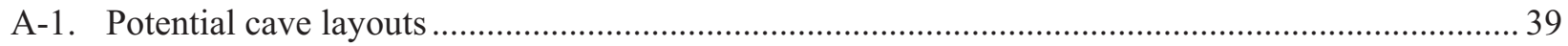

A-2. MFC-799, Sodium Processing Facility, floor plan with potential cave location........................... 40

A-3. MFC-793, Sodium Components Maintenance Shop, floor plan with potential cave location ......... 41

A-4. MFC-720, Transient Reactor Experiment and Test Facility, floor plan with potential cave location

A-5. MFC-765, Fuel Conditioning Facility, floor plan with potential cave location 
A-6. MFC-776, Zero Power Physics Reactor, floor plan with potential cave location

A-7. MFC-768, Experimental Breeder Reactor-II Power Plant, floor plan with potential cave location......

\section{TABLES}

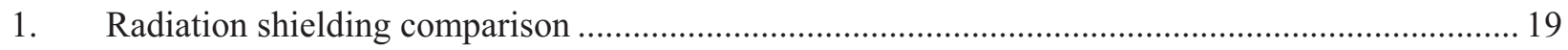

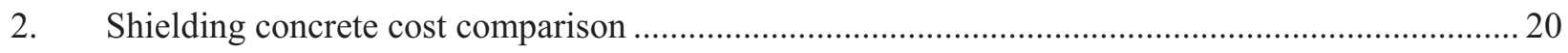

A-1. Alternative existing facility modifications to meet the Irradiated Materials Characterization

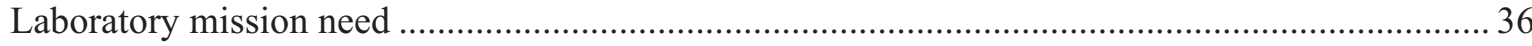

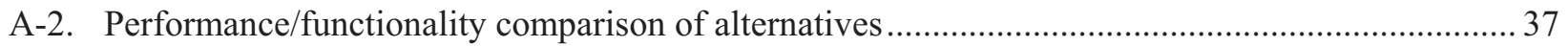

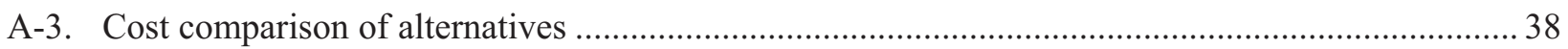




\section{ACRONYMS}

A

ANSI

CFR

DOE

EMI

GFCI

HFEF

HEPA

HVAC

IDAPA

IMCL

INL

$\mathrm{kV}$

kVA

LEED

MFC

NFPA

PSIG

TEV

V

VA

VAC ampere

American National Standards Institute

Code of Federal Regulations

U.S. Department of Energy

electromagnetic interference

ground fault circuit interrupter

Hot Fuels Examination Facility

high-efficiency particulate air

heating, ventilating, and air-conditioning

Idaho Administrative Procedures Act

Irradiated Materials Characterization Laboratory

Idaho National Laboratory

kilovolt

kilovoltampere

Leadership in Energy and Environmental Design

Materials and Fuels Complex

National Fire Protection Association

pounds per square inch gauge

technical evaluation study

volt

volts-amperes

volts-alternating current 


\section{Conceptual Design Report for the Irradiated Materials Characterization Laboratory (IMCL)}

\section{INTRODUCTION}

This document describes the design at a conceptual level for the Irradiated Materials Characterization Laboratory (IMCL) to be located at the Materials and Fuels Complex (MFC) at the Idaho National Laboratory (INL).

The IMCL is an 11,000- $\mathrm{ft}^{2}$, Hazard Category-2 nuclear facility that is designed for use as a state-of-the-art nuclear facility for the purpose of hands-on and remote handling, characterization, and examination of irradiated and nonirradiated nuclear material samples.

The IMCL will accommodate a series of future, modular, and reconfigurable instrument enclosures or caves. To provide a bounding design basis envelope for the facility-provided space and infrastructure, an instrument enclosure or cave configuration was developed and is described in some detail. However, the future instrument enclosures may be modular, integral with the instrument, or reconfigurable to enable various characterization environments to be configured as changes in demand occur. They are not provided as part of the facility.

\section{MISSION NEED}

To research and develop nuclear fuels in support of INL's reactor research mission, a new flexible, reconfigurable, post-irradiation fuels examination support capability is needed.

Reinvigoration of nuclear fuels and materials research is bringing new and different tools to post-irradiation examination and nuclear and radioactive materials characterization. These new tools, and the research materials examined with them, require unique, reconfigurable, accessible, modularized support facilities that are not presently available at INL.

The new laboratory operational model supported by this capability will promote and support continual implementation of state-of-the-art tools and technologies. The rapid evolution of analytical electron microscopes and the advent of high-performance computer interfaces with instruments were not envisioned when many of the existing facilities were constructed at INL. The rapid advances being made in technology signal the need for versatility in nuclear operations support and research facilities.

See PLN-3128, "Mission Need Statement for the Irradiated Materials Characterization Laboratory," for the project mission need statement.

\subsection{Mission Need Alternatives}

The following alternatives were evaluated during conceptual design for fulfilling the mission need as outlined in PLN-3128:

1. Do nothing

2. Relocate to alternate space (existing facilities)

3. Construct a new IMCL.

The "do nothing" alternative is eliminated from further consideration because currently no space is available that can house the post-irradiation research equipment that is being purchased without relocating existing operations or making improvements to existing available space. Appendix A contains the alternatives analysis report, which concludes that a new laboratory is the preferred alternative. 
The analysis compares six alternatives, five of which involve retrofit to existing facilities and the sixth being IMCL. The alternatives were analyzed on the basis of performance, functionality, and cost to establish the best alternative for meeting the mission.

The alternatives analysis identifies significant challenges in using existing facilities for housing characterization caves. It is difficult to provide the performance and functions required in old structures built for other purposes. The expense of removing existing features and retrofitting new features to meet the mission need is, in all cases, much higher than the cost of a new facility. The best location to perform the new and changing research demanded at MFC is in a new, purpose-built IMCL.

\section{PROJECT REQUIREMENTS \\ 3.1 Technical and Functional Requirements}

The IMCL requirements are identified in TFR-665, "Technical and Functional Requirements for the Irradiated Materials Characterization Laboratory." The basic functional requirements are as follows:

1. The IMCL shall provide a standalone state-of-the-art nuclear laboratory to support hands-on and remote handling, characterizing, and examining of irradiated and nonirradiated nuclear material samples.

2. The IMCL and support buildings/structures shall provide interior operational space for the following:

a. Shielded instrument enclosures for housing various scientific research instruments

b. Non-shielded instrument areas

c. Instrument support equipment

d. $\quad$ Restroom

e. Vestibules/airlocks at exterior doors, as required by the safety basis or temperature control needs

f. Operating gallery (typically in front of each instrument cave), with adjacent room near each cave for related research instruments and support systems not installed in the instrument caves

g. Maintenance corridor(s) providing utility and maintenance access to each cave

h. Hallways and corridors for personnel and equipment

i. Fire sprinkler riser room or area

j. Telecommunications closet

k. Personnel monitoring stations

1. Facility supervisor area with building support system status displays

m. Custodian closet

n. Heating, ventilating, and air conditioning (HVAC) and mechanical support equipment

o. Shipping/receiving

p. Gas bottle storage.

3. The IMCL shall be designed to handle and analyze irradiated and nonirradiated nuclear materials, while providing proper confinement of radioactive material and protection from radiation. 
4. The scientific research instruments installed in the IMCL are extremely sensitive to vibrations from rotating and reciprocating equipment. A method to isolate the research instruments from vibration shall be included in the design. Vibration performance within the instrument caves shall be as follows:
a. Maximum of $3 \mu \mathrm{m}$ at $4 \mathrm{~Hz}$ or below
b. Maximum of $0.5 \mu \mathrm{m}$ above $4 \mathrm{~Hz}$.

5. Magnetic field generating equipment shall be shielded or separated from instrument cave instruments in a way that fields in the instrument caves are less than $3 \times 10^{-7}$ Tesla, peak-to-peak for 50 and $60-\mathrm{Hz}$ frequencies and their harmonics. For other frequencies, they shall be less than $1 \times 10^{-8}$ Tesla peak-to-peak.

6. The facility and related structures and building services support systems in general shall be designed for a life of at least 30 years with reasonable maintenance.

7. The IMCL shall be designed for a normal occupancy of nine people per shift and peak occupancy of 15 people per shift.

8. The instrument caves shall have ventilation systems that provide a very stable air temperature. This shall, as reasonably achievable, require precise temperature control to a maximum change in air temperature of $1^{\circ} \mathrm{C}$ of change per hour.

9. The IMCL shall be designed to meet air pollution control regulations defined in IDAPA 58.01.100.

10. Radioactive liquid waste shall be collected in portable containers and manually transported to radioactive liquid waste treatment facilities at MFC for treatment.

11. Waste generated in IMCL will be managed in accordance with LWP-8300, "Transuranic Waste Handling."

12. As a minimum, IMCL shall meet the Guiding Principles of Executive Order 13423 and U.S. Department of Energy (DOE) Order 430.2B, "Departmental Energy, Renewable Energy and Transportation Management." If facility construction cost is in excess of $\$ 5 \mathrm{M}$, the facility shall be Leadership in Energy and Environmental Design (LEED) Gold certified.

13. The facility shall provide capability for future process gas installation in the instrument caves and around the perimeter of the operating gallery:
a. Argon gas: 0 to $2 \mathrm{scfm}$ at 90 psig at each isolated branch
b. Nitrogen gas: 0 to $2 \mathrm{scfm}$ at 90 psig at each isolated branch
c. P-10 gas: 0 to $2 \mathrm{scfm}$ at 90 psig at each isolated branch
d. Specialty No. 1 gas: 0 to $2 \mathrm{scfm}$ at 90 psig at each isolated branch
e. Specialty No. 2 gas: 0 to 2 scfm at 90 psig at each isolated branch.

14. Instruments and their support equipment shall be provided with suspect exhaust connections to continuously exhaust the instrument enclosure interior and support equipment (such as vacuum pumps).

a. During instrument operation in air atmosphere and possible breech of confinement boundary: Exhaust flow rate from 0 to $300 \mathrm{scfm}$, based on maintaining the pressure difference between instrument enclosure pressure and instrument interior pressure. In addition, this is based on a high-efficiency particulate air (HEPA)-filtered inlet and HEPAfiltered outlet on the instrument. HEPA filters shall be assumed to have initial 0.5 in. water gauge delta $\mathrm{p}$ clean and up to 3.5 in. water gauge when loaded and ready for change out. 
b. During instrument operation in inert gas atmosphere: Same as for operations during air atmosphere.

15. The facility shall have the capability to provide a very temperature-stable air environment within the instrument enclosures. The temperature shall be controlled in each instrument enclosure to a set point temperature with variation held to a maximum of $1^{\circ} \mathrm{C}$ per hour during normal operating conditions. In addition, each instrument enclosure shall have the capability of varying and maintaining its interior temperature over a range of temperatures and humidity levels.

16. Power provided shall accommodate the following instrument power requirements:

a. 208 to $240 \mathrm{VAC}, 40 \mathrm{~A}$, single phase

b. $\quad 230 \mathrm{VAC}, 23.8 \mathrm{~A}$, three-phase

c. $200 \mathrm{VAC}, 50 / 60 \mathrm{HZ}$, single-phase, $6 \mathrm{kVA}$

17. Instrument foundation size - each foundation shall be a minimum of 10 - $\mathrm{ft}$ wide $\times 8$ - $\mathrm{ft}$ front-toback.

18. Instrument overall size:

a. Width (across face of instrument cave) $=9 \mathrm{ft} 5 \mathrm{in}$.

b. Depth (front to back of instrument cave) $=8 \mathrm{ft} 0 \mathrm{in}$.

c. Height $=7 \mathrm{ft} 4$ in.

19. Instrument weight $-4,500-1 b$ maximum.

20. Instrument foundation loading - loading shall be designed for a $300-1 \mathrm{~b}$ per square foot minimum.

\section{PROJECT PLANNING \\ 4.1 Project Execution Plan}

The project execution plan (PLN-3537) describes how the project will be executed from final design through commencement of operation. Design, construction, and operation will be integrated throughout the project with the support of the Integrated Project Team, which provides representation from the myriad of disciplines involved in delivering this laboratory. Active involvement with DOE will be engaged, especially with implementation of the new DOE-STD-1189, "Integration of Safety Into the Design Process."

\subsection{Work/Organizational Breakdown Structure}

The scope of work is to design and construct a Hazard Category 2 nuclear facility to conduct research on both non-radioactive samples and samples of radioactive material that emit enough radiation to require shielding for workers. This laboratory will be flexible (i.e., handling different types of experiments) and reconfigurable (i.e., allowing the laboratory space to be changed to accommodate different experiments). Flexibility and reconfigurability are required to support the rapidly changing technology in research instrumentation and methodology.

To execute this scope, the work will be organized by the phase of the project, with the key phases being design, construction, and turnover.

The work breakdown structure and organizational breakdown structure are described in the project execution plan (PLN-3537). 


\subsection{Acquisition Strategy Alternatives}

The acquisition strategy for design and construction is discussed individually in the following subsections.

\subsubsection{Design}

Design, including nuclear safety engineering, will comprise a combination of in-house and subcontracted support based on qualifications.

For nuclear safety engineering, specifically preparation of the documented safety analysis, Nuclear Safety Associates won a competitive procurement to provide these services. Their work will be augmented with coordination and review from INL in-house nuclear safety engineering.

Qualifications for the architectural and engineering design will be prepared and a team assembled based on the demonstrated ability to provide those qualifications in the timeframe needed.

Specialty support, including vibration analysis, electromagnetic interference (EMI) design, and geotechnical investigation, will be procured through individual subcontracts based on qualifications and experience at INL.

\subsubsection{Construction}

Two alternatives for construction are being considered: best value award to a constructor near the beginning of final design and competitive award following final design to the lowest bid.

The best value award would entail soliciting proposals near the beginning of final design and awarding based on qualifications and cost structure, primarily overhead and profit. Qualifications would include demonstrated relevant experience for the company and the proposed project team. The selected constructor would be paid on a cost-plus basis for their constructability reviews and cost estimates during construction, then they would construct the facility based on a negotiated fixed price. This will provide the design team with a resource that can provide constructability and cost input throughout final design. Construction subcontract award following final design to the low bid would be a more traditional approach that maximizes competition but deprives the design team of constructability input.

The preferred approach to construction subcontracting is currently under consideration by the project team and Battelle Energy Alliance, LLC procurement.

\subsection{Siting Considerations}

An evaluation was performed (TEV-812, "MFC-IMCL Utilities Evaluation") to assess available areas that may be candidates for new construction at MFC. It evaluated access to utilities, general access to the site, impact on current and future structures, and bounding conditions such as subsurface limiting factors. Potential future facilities include IMCL, a Technical Support Building, two office buildings, a warehouse/storage/machine shop, a dial room, a post-irradiation facility, a radiological laboratory, a maintenance shop, an addition to the Hot Fuel Examination Facility (HFEF), a Fuel Fabrication Facility, temporary modular offices, and a non-radiological laboratory.

The evaluation includes an assessment of the current electrical capacity, including the projected capacity after the NORESCO project is complete and the boilers all become electric. This evaluation also assessed the current condition and capacity of the following:

- Potable/fire water system

- Sewage system

- Communications, including alarms, annunciation, computer, and Information Technology support capabilities. 
The infrastructure at MFC is currently capable of accommodating the increased demand required by the addition of IMCL. In addition to the factors included in the evaluation described above, proximity to related research facilities (such as HFEF and the proposed post-irradiation examination facility) also was included in selection of the location for IMCL. The list of candidate locations for siting IMCL was narrowed to two locations: near MFC-713 and north of MFC-785. Of the two candidate locations presented, the location north of MFC-785 provides the best solution primarily based on proximity to HFEF, where sample preparation for IMCL is likely to occur, ready access to most utilities, and freedom from interference with existing facilities (e.g., MFC-713) and proposed facilities (e.g., post-irradiation examination facility).

\subsection{Environmental Considerations}

Requirements under the National Environmental Policy Act and 10 CFR 1021, "National Environmental Policy Act Implementing Procedures," will be satisfied by preparation of an environmental checklist (INL Form 451.01, "Environmental Checklist Idaho National Laboratory"). Given that IMCL will be used to conduct nuclear fuels research and development, the probable outcome of the National Environmental Policy Act review is that the environmental checklist will cite MFC's overarching Environmental Checklist/Categorical Exclusion INL-07-010 R1 for analytical and research and development work. From an actual environmental aspects perspective, an air permitting applicability determination will be performed to determine if continuous emissions monitoring, a permit to construct (State of Idaho), or an approval to construct will be required.

\subsection{Safety Considerations}

A safety design strategy (INL/EXT-10-17890) has been prepared and provides the basic safety-indesign principles and concepts that will be used for IMCL. The following sections are excerpted from INL/EXT-10-17890.

In accordance with the requirements of DOE Order 413.3A, "Program and Project Management for the Acquisition of Capital Assets," safety must be integrated into the design process for new or major modifications to DOE Hazard Category 1, 2, and 3 nuclear facilities. The intended purpose of this requirement involves the handling of hazardous materials, both radiological and chemical, in a way that provides adequate protection to the public, workers, and the environment. Requirements provided in DOE Order 413.3A and DOE Order 420.1B, "Facility Safety," and the expectations of DOE-STD-1189-2008, "Integration of Safety into the Design Process," provide for identification of hazards early in the project and use of an integrated team approach to design safety into the facility.

\subsubsection{Preliminary Hazard Categorization}

Based on the preliminary assessment of the anticipated sample inventory and a comparison with DOE-STD-1027-92, "Hazard Categorization and Accident Analysis Techniques for Compliance with DOE Order 5480.23, Nuclear Safety Analysis Reports," IMCL would be initially categorized as a Hazard Category 2 nuclear facility. The categorization is based on the current anticipated maximum radiological inventory of 300 PEC. The 300 PEC is greater than the DOE-STD-1027-92 Hazard Category-2 threshold quantity of $56 \mathrm{Ci}^{239} \mathrm{Pu}$ and bounds any radionuclide distribution for anticipated samples from any source. This inventory provision will be further evaluated during development of the PDSA and documented safety analysis per NS-18101, "INL Safety Analysis Process," to determine if higher limits may be allowed. Additional inventory limits may be imposed based on criticality and shielding considerations that will be evaluated during development of the conceptual safety design report, PDSA, and documented safety analysis. 


\subsubsection{Safety Analysis Approach and Plan}

As a Hazard Category 2 nuclear facility, IMCL must meet specified nuclear safety requirements. The following requisite nuclear safety documentation will be developed as part of the project:

- $\quad$ Safety design strategy

- $\quad$ Preliminary hazards analysis

- $\quad$ Conceptual safety design report

- $\quad$ Preliminary documented safety analysis

- $\quad$ Final documented safety analysis.

This nuclear safety documentation also will be developed in accordance with DOE-STD-11892008 and NS-18101, "INL Safety Analysis Process," nuclear facility safety requirements.

\subsubsection{Seismic and Other Natural Phenomena Design Category}

Based on an initial review of the applicable facility hazards and in accordance with Section 4 of ANSI/ANS-2.26-2004, Categorization of Nuclear Facility Structures, Systems, and Components for Seismic Design, the IMCL will be Seismic Design Category 2. This determination is based on the assumption that a failure of an instrument cave will not cause significant radiological exposure to workers, the public, or the environment. As stated in the standard, no limit state identification is required for Seismic Design Category 1 or 2 systems, and the seismic evaluation of the facility will be performed in accordance with the International Building Code. In accordance with DOE-STD-1189-2008 requirements, other natural phenomena hazards and their impact on IMCL design, will be in accordance with DOE-STD-1020-2002, "Natural Phenomena Hazards Design and Evaluation Criteria for Department of Energy Facilities," as applicable.

\subsubsection{Confinement Strategy}

The IMCL confinement strategy consists of providing multiple layers between the radioactive samples and the facility workers, public, and environment. The portions of the instruments containing the nuclear material sample will be contained within sealed enclosures or that portion of the instrument will be sealed by design (e.g., the sample chamber of an electron microscope), providing primary confinement of any loose contamination. Samples will be introduced to the instruments using confinement boxes specifically designed for each instrument or transfer container. These boxes also are part of the primary confinement. The sample and instrument enclosure structures will provide the shielding necessary to shield the worker from the radioactivity of the samples and provide a secondary confinement boundary around scientific research instruments. While located within shipping casks and transfer containers, samples will be confined within these structures. The outer facility structure and SES will provide a tertiary confinement boundary to the public and the environment.

\subsubsection{Fire Mitigation Strategy}

Potential fire and subsequent loss of confinement may result in a material release, leading to a radiological or chemical exposure hazard to the facility workers, collocated workers, offsite public, or the environment. A fire hazards analysis will be performed as part of the design process to determine the need for fire detection and suppression systems to be installed throughout IMCL. Because the lifting and handling of casks at this facility may require use of diesel powered trucks and forklifts, these vehicles introduce the potential for a vehicle fire that is postulated to occur during transport or during cask unloading evolutions. The fire hazards analysis will specifically take this postulated fire scenario into account and identify appropriate preventative and mitigative features and administrative controls for implementation during these process operations. Based on the results of the fire hazards analysis, the 
design strategy will incorporate appropriate fire prevention and mitigation features (e.g., fire sprinklers, combustible material controls, and fire-fighting controls).

Fire protection for IMCL will adhere to requirements of the NFPA codes and the International Building Code. Life safety/means of egress will comply with NFPA 101, "Life-Safety Code." In addition, IMCL will comply with NFPA 801, "Standard for Fire Protection for Facilities Handling Radioactive Materials."

\subsubsection{Criticality}

In the conceptual design stage of IMCL, preliminary evaluations indicate that the material process streams for the facility may contain significant quantities of fissionable material such that a criticality evaluation is required. Further evaluation will be made on the need for criticality safety requirements (e.g., specific inventory controls and packaging configurations for fissile materials) pertaining to the proposed IMCL during development of the PDSA.

\subsubsection{Anticipated Safety Functions}

Safety-significant SSCs are hazard controls for which credit is taken, either preventive or mitigative, to meet the evaluation guidelines for the facility and collocated workers. Based on results of the preliminary hazard identification for IMCL, it is not anticipated that inhalation dose consequences will exceed the evaluation guidelines to the facility and collocated workers. It also was concluded that the potential exists for direct radiation exposure consequences exceeding evaluation guidelines to the facility worker. The shielding enclosure walls/roof, shipping casks, and other shielded containers were identified as structural components that would protect the facility worker from these consequences. Because the shielding enclosure walls/roof, shipping casks, and other shielded containers provide a radiation shielding function for some operations, they are preliminarily designated as safety-significant SSCs for facility planning purposes at this initial state of the design.

\subsection{Quality Considerations}

A Quality Level Determination (MFC-000981) using the indirect risk analysis method has been performed for the IMCL conceptual design. The conceptual design activities are Quality Level 3. Prior to preliminary/final design, the quality level determination for the facility system, structures, and components will be performed once systems and components have been defined and their function as hazard controls determined.

\subsection{Security Considerations}

The IMCL facility inventory was evaluated against the graded safeguards criteria found in DOE Manual 470.4-6, Chg 1, "Nuclear Material Control and Accountability." The facility will be classified as a Safeguards Category IV facility. No security clearance will be required for facility access.

Entry to the support building will be uncontrolled. Card reader access to the laboratory facility will be provided at the entrance to the laboratory space from the support building and the exterior shipping bay door. The overhead doors will be controlled from the interior of the shipping bay. All other personnel doors within the operating and maintenance galleries will be exit-only and locked with a Level III lock and core.

\subsection{High-Performance Sustainable Building Considerations}

The IMCL will be designed and constructed using sustainable building considerations per DOE Guide 413.3-6, "High Performance Sustainable Building," and INL/EXT-10-17808, Revision 0, INL High Performance Building Strategy. As a minimum, IMCL shall meet the Guiding Principles of Executive Order 13423 and DOE Order 430.2B, "Departmental Energy, Renewable Energy and Transportation Management." In addition, the building will be designed to be LEED certified, with 
"Gold" certification as a goal as reasonably achievable in accordance with the U.S. Green Building System LEED 2009 for New Construction and Major Renovation rating system. A design charette was held with the project team and Battelle Energy Alliance, LLC LEED-accredited professionals to define the project sustainability goals. Appendix B contains the draft LEED project checklist.

Site selection design strategies include selection of a site that has been previously developed; use of existing parking and bus infrastructure; inclusion of bicycle storage, stormwater quantity and quality control; reduction of heat-island effects through high solar reflectance index materials for roofing and hardscape materials; and reduction of light pollution.

Reducing or eliminating irrigation potable water demand and reducing building potable water use will be a design focus. Energy performance will be optimized with $30 \%$ reduction as an energy-savings goal. Enhanced commissioning and measurement and verification of building energy-intensive systems will ensure the building is performing at its optimum energy efficiency.

Recycled product-containing and regionally sourced and manufactured materials will be selected where available. Low-emitting materials will be selected and increased ventilation will be provided to optimize indoor environmental quality. Individual controllability of lighting and thermal control will be provided where applicable.

\subsection{Risk Management}

The following list provides the key risks presented by the design. These risks and other project risks are more thoroughly analyzed in terms of probability, impact, and mitigation, in the risk management section of the project execution plan.

- Design costs exceed baseline budget

- Time to complete design exceeds baseline schedule

- Actual construction costs exceed estimates

- Features as designed do not meet operational requirements

- Design expertise is not available when required

- Construction documents (e.g., drawings and specifications) do not provide adequate detail or clarity.

These risks will be managed throughout the project.

\section{FACILITY DESIGN DESCRIPTION}

\subsection{Facility Overview}

The IMCL is an $11,000-\mathrm{ft}^{2}$ facility designed for use as a state-of-the-art nuclear facility for the purpose of hands-on and remote handling, characterization, and examination of irradiated and nonirradiated nuclear material samples. Appendix D contains conceptual-level drawings for the facility.

The IMCL will accommodate a series of future, modular, and reconfigurable instrument enclosures or caves. To provide a bounding design basis envelope for the facility-provided space and infrastructure, an instrument cave configuration was developed and is described in some detail. However, the future instrument enclosures may be modular, integral with the instrument, or reconfigurable to enable various characterization environments to be configured as changes in demand occur. They are not provided as part of the facility.

An operating gallery is located along the cave fronts and a maintenance gallery supports maintenance and cave entry on the back side. A sample preparation cave may be provided as a bid option 
for sample receipt and storage and future installation of sample preparation gloveboxes. A shipping and receiving bay helps maintain a consistent indoor atmosphere when receiving deliveries of samples or equipment. A structurally independent annex provides EMI and vibration-isolated space for electrical and mechanical equipment, as well as supports space such as offices, janitor rooms, and restrooms.

The primary function of this facility is to provide a state-of-the-art laboratory that is efficient, flexible, and dedicated to the analysis and characterization of irradiated and nonirradiated nuclear material samples. The facility will be configured to house future program-provided nuclear material scientific research instruments. Future programs will be responsible for procurement, design, and construction of the research instrument, the necessary shielding and enclosure, and interface of the instrument with the facility-provided infrastructure.

Each shielded instrument cave will be designed such that the front wall and back walls will be replaceable over the life of the facility. The front wall will be referred to as the "front" and the back wall as the "back." These will be unique components designed for a specific mission or a scientific research instrument that is located inside of the particular cave. Generally, research personnel interface with the scientific research instrument in the cave at the "front" via remote-handling means. The "front" may contain a shielding window for viewing, feedthroughs, insertion ports, or manipulators for remote manipulation of the scientific research instruments in the cave from the operating gallery. The "back" will typically contain a manned shielded entry door and any other interfaces required by the mission.

The instruments will likely be located within a glovebox or enclosure when installed in the instrument caves. These gloveboxes may be an inert atmosphere enclosure, if required. The gloveboxes may interface with the instrument cave "front" shielded windows, penetrations, pass-throughs, manipulators and an intra-cave sample transfer system, allowing a researcher to remotely operate the instrument.

The facility will provide power, fire protection, process gas, and ventilation infrastructure to facilitate future instrument and enclosure installation and operation of the instruments. The routing of utilities from the facility's utility infrastructure will be the responsibility of the instrument programs.

\subsubsection{General Personnel and Equipment Traffic Flow}

Personnel entry into the facility will be through the support building. Samples and equipment will enter IMCL through the shipping bay. A forklift will remove the sample cask, instrument, or piece of equipment from the delivery vehicle parked outside and transport it into the shipping bay, allowing the outside overhead door to be closed. The inside overhead door is opened and the sample cask or piece of equipment is brought into the facility. The base assumption for the facility is that irradiated samples will be directly inserted into the instrument caves. If removal of the shielded sample from a transportation cask is required, the shipping bay will contain a hoist that can be used.

\subsubsection{Instrument Caves}

To provide a bounding design basis envelope for the facility-provided space and infrastructure, an instrument enclosure or cave configuration was developed and is described in some detail. However, the future instrument enclosures may be modular, integral with the instrument, or reconfigurable to enable various characterization environments to be configured as changes in demand occur. They are not provided as part of the facility and their configuration is only an assumption.

5.1.2.1 Instrument Cave Front and Back Walls. A primary function of this facility is to provide a reconfigurable, flexible, and functional structure that allows replacement of the scientific research instruments that will be installed inside. This flexibility will allow each instrument cave to be reconfigured to accommodate present and future state-of-the-art-type material characterization instruments in a hot laboratory type of facility. This flexible feature of the instrument caves in IMCL will allow for a very functional and long mission life. 
To achieve this primary function of flexible functionality, it is assumed each instrument cave's front wall and back wall will be left open. A particular instrument cave front wall and back wall will be installed at a later date, by others, when a particular research instrument has been selected and funded for a specific research mission. Design and installation of these instrument cave front wall and back wall will be the responsibility of the scientific research group responsible for the instrument that will be installed in a particular instrument cave. This flexibility will allow for designing the location and placement of such things as viewing windows, remote manipulators, and process and utility feedthroughs for the specific scientific research instrument that will be installed in that instrument cave. At the end of an instrument's research grant/mission, the instrument cave fronts and backs can be removed along with the instrument, making the instrument cave ready for its next research mission.

To allow for replacement of these fronts and backs, the mating or interface surfaces of the permanent side walls, floor and ceiling of each instrument cave will be designed to provide the following features:

- Ease of attachment to allow relatively easy installation and removal for the specially fabricated fronts and backs to the permanent cave structure

- Tight air infiltration leakage seals between the permanent structure and the fronts and backs, so that the sealed instrument cave will form a secondary confinement boundary around the research instrument

- Elimination of radiation shine paths via stepped or overlapping joints between the permanent cave surfaces (sidewalls, floor, and ceiling) and the fronts and backs

- Structurally adequate permanent structure to support and attach the fronts and backs to in order to meet the necessary seismic safety design criteria for IMCL.

The instrument cave fronts will be replaceable to allow different configurations of mechanical telemanipulators, viewing windows, feedthroughs, and transfer ports. The instrument cave backs can similarly be changed out to accommodate personnel entry doors and similar viewing and handling equipment as the fronts. Instrument cave fronts and backs can be assembled in place from several pieces or as one large piece. Each piece will be transported through the shipping bay, operating gallery, and maintenance gallery, using an appropriately sized forklift or air pallet and other material-handling devices, such as dollies and portable gantry or jib cranes.

The cave structure's jamb and header features, where these fronts and backs will attach to, will be designed with cast-in structural steel framed steps and tapped holes. Steel plates will be embedded along these steps to provide equivalent shielding to the surrounding cave concrete surfaces. These cast-in steps will be designed to allow ease of attachment of the fronts and backs by providing tapped holes at appropriate spacing around the jambs and header for bolting the ends of the fronts and backs. The overriding design objective will be providing structural tapped holes attachment points in lieu of having to drill and set expansion or epoxy anchor bolts or welding for attaching each front or back over the life of the facility.

Adjacent to, but part of the cast-in steps, will be narrow metal channels. These channels will be located on both sides of the framed opening - operating gallery/maintenance gallery side and inside of the instrument cave. This will allow a flat rubber gasket and compression cover bar to span across the joint between the permanent structure and temporary front or back. On the permanent cast-in side of the joint, the screw fasteners will attach through clearance holes in the compression cover bar and gasket and fasten to nuts in the metal channel. These screws will compress the gasket to form the seal. Screws on the front or back side of the joint will compress the gasket on this side of the joint. This same description applies to the other side of the framed opening. 
The sill will have an embedded, welded, steel structure that will provide a shallow recess that the front or back will sit in, thus eliminating a radiation shine path under the bottom of the front or back if they just sat on top of the facility floor. On both sides of the sill, there will be narrow metal channels embedded in the floor. These will help form attachment locations for a rubber gasket seal. Both sides of the sill will have sealed gasket joints. These will be formed using a steel angle and gaskets, instead of the flat compression bar for the jambs and header.

Across the headers of each cave opening will be a cast-in-place steel plate. This plate will add to the flexibility feature by providing a structural attachment point for anchoring supports for shield doors, and related structural anchoring of fronts and backs related items. These plates will have tapped holes for bolting structural attachments to for anchoring.

5.1.2.2 Intra-cave Pneumatic Transfer System. Provisions for the future design and installation of a system to transfer samples between caves have been provided. It is anticipated that future sample transfers to a particular research instrument would be made via a remotely operated intra-cave pneumatic transfer system. This system would likely consist of individual pneumatic transfer tubes between each cave. The system that forms the basis for this design is described in the following paragraphs.

Some samples will have a relatively high source term, which will require them to be shielded to prevent unwanted high personnel radiation dose exposure. Shielding will be accomplished by routing the transfer tubes through an in-floor covered trench. The transfer tubes will be located in the very bottom of the trench with shielding materials stacked above the tubing, but still within the confines of the trench. The trench will have sealed bulkheads where it passes under a cave wall so that the confinement boundary of the cave interior is maintained. The trench will be covered with removable steel plates that will be flush with the surrounding concrete floor. The trench also provides the most flexibility for future changes to tubing as individual instrument configuration requirements change over the lifetime of the facility. A technical evaluation was performed and the routing decision for the rabbit system was documented in TEV-861, "Technical Evaluation of a Future Intra-Cave Transfer Tube Routing for the IMCL."

The major components of the intra-cave pneumatic transfer system will be the following:

- Sample carriers

- Receiver/sender terminals at ends of transfer tubing

- $\quad$ Transfer tubing network

- Radiological shielding around transfer tubing

- Gas supply and exhaust manifold (vacuum pump, valves, and filters)

- Control system.

At this time, only the in-floor trench and the transfer tubing network will be installed for future intra-cave transfer capability.

The sample transfer tubing will be 3 -in. outside diameter $\times 0.049$-in. wall thickness round metal tubing. The tubing will be galvanized carbon steel or stainless steel. Connections between tubes will be butt end type with Morris (industry vendor's name for their coupling product) style compression clamp type couplings for all tubing materials, socket-welded couplings for stainless steel tubing only, or brazed socket couplings for galvanized tubing. These are the typical joining methods used in other successfully operating pneumatic transfers at MFC.

The tubing and couplings are rated at 20-psig internal pressure. Most of the out-of-cave tubing joints will use Morris couplings that form an air-tight seal. The remaining tubing joints will be silverbrazed or welded. Each Morris coupling has an internal insert (gasket protector), a neoprene gasket (gas 
seal), and an outer clamp. Morris couplings provide a relatively easy method to disassemble the tubing in the event a carrier becomes stuck.

5.1.2.3 Cave/Ceiling Penetrations. Each instrument enclosure or cave will require many common utility services to be furnished to its interior. These utilities are best furnished via penetrations through the ceiling of each cave and include the following:

- General cave air supply and exhaust

- Instrumentation tubing for cave interior pressure sensing

- Pressure/vacuum piping for pneumatic transfer systems

- Electrical power needs, such as general lighting

- Electrical control wiring

- Inert enclosure pressure and atmospheric purity control

- Fire sprinkler piping

- Fire alarm wiring

- Spare penetrations for future and instrument user needs.

Specific research mission utilities will be brought into the cave through the cave fronts, backs, or a utility corridor side penetration. Some characterization instruments being considered for use in this facility have very short connection cables and tubing/piping between the instrument and its support cabinets. These support cabinets are required to be located outside of the instrument cave. The only way to accommodate these short connection situations is with the use of in-floor penetrations under the shielding wall of the cave.

Common utilities will be brought into each cave through specially designed penetrations in the ceiling. The following two basic types of penetrations will be used:

1. Directly embedded rigid conduit for electrical and communication/data wiring

2. Stepped flanged pipe-type penetrations for all other services.

The stepped flanged pipe-type penetrations will give the facility versatility to change out the utility service line going through it as missions change or evolve. Several spare penetrations will be installed for future use as mission needs dictate. Liquid utilities, such as fire sprinkler water, will be piped into the cave via these stepped flanged pipe-type penetrations, which will allow them to be changed out in the future in the event piping corrosion requires their replacement.

Both penetration types will be cast-in-place during placement of the ceiling structure concrete. These penetrations must comply with the following two major design requirements:

1. Penetrations shall provide the same amount of radiation attenuation as the surrounding concrete.

2. Penetrations shall form a relatively air-tight boundary as good practice in case future instrument configurations require this feature.

For the directly embedded penetrations, there will be two available sizes of rigid conduit: $3 / 4$ in. and $1 \mathrm{in.} \mathrm{Larger} \mathrm{diameter} \mathrm{conduit} \mathrm{may} \mathrm{be} \mathrm{used} \mathrm{if} \mathrm{determined} \mathrm{necessary} \mathrm{in} \mathrm{the} \mathrm{final} \mathrm{design} \mathrm{stage} \mathrm{of} \mathrm{this}$ project. Each conduit will have an offset consisting of two 90-degree bends approximately midway between the bottom and top ceiling surfaces. Additional solid steel will be placed strategically near each bend to provide proper shielding to radiation shine that would travel straight or near straight paths up the straight sections of the conduit. These conduit sizes are very common for handling the general electrical power and control requirements of most of the facility support equipment in the cave. If very large 
conduit or short distance connections are required, special feedthroughs will be designed and provided as part of the cave front and back or through the floor trenches.

The other types of penetration that will be used are stepped flanged pipe types. These will have a three piece type design, consisting of the following:

1. Outer sleeve

2. Plug

3. Shielding.

The outer sleeve will consist of a stepped hollow tube with a flange welded on the top side. The stepped tube will have a larger diameter tube on the upper half and a smaller tube on the bottom side. The top of the flange will be placed so it is flush with the top concrete surface. This flange will have tapped holes in it and an exposed machined face for proper o-ring sealing between it and the second piece of the design, the plug.

The plug will have a flange on top with a smaller stepped tube for it to fit into the outer sleeve. The overlapping tubes will result in a stepped design, which will eliminate a direct radiation shine path between the two pieces. The flange of the plug will have two o-rings on its bottom face for a static face seal against the flange of the outer sleeve, thus making the assembly air-tight, if required by a specific program. The plug will contain the pipe or tubing that passes through the penetration.

The shielding will form the last part of these removable penetrations. The shielding will allow the penetration to maintain the same shielding equivalency as the surrounding concrete ceiling. For a larger diameter tube or pipe that passes through the penetration, the radiation shine upward axially through the pipe/tube must be shielded. This is accomplished by putting a 90 degree elbow on the pipe/tube above where it extends above the top flange. Steel shielding or other dense shielding materials will be stacked above the pipe/tube to attenuate this radiation. For penetrations that have small diameter tubing, such as $1 / 2$-in. outside diameter, the tubing will be offset midway in the plug and the interior volume of the plug will be filled with lead shot.

\subsection{Site Preparation}

\subsubsection{General Layout and Orientation}

The IMCL will be located on the north side of MFC within the existing security fence, and just north of the existing HFEF. This location was selected based on project-specific siting considerations previously discussed (see Section 4.4).

The building site layout is arranged to provide an integral arrangement with existing structures and provide ease of pedestrian access between HFEF and the new IMCL. Consideration was given in building orientation and site paving to provide ease of access for delivery vehicles and sample transport vehicles to access the laboratory high bay and mechanical room delivery doors. The building orientation also will provide the greatest opportunity for optimization of energy performance.

\subsubsection{Existing Soil Conditions}

Previously performed soil testing in the proposed construction area indicates that there are two layers of soil over bedrock in the area of the IMCL building location. The upper layer is a silt-sand-clay mixture. This soil contains windblown fines in which the bearing capacity is greatly reduced when the soil is wet. This soil layer extends from the surface down 3 to $8 \mathrm{ft}$ and is susceptible to frost movement.

The lower soil layer is a gravel-silt-sand mixture. This layer of soil consists of fractured lava rock. Voids in the fractured rock have been filled to some extent with fines from the layer above. The layer extends from 3 to $8 \mathrm{ft}$ below ground surface down to the top of bedrock. The depth of bedrock varies and can be as deep as $22 \mathrm{ft}$ in some areas. 


\subsubsection{General Site Work and Demolition}

Site preparations for construction of IMCL will include the clearing of materials currently staged on the proposed building site; removing the existing MFC-750 structure; delineating the construction area from general access; designating equipment laydown and soil stockpile areas; and general site grading and preparations to properly manage storm water runoff and windblown dust during construction.

Based on existing soil conditions in the area, it is anticipated that areas for structural footings will require excavation of unacceptable soil to a depth of approximately 5 to $8 \mathrm{ft}$ to provide adequate structural support. Backfill around the footings will be compacted structural fill, such as pit run gravel. It is also anticipated that unacceptable soil beneath the slab will be removed and replaced with a structural fill (pit run gravel) to a minimum depth of between 1 to $3 \mathrm{ft}$ beneath the building slab.

Fill will be imported to raise the finished floor elevation a minimum of 6 in. above existing ground elevation to ensure drainage away from the facility. Final finished floor elevation will be determined in the next design phase after a topographic survey has been completed showing existing drainage patterns in the area. The finished floor elevation will allow final grading to direct drainage away from the facility.

Concrete sidewalks, door stoops, and aprons will be provided around the facility to provide durable access to the building. Concrete pavement drive paths will be constructed from the high bay doors of the IMCL to the existing road located between IMCL and HFEF.

The site will be landscaped with a combination of water-efficient native or adapted species and gravel to provide a design that will minimize maintenance and potable water use for irrigation purposes.

\subsection{Utilities}

\subsubsection{Domestic Waste Water (Sanitary Sewer)}

Sanitary sewer service will be routed from the west side of the office where the restrooms are located to the existing MFC sanitary sewer system. It is anticipated that the service will require a small lift station to deliver waste to the nearest existing sanitary sewer manhole, located southwest of Building 714. Gravity sewer pipe leading to the lift station will be 4-in. ABS. Piping from the lift station to the existing manhole will be polyvinyl chloride (to be sized with lift station pump during the next phase of design).

\subsubsection{Electrical Distribution}

Electrical service to the new IMCL will be provided by a new pad mount, 1000-kVA, 13.8-kV, 480/277-V transformer located to the west of the facility. The transformer will be a fluid-filled type with Envirotemp FR3 dielectric fluid. The 13.8-kV feed to the 1000-kVA transformer will loop feed off the 711 Substation primary. A new $15-\mathrm{kV}, \# 4 / 0,133 \%$ insulation copper cable will route in new ductbank, with one 4-in. conduit, from the 711 Substation to the new pad mount transformer. The existing 711 Substation in its present state and with new heating loads from the NORESCO Project coming online does not have enough capacity on the $480-\mathrm{V}$ side to feed IMCL. The 711 Substation primary $13.8-\mathrm{kV}$ feed has capacity to loop feed the new IMCL transformer.

A new ductbank with three 4-in. conduits, each with four \#600 kcmil and a \#2/0 ground, will route from the transformer secondary to a main service panel located in the IMCL electrical room. The main service panel will be rated for service entrance, have a 1200-Amp main breaker, and be equipped with ground fault protection.

\subsubsection{Fire and Potable Water Distribution}

MFC uses a shared water system for potable water and firewater. Because of this, only one water service line will be provided to IMCL. This service will consist of an 8-in. ductile iron pipe connected to the MFC water main that will be routed from the southeast and then stub-up into the mechanical room 
located on the south side of the facility. Firewater and potable water within the facility will be split into separate systems and routed from the stub-up. A reduced pressure backflow prevention device will be installed on the firewater supply.

Some fire hydrants may require review for relocation based on their proximity to the facility. A minimum distance of $40 \mathrm{ft}$ will be required between fire hydrants and IMCL. Based on a future topographic survey with locations of surface features, this will be evaluated during the next phase of design.

\subsubsection{Telecommunications/Alarms Distribution}

The IMCL will require a high bandwidth fiber optic link to support facility operations and research activities. Presently, no telecommunications route exists on the north end where IMCL is sited. There are telecommunications ductbank and manholes to the south of HFEF, but the existing ducts are filled to capacity. Some ducts contain abandoned cables, but attempting to remove them will have a high probability of causing damage and possibly taking the existing active cables out of service, requiring lengthy and expensive repairs. The best course of action is to install a new ductbank from the proposed new MFC dial room to IMCL. If the new MFC dial room does not proceed to construction, the ductbank will be required to extend into the Building 752 basement where the existing MFC dial room is located. The ductbank will contain four 4-in. conduits and be approximately 1,800 ft in length.

A 48 fiber single mode cable and a 100 pair copper cable will route to IMCL through the new duct bank system from the new dial room. The 48 fiber cable will terminate in a new 48 port patch panel in the new MFC dial room and in the IMCL telecommunication room. The 100 pair copper cable will terminate at a building protector in both the IMCL telecommunication room and the new MFC dial room.

The 100 pair copper cable will be used for voice and special circuits. Special circuits will consist of two low-level audio signals for the MFC plant paging system. A new paging amplifier will be installed in IMCL to broadcast voice paging announcements throughout the facility.

The fire alarm system shall have eight single mode fibers dedicated for use by this system. These fibers shall run between the new MFC dial room and a new fire alarm dedicated patch panel at IMCL. The new fire alarm panel shall connect to the high speed Notifier-net network via these fibers. Emergency communication data also may use these fibers to be announced over the fire alarm system.

\subsection{Architectural and Structural}

\subsubsection{Occupancy Classification}

International Building Code 2009 classifies this building as Group F occupancy. International Building Code Table 307.1(2) footnotes e and f, restricts highly toxic material to a maximum of $40 \mathrm{lb}$. This exceeds the anticipated quantities that will be used within the facility; therefore, the facility will not require Group H occupancy designation. The NFPA 101, "Occupancy is Industrial - Ordinary Hazard," and TEV-811, "Irradiated Materials Characterization Laboratory (IMCL) Occupancy and Life Safety Code Analysis," summarize the International Building Code and NFPA 101 requirements for the facility.

\subsubsection{Fire Resistance}

No fire resistive construction is required within the fire sprinklered building and the distances to property lines allow exterior walls to be of non-fire resistive construction.

\subsubsection{Accessibility Requirements}

All areas of IMCL will meet the requirements of the Americans with Disabilities Act. 


\subsubsection{Energy Conservation}

Because of the tight tolerances for temperature fluctuation in the caves, the exterior walls will be well insulated and will provide thermal mass. The thermal mass will be the solid grouted masonry block structural portion of the walls. Four-inch masonry veneer will protect the insulation sandwiched between the two wythes of block.

\subsubsection{Facility Architectural Description}

The IMCL will be a single story, slab-on-grade, masonry block structure with steel roof joists and deck and a low-sloped, internally drained roof. The layout accommodates hot cell caves and general open laboratory space for installation of additional instruments, gloveboxes, or fume hoods and a shipping bay.

Initially, four caves will be provided. The caves will be accessible from two sides for loading and unloading experiments and from the top for accommodating utilities. A utility corridor is provided on one side of the cave to accommodate instrument support equipment such as racks, chillers, and vacuum pumps. The building height will accommodate workers accessing utilities located over the tops of the caves.

A shipping bay is located on one end of the facility to accommodate large equipment (instruments, sample casks, and instrument cave fronts or backs) entry into the facility by means of forklifts, air pallets, or pallet jacks, and minimize the temperature change impact from the overhead door opening into the laboratory. Two $12-\mathrm{ft} \times 16-\mathrm{ft}$ insulated, overhead doors will be provided.

Four emergency exits are provided around the perimeter of the laboratory space and are not intended for normal entry. Entry to the laboratory space will be through the support building.

Because significant material handling from forklifts, air pallets, or pallet jacks will occur in the facility, a hard-surfaced wall material was chosen to resist potential impact from the material handling equipment. NFPA 801 requires construction that can confine a potential radiation contamination incident and shall include surface finishes that are easy to clean.

The IMCL support building will facilitate personnel entry into the laboratory space and provide space for the following support functions:

- Mechanical HVAC and HEPA filters

- Electrical

- Telecommunications

- Office for facility management and radiological control/health physics support personnel

- Restrooms, locker, and changing space.

The IMCL Support Building will be constructed of either a similar wall construction as the laboratory facility or consist of a metal building system with metal stud wall framing and an exterior insulation finishing system and exterior finish and painted gypsum board interior finish. Walls in the offices, restrooms, Janitor's room, electrical room, fire riser room, telecommunications room, transfer vestibule, and hallways will be metal stud-framed with painted gypsum board and rubber base.

Ceilings will be left open to the structure in the laboratory and the mechanical room in the support building. The offices and restrooms will have lay-in acoustical tile. Both roofs will be enclosed with 42-in. high parapets to accommodate maintenance and access without fall protection constraint and weatherproofed with an ethylene propylene diene monomer (EPDM) roofing system.

Floor finishes will be sealed concrete in all areas. 


\subsubsection{Building Material Selection}

A technical evaluation was performed to determine the construction methods and materials that will best meet the needs of IMCL (TEV-847, "Construction Material Selection for the Irradiated Materials Characterization Laboratory"). Project requirements and performance criteria based on the technical and functional requirements and project team members were used to evaluate construction alternatives. The following construction alternatives were considered:

- Pre-engineered steel building

- Hot rolled steel framed building

- $\quad$ Stick framed building (load bearing walls with steel studs)

- Masonry building

- Pre-cast concrete building

- Cast-in-place concrete building.

These alternatives were evaluated against the following performance considerations:

- Thermal mass and insulating capability

- Effect on seismic design

- Fire performance

- Vibration damping performance

- Adaptability for future modifications

- Effect on construction schedule

- Protection from wind-born objects

- Appearance

- Ability to maintain negative building pressure.

The evaluation considered the effect of the exterior building walls only. The type of roof construction and the effect it has on the building was not evaluated in this study. It was anticipated that the roof system would be addressed separately after the wall construction method was established.

Wall construction methods were evaluated directly against each other using a paired comparison to weigh how well each method met the project performance criteria. The paired comparison weight was combined with a performance criteria importance factor to determine the final ranking of each construction alternative. Costs of the highest-ranked options were evaluated and compared. Costs for a metal building system also were included as a "lowest cost" option and is an option for the support building construction.

Based on assumptions made for conceptual design and the current direction of the project, a masonry building was determined to be the most cost-effective type of building to meet the mission of the facility at this point of the design process.

\subsubsection{Building Exterior Walls}

The exterior walls for the laboratory and support buildings will be constructed of 8 -in., nominally wide, concrete masonry units. The hollow portions of the concrete masonry units block will be grouted solid and will contain reinforcing steel. Cost considerations may require the support building to be 
constructed using an engineered metal building with a low-slope roof, metal stud, and EIFS-finished exterior walls.

The concrete masonry unit wall will support dead and live loads from the building roof system. It also will provide lateral support to resist wind and seismic forces on the entire building. Reinforcing steel in the concrete masonry unit wall will provide strength to resist bending forces on the wall resulting from wind pressure perpendicular to the wall.

\subsubsection{Building Roofing System}

Roof construction for the laboratory building will be steel joist, metal decking, rigid insulation, and a single-ply membrane roofing system. If the support building wall system is masonry, the roof construction will be similar. If the support building structural system is an engineered metal building, the roofing will be metal decking, rigid insulation, and single-ply membrane supported on the low-slope metal building roofing purlins.

\subsubsection{Instrument Cave Walls}

The instrument cave walls were designed for shielding experiments located within. Several shielding cases of varying dose and shielding material were evaluated and the results are shown in Table 1 .

For an enveloping facility design basis, the instrument enclosures or caves will be assumed to be constructed of reinforced concrete walls. The walls will be assumed to be $36 \mathrm{in}$. thick to provide radiological shielding properties required for project experiments. A cost evaluation was performed to determine if high-density concrete was an economical alternative to normal density concrete. As shown in Table 2, the high-density concrete was significantly more expensive and the savings in wall thickness did not compensate for the higher cost.

Table 1. Radiation shielding comparison.

Thickness/Dose Rate (inches/mR/hr) ${ }^{2}$

\begin{tabular}{|c|c|c|c|c|c|c|c|}
\hline $\begin{array}{c}\text { No. of } \\
3 \mathrm{Ci} \\
\text { Sources }\end{array}$ & $\begin{array}{c}\text { Total } \\
\text { Curies }\end{array}$ & $\begin{array}{c}\text { Normal } \\
\text { Concrete } \\
2.35 \mathrm{~g} / \mathrm{cm}^{3}\end{array}$ & $\begin{array}{l}\text { High Den } \\
\text { Concrete }^{1} \\
3.35 \mathrm{~g} / \mathrm{cm}^{3}\end{array}$ & $\begin{array}{l}\text { Steel Shot } \\
4.0 \mathrm{~g} / \mathrm{cm}^{3}\end{array}$ & $\begin{array}{l}\text { Solid Steel } \\
7.86 \mathrm{~g} / \mathrm{cm}^{3}\end{array}$ & $\begin{array}{l}\text { Lead Shot } \\
6.8 \mathrm{~g} / \mathrm{cm}^{3}\end{array}$ & $\begin{array}{l}\text { Solid Lead } \\
11.35 \mathrm{~g} / \mathrm{cm}^{3}\end{array}$ \\
\hline 10 & 30 & $35 / 0.38$ & $25 / 0.44$ & $22 / 0.46$ & $11.75 / 0.41$ & $10.25 / 0.46$ & $6.25 / 0.48$ \\
\hline 8 & 24 & $34 / 0.44$ & $25 / 0.35$ & $22 / 0.37$ & $11.50 / 0.44$ & $10.00 / 0.49$ & $6.25 / 0.38$ \\
\hline 6 & 18 & $33 / 0.47$ & $24 / 0.44$ & $21 / 0.49$ & $11.25 / 0.44$ & $9.75 / 0.50$ & $6.00 / 0.47$ \\
\hline 4 & 12 & $32 / 0.46$ & $23 / 0.50$ & $21 / 0.33$ & $11.00 / 0.39$ & $9.50 / 0.45$ & $6.00 / 0.31$ \\
\hline 2 & 6 & $30 / 0.48$ & $22 / 0.42$ & $20 / 0.30$ & $10.25 / 0.45$ & $9.00 / 0.40$ & $5.50 / 0.41$ \\
\hline 1 & 3 & $28 / 0.50$ & $21 / 0.35$ & $18 / 0.47$ & $9.75 / 0.39$ & $8.50 / 0.36$ & $5.25 / 0.33$ \\
\hline
\end{tabular}

1. A sensitivity of $1 \mathrm{in}$. was used for normal concrete, high density concrete, and steel shot. A sensitivity of 0.25 in. was used for solid steel, lead shot and solid lead.

2. Shield was modeled with a mass-less point source located $1 \mathrm{ft}$ from the inside surface and the dose rate was measured at $1 \mathrm{ft}$ from the outside surface. 
Table 2. Shielding concrete cost comparison.

\begin{tabular}{|c|c|c|c|c|c|c|c|c|c|c|c|c|}
\hline & \multicolumn{3}{|c|}{ 2.5 High Density Conc } & \multicolumn{4}{|c|}{ 2.0 High Density Conc } & \multicolumn{5}{|c|}{ 3.0 Normal Wt Concrete } \\
\hline & Width & Height & Thick & cy & Width & Height & Thick & cy & Width & Height & Thick & cy \\
\hline N Wall & 31.5 & 10 & 2.5 & 29 & 30 & $0 \quad 10$ & 2 & 22 & 33 & 310 & 3 & 37 \\
\hline E Wall & 17 & 10 & 2.5 & 16 & 16 & 10 & 2 & 12 & 18 & 10 & 3 & 20 \\
\hline W Wall & 17 & 10 & 2.5 & 16 & 16 & 10 & 2 & 12 & 18 & 10 & 3 & 20 \\
\hline S Wall & 31.5 & 10 & 2.5 & 29 & 30 & 10 & 2 & 22 & 33 & 10 & 3 & 37 \\
\hline Middle Wall & 12 & 10 & 2.5 & 11 & 12 & 10 & 2 & 9 & 12 & 10 & 3 & 13 \\
\hline Roof & 31.5 & 17 & 2.5 & 50 & 30 & 16 & 2 & 36 & 33 & 18 & 3 & 66 \\
\hline Total & & & & 151 & & & & 113 & & & & 193 \\
\hline Cost & & & & $\$ 150,509$ & & & & $\$ 112,593$ & & & & $\$ 33,717$ \\
\hline
\end{tabular}

\subsubsection{Instrument Cave Wall Footings}

Footings under the instrument enclosure or cave walls will be constructed of reinforced concrete. The current estimated size of the footings is 12 -in. thick and 48 -in. wide. The footings will be required to bear on the gravel-silt-sand soil layer located approximately 3 to $8 \mathrm{ft}$ below ground surface.

\subsubsection{Floor Design}

Floors throughout both buildings will be reinforced, cast-in-place concrete. In areas where heavy floor loading is expected due to transportation of future instrument enclosure components (such as the shipping bay, operating and maintenance galleries), the floor may be up to 8 to 12 -in. thick, with the final thickness determined during final design. Concrete finishing tolerances will be specified for potential use of air pallets within the facility and will be based on specific air pallet equipment as determined by the project. Floors in non-traffic loaded areas will be 5-in. thick.

\subsubsection{Vibration Isolation}

Vibration isolation features include separating the support building structurally from the laboratory building. A layer of rigid insulation will be placed within the joint between the two structures. Baffles within the ductwork may be required to limit noise and vibration within the laboratory facility.

Thickened vibration isolation pads will be provided in each instrument enclosure or cave future location to minimize vibration transfer to the instruments. Additional vibration isolation pads will be provided in the operating gallery for additional instrumentation installation.

A site survey was performed by Colin Gordon and Associates to evaluate the vibration and EMI conditions at the IMCL site. Results showed that ambient vibration levels were very low and capable of meeting the stringent vibration criterion appropriate for IMCL. EMI levels also were very low. The report produced as a result of the survey is provided in Appendix C.

\subsubsection{Natural Phenomena Design}

Seismic design will be in accordance with DOE-STD-1189, "Integration of Safety Into the Design Process," Seismic Design Category 2. Seismic Design Category 2 corresponds to ASCE 7-08 Occupancy Category III or IV design criteria.

Wind criteria will be per DOE-STD-1020, Performance Category 2. ASCE 7-08 will be followed, using the corresponding Occupancy Category used in the seismic calculations to determine the Importance Factor. ASCE 7-08 will be used for snow load determination in a similar manner. 


\subsection{Mechanical - Hot Cell Equipment}

\subsubsection{Inter-building Pneumatic Transfer System}

IMCL will be constructed with an in-floor trench and a below-grade, exterior penetration that will extend to the exterior of the building. This trench will allow the future installation of an inter-building pneumatic transfer system. This future system will allow characterization samples to be transported inside of a small carrier through an interconnecting transfer tube between HFEF and IMCL. This system will be known as the inter-building pneumatic transfer system.

The future system will consist of a single transfer tubing that will allow a sample carrier to be transferred in either direction between the two buildings. Samples will be contained within special sample containers or carriers, commonly referred to as "rabbits."

As part of design and construction of the IMCL facility, the only part of this future inter-building pneumatic transfer system that will be designed and installed will be a cast-in-place floor trench with floor cover plates that will be removable.

The future system will be similar in operation to a planned pneumatic transfer system between the HFEF Decon Cell Window 3D and the Neutron Radiography Reactor, except this future system will use carriers and tubing larger in diameter. Carriers will be propelled through the transfer tubing by a combination of a vacuum in front of the carrier and atmospheric pressure behind it. The vacuum will be produced by a blower and routed through a piping manifold system. This system will use a single 2-1/4in. outside diameter $\times 20$-gage wall thickness steel tubing for the transfer tube. The system will be capable of sending carriers between facilities in either direction. This system will operate between air atmosphere equivalent confinement zones.

The pneumatic transfer carriers (for carrying samples and specimens inside) that will be used in this system are shown in MFC Drawing Numbers W0151-0078-EC and W0151-0078-PL. The future transfer tubing between the two buildings will be buried underground along with an electrical conduit for carrying control signals between the two buildings' control panels. The tubing will be routed south around any obstacles and enter the west end of the HFEF basement.

\subsection{Mechanical - Facility}

\subsubsection{General}

Mechanical systems provided for the new laboratory will include piped utilities and HVAC for year-round operation and occupant comfort. The HVAC control system will be digital-based and provide temperature tolerances consistent with laboratory user space requirements. The laboratory will have a specialized confinement exhaust system (suspect exhaust) dedicated to operation of the instrument caves, operating/maintenance galleries, and the support building mechanical room. Mechanical system energy efficiency will be considered to minimize laboratory energy usage to the extent practical and consistent with current energy codes and standards. New laboratory service piping will be connected to the existing MFC underground pipe utilities. These utilities will include firewater and sanitary sewer.

\subsection{Heating, Ventilating, and Air Conditioning}

\subsubsection{Laboratory Heating, Ventilating, and Air Conditioning}

To ensure that experimental operations within IMCL are not impacted by harsh weather extremes, the outside design temperatures are based on a $-30^{\circ} \mathrm{F}$ winter temperature and $100^{\circ} \mathrm{F}$ summer temperature. These temperatures are more conservative than those typically used at INL. However, given the tight temperature requirements for the instrument caves, it was determined that these design temperatures would give full mission capability year around. 
Heating and cooling will be provided by a single air-handling unit. This unit will condition the outside air to a $55^{\circ} \mathrm{F}$ discharge temperature to the building. This temperature is a common discharge temperature for cooling in the summer months. In the winter, duct heaters will elevate the supply air temperature to the desired temperatures in the instrument caves, operating/maintenance galleries, and the support building mechanical room. See Appendix D, Drawing HV-3, "HVAC Exhaust Flow Diagram".

Heating will be provided by electric resistance heat while cooling will use a chilled water loop with an air-cooled chiller. A chilled water system is being employed due to the fact that it has a much better capability of maintaining tighter temperature control. Electric resistance heat will be used with siliconcontrolled rectifier controls for tight temperature control.

Variable air volume boxes will control supply air flow to the areas as determined by space temperature conditions.

Instrument cave temperatures will be controlled to a maximum of $1^{\circ} \mathrm{C}$ per hour. Each instrument cave will have the capability of varying and maintaining its interior temperature over a range of temperatures between 68 and $78^{\circ} \mathrm{F}$.

A HEPA filtration section will be installed within the HVAC unit along with a high-efficiency duct filter section leading to the instrument caves to reduce dust penetration into the building and especially the instrument caves.

A unit heater will be installed within the fire riser room for freeze protection. The shipping bay and support building mechanical room will have unit heaters installed local to the overhead doors for supplemental heating when the doors are opened in the winter.

All HVAC units and duct systems will comply with American Society of Heating, Refrigeration, and Air-Conditioning Engineers and Sheet Metal and Air Conditioning Contractors National Association design and installation standards.

The laboratory HVAC unit will be located on the roof of the support building just above the mechanical room.

\subsubsection{Office Area Heating, Ventilating, and Air Conditioning}

The support building's office HVAC system will provide for year around operation and comfort of the building's occupants. The HVAC system design will be capable of producing a quality indoor environmental condition required for day-to-day operations. Building heating and cooling systems will be state-of-the-art, energy efficient, and flexible for future needs and modifications. The office area will be provided with environmental control to $\pm 2^{\circ} \mathrm{F}$ of the space set point temperature of $76^{\circ} \mathrm{F}$ (cooling) and $72^{\circ} \mathrm{F}$ (heating). In addition, the offices will be provided with individual adjustable room temperature controllers (T-stats).

General exhaust also will be provided in the restrooms. Ventilation will be provided per American Society of Heating, Refrigeration, and Air-Conditioning Engineers Standard 62.1.

The office HVAC unit will be located on the roof of the support building just above the office area.

\subsubsection{Heating, Ventilating, and Air Conditioning System (Telecommunications/ Electrical Rooms)}

The telecommunications and electrical rooms will be equipped with separate split system air conditioners to provide adequate equipment cooling. The air conditioners were sized based on typical heat loads for these rooms per square foot. Electrical rooms typically use equipment that generates 10 watts of heat per square foot, while telecommunications rooms typically use equipment that generates 40 watts of heat per square foot. The condensers for these rooms will be located on the roof of the support building. 


\subsubsection{Suspect Exhaust System}

A specialized suspect exhaust air system will be provided for each instrument enclosure or cave, the operations/maintenance galleries, and the support building mechanical room. All laboratory suspect exhaust air will be discharged to atmosphere, no recirculation of the exhaust air will be allowed. Laboratory suspect exhaust air will be discharged via an exhaust air stack. HEPA filtration will be provided in the exhaust air stream serving these areas. HEPA filters shall be capable of in-place-testing and change-out.

The instrument enclosures or caves will be kept at a recommended confinement differential negative pressure of -0.1 to -0.15 in. water gauge with respect to the operating/maintenance galleries (secondary confinement).

The operating/maintenance galleries will be kept at a recommended confinement differential negative pressure of -0.1 to -0.15 in. water gauge with respect to atmosphere (tertiary confinement).

The transfer corridor between the maintenance gallery and the support building will be kept at a slight negative pressure with respect to the office area.

The shipping bay will be the only area within the laboratory that is maintained at a positive pressure with respect to the outside and is done to reduce dust infiltration during shipments to the building.

Building exhaust will be via a single-stage, Flanders HEPA filter bank in a $4 \times 4$ filter matrix that includes HEPA filters, pre-filters, test inlets, test outlets, differential pressure indicators, and bubble-tight dampers. The building exhaust will be through a bag-in/bag-out HEPA filter system.

The main HEPA filter bank will be located in the support building mechanical room with adequate space on both sides for testing and bag-in/bag-out operations.

Each instrument cave will be equipped with a HEPA filter on the exhaust duct from each cave. These filters are a Flanders G-1 round housing with integral test ports, differential pressure indicators, and bubble-tight dampers. The filter housings will set on top of the instrument caves and will be configured for ease of testing and bag-in/bag-out operations.

Two exhaust fans will be located on the roof of the support building mechanical room and ducted into the stack. There are two exhaust fans for redundancy and they will be tied into the building standby power generator. The exhaust fans will be equipped with variable frequency drives to balance the laboratory areas to obtain the required negative confinement air pressures.

The exhaust system has been sized to accommodate future fume hoods and gloveboxes that will be installed by IMCL programs. During final design, the locations for exhaust connections within the operating/maintenance galleries will be identified.

\subsubsection{Exhaust Stack and Emissions Monitoring Capability}

The IMCL facility is dedicated to analysis and characterization of nuclear and non-nuclear materials. As such, the instrument caves, operating/maintenance galleries, and the support building mechanical room will be exhausted through a HEPA-filtered stack. Analysis will be performed on the projected air emissions and a determination will be made as to whether effluent monitoring is required for compliance with 40 CFR 61, "National Emission Standard for Hazardous Air Pollutants," Subpart-H, "National Standards for Emissions of Radionuclides Other than Radon from Department of Energy Facilities." If analysis determines that an emissions monitoring system is required, the current stack design will easily accommodate the installation of a system that complies with guidance presented in ANSI N13.1-1999, "Sampling and Monitoring Releases of Airborne Radioactive Substances from the Stacks and Ducts of Nuclear Facilities." This includes critical stack dimensions, the stack access platform and ladder, and a future location for an air emissions monitoring cabinet that would be housed within the 
support building mechanical room. Four blanked-off sample/inspection ports and the mixing box will be included in the stack design to accommodate a future monitoring system. Stack velocity will be kept above 3,000 fpm.

\subsubsection{Heating, Ventilating, and Air Conditioning Controls}

HVAC controls will be state-of-the-art and consist of a fully compliant BacNet direct digital control system. This system also will be consistent with building management systems provided by major building automation equipment manufacturers. The building management systems will be a microprocessor-based design to optimize equipment performance and monitor the HVAC system. The system will use a graphical user interface and have trending, scheduling, live graphics, set-point adjustments, and alarm indication. The control system used for IMCL will interface with the main control system being integrated into the Noresco contract currently being implemented at MFC. The control system to be used in this case is manufactured by Allerton.

\subsubsection{Differential Pressure Monitoring System}

Instrument cave pressurization controls will be provided for a safe laboratory work environment.

Pressure differential control will be provided by adjusting the make-up air supply to the caves at a slightly less flow rate than the exhaust flow (-0.1 to -0.15 in. water column) with respect to the operating/maintenance corridors. The operating/maintenance corridors also will be provided with similar differential controls with respect to atmosphere. The control system will monitor room differential pressure, make necessary automatic adjustments to control dampers and exhaust fans, and provide local indication and alarm functions. Laboratory controls will be integrated with the building monitoring system control system. The Ashcroft XLpd series of transmitters with \pm 5 inches of water and $\pm 0.5 \%$ accuracy will be used to measure the pressures. The differential pressure system will interface with the building monitoring system. The digital pressure monitoring system will be powered from a $24-\mathrm{Vdc}$ power supply fed from an uninterruptible power supply.

Each confinement area will be provided with a status and alarm monitoring system. This system will monitor conditions within the laboratory and notify the occupant of problems or unsafe conditions. There will be a 19-in color summary display, light stack, audible alarm, and alarm acknowledge push button inside the main entrance to the facility that will provide an overview of the whole facility. In addition, the system will monitor the health and status of other building systems such as HVAC status and exhaust flows.

\subsubsection{Instrument Cave Airflow Distribution}

Airflow (supply and exhaust) and acoustical noise from HVAC fans negatively impact the experimental equipment within each instrument enclosure or cave. Future design of the airflow distribution shall take into account the location and configuration of equipment within each enclosure. Air flows should not be directed toward experimental equipment and a sound attenuation design should be used within the ductwork to reduce acoustical noise emanating from HVAC fans. At this time, flanged inlet and exhaust connections will be stubbed down into the enclosures approximately 6 in. from the ceiling of each enclosure at opposite corners to achieve proper air flow patterns.

\subsubsection{Energy Conservation}

Mechanical system energy conservation will meet voluntary commercial energy standards per 10 CFR 434, American Society of Heating, Refrigeration, and Air-Conditioning Engineers Standard 90.1, and the International Energy Conservation Code 2003. Specifically, variable frequency drives will be used on laboratory supply and exhaust fan(s) to reduce energy consumption and high-efficiency condensing units will be provided for direct expansion cooling units. 


\subsubsection{Heat Recovery System}

The heat recovery system is a glycol and water loop system that transfers energy from the HEPA-filtered laboratory exhaust to the supply air of the main HVAC unit. Mixing of the exhaust air stream and supply air stream is not allowed. This system is intended to operate only in the heating season.

\subsubsection{Water Use Reduction and Energy Efficiency}

Monitoring water consumption (water meter) and using water efficient fixtures will help reduce water use. A tankless water heater system also will be used to heat water only when called for instead of keeping a tank of water heated continuously.

\subsection{Piping and Plumbing}

\subsubsection{Potable Water}

The firewater/potable water service at MFC is a combined system. As such, the potable water line will be tapped off the fire riser within the fire riser room of IMCL. Initial calculations indicate the need for a 2-in. tap. Appropriate backflow prevention shall be provided to isolate the systems in accordance with ES\&S-TI-027, "INL Technical Interpretation, Potable Water Protection from Radioactive Contamination," Revision 3, February 27, 2008, and the "Cross Connection Control Manual," Pacific Northwest Section of the American Water Works Association.

At minimum, a double check valve assembly will be required. Note: If it is determined that a reduced pressure backflow assembly is required, provisions for valve discharge drainage shall be provided. Potable water will be reduced in pressure (below $80 \mathrm{psig}$ ) and distributed throughout the support building to required fixtures (including the potable hot and cold water systems). A flow totalizer also shall be installed to monitor facility water usage in gallons. All fixtures shall have appropriate backflow prevention devices, assemblies, and methods per the Uniform Plumbing Code and the Pacific Northwest Section American Water Works Association "Cross Connection Control Manual." Potable water piping material will be Type L copper tube.

All building plumbing systems will conform to the Uniform Plumbing Code and the International Mechanical Code. Other piped utilities will conform to ASME B31.9, "Building Service Piping," and ASME B31.3, "Process Piping," as applicable.

Building potable water piping will be protected from water hammer by installation of water hammer arrestors in accordance with the Uniform Plumbing Code and will be sterilized after installation and prior to use.

Because of the radiological nature of the process within the building, it is suspected that premise protection for cross-contamination will be required pending review by environmental, safety, health, and quality assurance.

Potable water will not be used for non-potable uses (i.e., potable water will not be routed to instrument caves, future installed fume hoods, gloveboxes, and laboratory sinks, or HVAC equipment).

As part of the potable water distribution, appropriately sized water lines will be run into both the maintenance gallery and the support building mechanical room to accommodate the potential for safety showers and laboratory water in the event they are needed in the future. These two pipes will be capped just inside each room.

\subsubsection{Domestic Plumbing Systems}

Domestic plumbing fixtures that will be installed within the support building include: a tankless water heater, two water closets, two lavatories, a water cooler, and a service/mop sink in the janitor's closet. 


\subsubsection{Instrument Air}

An instrument air system will be provided for IMCL. The instrument air system will consist of a packaged compressor and receiver tank located in the support building mechanical room, with a piped distribution to the manifold above the sample cave. The air supply requirement for this building is $60 \mathrm{scfm}$ at a nominal 100-psig pressure. Air purity shall conform to ISO 8573.1, Quality Class 1.1.1, which provides for an air line filter that removes $70 \%$ of oil aerosols and all solid particles one micron and larger, an oil removal filter that removes $99.999 \%$ of oil aerosols and all solid particles 0.01 microns and larger, and a low dew point desiccant dryer that produces pressure dew points as low as $-100^{\circ} \mathrm{F}$. The piping material shall be carbon steel. For vibration isolation, the compressed air system shall set on a vibration isolation pad.

\subsubsection{Process Gas Piping System}

Compressed gases will be supplied by means of Department of Transportation-rated bottles located outside the laboratory building. These bottles shall be stored in a weather-protected enclosure for safe and easy access year-around. Forklift access shall be required to this area. The gases shall consist of argon, nitrogen, P-10, and specialty gases as needed. Gas pressures will be delivered at a pressure of 90 psig and will be run into the building in separate piping headers. A piping manifold will be set up to accommodate the needed gas piping runs to each instrument cave. The programs will be responsible for installation of the required gas piping to each instrument cave from this manifold. Piping material used will be stainless steel.

\subsection{Fire Protection}

\subsubsection{Alternatives and Trade Studies}

Several different types of an active fire protection system were evaluated in TEV-851, "IMCL Fire Protection System Selection." The conclusion of this evaluation was that the selected fire system for this installation would be a wet pipe sprinkler system.

\subsubsection{Passive Features}

The fire riser room is the only room planned to have fire-rated construction with exterior access. This would allow the inspection of the fire water riser and control valves during the early stages of a fire scenario to ensure the system is operational. All other construction features will use non-combustible construction with exits arranged to limit the required travel distance to less than the minimum required by the Life Safety Code.

\subsection{Electrical}

\subsubsection{Normal Power}

Both normal and standby power will be distributed throughout the facility. The building service will be at $480 \mathrm{~V}$, three-phase to supply the majority of mechanical loads. A step-down transformer will supply the 208/120-V, three-phase and single-phase power to lighting, receptacle loads, and the balance of the mechanical loads. Electrical circuits and capacity will be dedicated and available to serve future project needs at instrument caves. Unique construction methods are required to mitigate the detrimental influences of EMI on instruments. Many of these strategies are described in later electrical sections of this report.

Energy efficient fluorescent lighting with a combination of automatic and manual load reduction controls will be used in office and laboratory support areas. Instrument cave access and convenience lighting also will employ fluorescent lighting with ballasts located outside of and remote to the caves to further mitigate EMI immediately adjacent to sensitive instruments. High-intensity discharge lighting with remote ballasts, located in the mechanical room, will be used for the maintenance gallery, operating 
gallery, shipping bay, and exterior illumination. Lighting budgets and controls are intended to satisfy LEED and energy conservation codes.

\subsubsection{Uninterruptible and Standby Power}

The facility requires only two classes of power: normal power and standby power. No general uninterruptible power will be provided. Uninterruptible power will be supplied to finite loads through commercially available, stand-alone, cord-and-plug connected devices dedicated to respective loads (i.e., the evacuation notification system and network switch). Uninterruptible power necessary for research equipment will be provided by the respective research project. The location of uninterruptible power supply power conditioning equipment must be considered and evaluated on a case-by-case basis. Standby power will be provided by a standby diesel generator set via an automatic transfer switch and dedicated distribution equipment. Separate distribution panels and wiring will be provided for each class of power.

An evaluation was performed to determine if an existing spare diesel generator located at the Fuel Conditioning Facility would realize cost or schedule savings. TEV-804, "FCF Spare Diesel Generator Evaluation for Use at IMCL," concluded that a new packaged generator system is the best option for standby power.

\subsubsection{Facility Electrical Distribution}

Distribution panels will be located in the electrical room of the support facility to provide distance and structural isolation from the experiments. Dedicated fusible disconnect switches will provide flexibility in supplying branch circuits to each cave. Both $480-\mathrm{V}$ and $120 / 208-\mathrm{V}$ sources will be available to each cave through fusible disconnect switches and permanently installed raceways sized to accommodate the largest predictable loads. Other laboratory loads will be supplied from compatible phase and voltage sources from the appropriate class of power.

20-A, 120-V, single-phase receptacles will be provided in continuous wireways in all laboratory and support facility areas. Special purpose receptacles will be provided and located in areas of the facility to support known needs. In general, the $120-\mathrm{V}$ receptacles will be spaced to minimize the need for extension cord use. All lighting and convenience receptacles will be supplied from standby power and will be labeled to reflect these conditions. Convenience receptacles will be provided at all potential fume hood locations. All receptacles near sources of water will be of the ground fault circuit interrupter (GFCI) type. For ease of GFCI testing in accordance with Occupational Safety and Health Administration regulations, GFCI circuit breakers will not be used for receptacles and the feed through feature on the GFCI receptacles will not be used. Receptacles to assist in administrative, maintenance, and repair activities will be provided in the support building, shipping bays, maintenance gallery, and the operating gallery. When appropriate, these receptacles also may be used for operation of experiments.

Consideration will be given during final design to the use of a balanced, very low noise distribution system per National Electric Code Article 647, "Sensitive Electronic Equipment."

$480-\mathrm{V}$, three-phase power will be provided for ventilation and environmental conditioning systems. The main facility exhaust system requires standby power.

\subsubsection{Exterior Electrical Distribution}

$120-\mathrm{V}$ convenience receptacles will be provided along the exterior of the building and adjacent to access doors. These receptacles will be of GFCI type and will be protected from the elements per National Electric Code requirements.

\subsubsection{Lighting}

Energy conservation and EMI mitigation will be the top considerations in designing the lighting system for the facility. Daylight harvesting will be used whenever possible. Fixtures will be manually or 
automatically controlled such that lamps may be de-energized to reduce the connected lighting load in a reasonably uniform illumination pattern by at least 50\%. T8 lamps will be used for fluorescent lighting needs throughout the facility. Lamps must pass the federal toxicity characteristics leaching procedure test for classification as non-hazardous waste. State-of-the-art luminaries and electronic ballasts that have been designed to optimize light output of the lighting system will be used. Occupancy and photo sensors will be used wherever practical throughout the facility. Careful attention will be paid to the distribution of brightness over the luminaire aperture to ensure that distracting contrast differences are minimized and to mitigate lighting pollution from exterior fixtures. Industrial-type open fluorescent luminaries will be provided in the mechanical space of the support facility. Design illumination levels will be in accordance with the Illuminating Engineers Society handbook.

Security and egress lighting will be provided around the perimeter of the building and near personnel and vehicle access points. This lighting will be controlled by a photo electric switch and will come on at dusk and go off at dawn. Lighting for personnel safety will be provided along egress paths. Approximately 1 foot-candle of light will be provided at all times near areas anticipated to be accessed by personnel. All exterior fixtures will have metal halide light sources and will be dark-sky compliant.

As part of the EMI mitigation strategy, all lighting will be $120 \mathrm{~V}$ and no ballasts will be located in the operating gallery, maintenance gallery, or shipping bay. Ballasts supplying exterior lighting mounted to the laboratory also will be located remotely in the support facility.

\subsubsection{Construction Methods for Mitigating Alternating Current Extremely Low Frequency Magnetic Fields}

Each single-phase circuit must have a dedicated neutral with each phase to ensure maximum magnetic field cancellation along the conduit paths. All neutral conductors must be tested for unintentional grounding. The final testing report must be submitted to the engineer/EMI consultant for review.

In EMI sensitive areas (including caves, maintenance gallery, and operating gallery), all circuit conductors (phases, neutral, and grounding) should be in close physical proximity for maximum magnetic field cancellation. Nylon wire ties will be used at switchboards, in pull boxes, wire-ways, surface metal raceways, and at equipment termination points to minimize conductor separation.

Circuits (power, signal, or telecommunications) should not be routed above or below EMI-sensitive laboratories, except those circuits required for the specific use of the laboratory. All conduits (power, signal, or telecommunications) should be routed to provide maximum separation distance from future instruments. All branch and lighting circuits must have dedicated neutrals that follow each phase conductor.

All primary feeders within $50 \mathrm{ft}$ and inside of the building must be in rigid galvanized steel conduits. All 480/277-V and 208/120-V high current feeders within $50 \mathrm{ft}$ and inside of the facility must be in rigid galvanized steel conduits. All circuits $100 \mathrm{~A}$ and higher must be in rigid galvanized steel conduits. Electrical metallic tubing conduit may be considered for circuits less than 100 A. Twisting the phase and neutral conductors decreases EMI emission profiles in electrical metallic tubing conduits; however, the effect is minimal for rigid galvanized steel conduit. It is recommended that phase and neutral conductors be twisted in electrical metallic tubing conduits, but not necessarily for conductors in rigid galvanized steel conduits.

Electrical equipment should not be located within $16.4 \mathrm{ft}$ of the EMI-sensitive tool columns or instruments. Electrical conduits $100 \mathrm{~A}$ and higher must be routed to ensure maximum separation distance from the EMI-sensitive tools. It is recommended that switchgear and electric rooms be simulated under average and peak loads to verify the potential EMI. Alternating current extremely low frequency magnetic shielding may be recommended for switchgear and electric rooms to ensure tool compliance when sufficient distance and separation is not achievable. 
Busways of any size in scientific and research buildings are not recommended unless the busway EMI emissions simulations reflect negligible interference and the appropriate distance to EMI-sensitive tools is satisfied. If busways are specified, it may be necessary to install magnetic shielding systems around the electrical room to attenuate the magnetic field emissions in adjacent EMI-sensitive laboratories and offices.

Neutral conductors in three-phase, four-wire systems serving panel boards supplying single-phase, nonlinear electronic load equipment should be properly sized to handle the increased currents associated with the triplen harmonics and any phase imbalances. These increased currents cause additional heating due to the proximity of heating effects and the increased losses of the neutral conductor. The recommended practice is to oversize the neutral conductor to a minimum of one trade size larger than the phase conductor ampacity or use two neutral conductors sized the same as the phase conductor. If two neutral conductors are run in parallel, the size of the individual neutral conductors must be at least \#2 American wire gauge.

It is recommended that Underwriters Laboratory and K-rated, dry-type transformers be considered for their response in supplying non-sinusoidal load currents. The K-factor relates a transformer's capability to serve varying degrees of nonlinear load without exceeding the rated temperature-rise limits. The K-factor is the ratio of stray losses in the transformer winding for a given non-sinusoidal load current to the stray losses in the transformer winding produced by a sinusoidal load current of the same magnitude. These transformers are typically specially designed to handle the increased heating effects and neutral currents produced by nonlinear electronic load equipment. The following are some of the design features:

- $\quad$ The neutral bus is rated at $200 \%$ of the secondary full load ampere rating to accommodate the large neutral currents that principally result from triplen (third) harmonics and phase imbalance. The transformer neutral bus rated at $200 \%$ is capable of accommodating oversized or multiple neutral conductors.

- $\quad$ The winding conductors are specially configured and sized to minimize heating due to harmonic load currents. They have special configurations and sizing such as multiple, parallel conductors that help reduce the skin effect of the higher frequency harmonics and accommodate the triplen harmonics that circulate in the transformer's primary (delta) windings.

- $\quad$ Cores are specially designed to maintain flux core density below saturation due to distorted voltage waveforms or high line voltage.

\subsubsection{Lightning Protection and Grounding}

A lightning risk assessment will be performed during final design to determine the warranted level of lightning protection.

A grounding system suitable for a laboratory setting and compatible with electromagnetic interference reduction strategies will be provided.

\subsection{Communication and Alarms}

\subsubsection{Fire alarms}

Fire alarms will be provided by connecting a new fire alarm control panel into the existing high speed Notifier-net fire alarm network. All equipment shall be UL 864, 9th edition listed. Notification appliance will consist of both strobes and speakers. Speakers will be driven by a digital voice command system and associated digital amplifiers. This system will be arranged to provide all evacuation and take cover tones and be capable of providing live voice messaging meeting NFPA 72 mass notification requirements. 


\subsubsection{Telecommunications}

General: Telephones, INL public and MFC private network access, and an intercom/paging system will be provided in the facility. Telephone and network services will be extended from the new MFC dial room via a new ductbank to a new telecommunications room in the facility. The intercom/paging system will originate in the new communications room and interface with the telephone system. The facility monitoring and alarm system will be tied into the building paging system for remote alarm enunciation.

Telephone: A 100 pair \#24 AWG filled ALPETH outside plant copper communication cable will be installed from the new MFC dial room to the new facility. The outside plant cable will terminate at a building protector located on the telephone backboard in the facility communication room.

Modular voice/data outlets will be located throughout the facility. Two unshielded twisted pair 4 pair \#24 CAT 6 or higher rated cables will be installed from the telephone backboard to each receptacle. The voice cable will be cream colored and the data cable will be blue. Voice/data receptacles will be located in the administrative areas and throughout the laboratory at strategic locations to support operations. Dedicated communications raceways will be provided to minimize unintended signal noise. Each cave will have at least two voice/data receptacle.

Network access: A 48 single-mode fiber optic cable will be installed from the MFC network switch and patch panels in the new MFC dial room to the new facility.

Freestanding equipment racks with rack-mounted network switches, power automatic transfer switch, uninterruptible power supply, data patch panels, and a single-mode fiber optic patch panel will be installed in the facility communications room. The single-mode fiber optic cable from the new MFC dial room will terminate at the rack-mounted fiber optic patch panel.

No wireless access points will be installed in the facility to mitigate radio frequency interference undesirable to experiment operation. Further consideration will be given during final design to the potential use and benefits of wireless networks.

A single-zone intercom/paging system will be installed in the facility. The system will provide telephone accessed one-way voice paging. The paging amplifier will be installed in the communications room.

Ceiling-mounted paging speakers will be installed throughout the administrative areas of the facility to satisfy notification requirements. Wall-mounted paging speakers will be installed in the maintenance and operating areas of the facility.

No cable tray will be used in the operating areas of the laboratory. Any cable tray systems considered in the support facility during final design will be weighed against the potential negative EMI effects on instruments. All power circuits will be run in rigid conduit. Control circuits and circuits for the telephone, network, and paging system cables in administrative areas will be run approximately $1 \mathrm{ft}$ above the suspended ceilings in administrative areas.

A reinforced concrete duct bank, with four 4-in. conduits, will be installed from the new MFC dial room and route on the west side of the plant and terminate at a new telecommunications manhole/vault near the IMCL facility. A new ductbank with two 4-in. conduits will route from the telecommunications manhole/vault to the new telecommunication room of the facility. The conduit/ducts will be installed under the support facility floor slab and will stub up into the respective rooms.

Any backboards necessary for telecommunications equipment will be 3/4-in. fire-retardant plywood painted with fire-retardant paint. The backboard will cover the wall on which it is mounted from 18 in. above the finished floor to $7 \mathrm{ft}$ above the finished floor. A copper ground bar will be installed at each backboard. The ground bar will be bonded to the building grounding system.

Communications power will be supplied by a 120 -VAC, standby powered, convenience receptacle via a load-specific, cord-and-plug connected uninterruptible power supply. At a minimum, a primary 
20-A, 120-V, dedicated receptacle and a shared 20-A, 120-V alternate power receptacle will be provided to each communications rack. The primary feeder will supply the rack uninterruptible power supply, the uninterruptible power supply output will supply the rack's primary power supply and the alternate feeder will supply the rack's redundant power supply.

\subsubsection{Building Evacuation System}

A building evacuation system will be provided. The system will consist of one or two 120-VAC Federal Signal Model 1 sirens that are controlled by the sitewide evacuation system. This control will be from the evacuation system in the MFC dial room. The power for the sirens will come from a load-specific uninterruptible power supply that is supplied by a standby power receptacle.

\subsubsection{Security/Access Control}

Card readers will be provided at the door between the laboratory area and the support building and the exterior shipping bay door, but will not impede egress.

\subsubsection{Long-lead Critical Equipment}

Long-lead equipment includes HEPA filters, transformers, and the standby generator. The HEPA filters are the most critical item with a long-lead of 6 to 10 months.

\section{COST ESTIMATE}

The capital cost of the project is $\$ 9.5 \mathrm{M}$ with contingency and escalation. A breakdown of the spending plan can be found in the project execution plan (PLN-3537).

\section{SCHEDULE}

The estimated, conceptual project schedule includes the following tasks and projected dates:

- Conceptual design:

- Safety design strategy

- Conceptual safety design report

- Preliminary/final design

- Fabrication/construction

- Readiness/closeout
December 2009 to June 2010

December 2009 to May 2010

December 2009 to May 2010

June 2010 to January 2011

February 2011 to May 2012

June 2012 to November 2012. 
Appendix A

Mission Need Alternatives 


\section{Appendix A Mission Need Alternatives}

1. Introduction

A group of people from nuclear operations and system engineering who have worked at MFC for several years and are very familiar with the facilities at MFC met to identify existing facilities that could be reconfigured to meet the mission need. The group screened out existing facilities that were not considered practical based on space, ventilation, utilities, structural integrity, existing safety basis, or interference with existing operations. The facilities that were considered practical were visited by the evaluation team to gather appropriate data for developing the alternatives for this analysis.

Six facilities at MFC have space that may be suitable for supporting irradiated materials characterization caves as alternatives to building a new facility (i.e., IMCL). These facilities are the Sodium Process Facility, the Sodium Components Maintenance Shop, the Transient Reactor Experiment and Test facility, the Fuel Conditioning Facility, the Zero Power Physics Reactor, and the Experimental Breeder Reactor-II Power Plant. This analysis compares the alternatives on the basis of performance, functionality, and cost to establish the best alternative for meeting the mission need of a flexible, reconfigurable Hazard Category 2 laboratory to support new and changing research equipment, while providing radiation shielding and protection from vibration and electromagnetic interference.

2. Alternatives to Meet IMCL's Mission Need

For purposes of the analysis, two main cave configurations were considered (shown in Figure A-1): (1) a series of four rectangular caves of approximately $920-\mathrm{ft}^{2}$ total footprint and (2) an octagonal cave configuration of $410-\mathrm{ft}^{2}$ total footprint with four experiment regions that fit within. Each configuration is designed with several removable walls to facilitate irradiated material experiments.

3. MFC-799, Sodium Process Facility/MFC-793, Sodium Components Maintenance Shop

The Sodium Process Facility (Figure A-2) and Sodium Components Maintenance Shop

(Figure A-3) are each too small to meet the mission independently, so they are considered together. Both facilities are currently designated for decommissioning and demolition. The Sodium Components Maintenance Shop currently is using the area where caves could potentially be installed for sodium processing and the Sodium Process Facility is listed as an alternate processing location for sodium waste. In order to use these facilities for caves, a programmatic decision would need to be made to stop sodium processing at the Sodium Components Maintenance Shop and remove the Sodium Process Facility from further consideration to process sodium waste. Another limiting factor is that there is a cleaning pit in the middle of the Sodium Components Maintenance Shop. This pit would need to have equipment and structural members removed to make the space useable.

The process exhaust for the Sodium Components Maintenance Shop is HEPA-filtered and exits the facility to a stack. It is not practical to connect a ventilation system from the Sodium Process Facility to the stack system at the Sodium Components Maintenance Shop because of the distance between the buildings and because the stack is on the opposite side of the Sodium Components Maintenance Shop. 
4. MFC-720, Transient Reactor Experiment and Test Facility

A large quantity of space is available inside the Transient Reactor Experiment and Test Facility (Figure A-4). Both the main area near the reactor core and the laydown area have sufficient space to contain the caves. In order to use the space, a decision would need to be made that the reactor will never be used again because, currently, consideration is still being given to the possibility of restarting the reactor. In addition, the Department of Homeland Security operates security programs in the facility, which would have to be conducted elsewhere. The Transient Reactor Experiment and Test Facility is located approximately 1/2-mile outside the MFC fence line; sample transfer at this distance and outside the fence would be burdensome.

5. MFC-765, Fuel Conditioning Facility

The mockup space within the Fuel Conditioning Facility (Figure A-5) would require relocation of the current HFEF mockup activities that take place in this area. Reconfiguring a separate facility at MFC or building a new facility for HFEF mockup activities would be required. The mockup space is actively being used to mockup equipment and processes to be performed within HFEF; therefore, any alteration of these capabilities could potentially cause delays in HFEF operations. Rooms 32A and 32B could have walls removed to create space in Room 10A, where a single cave could reside. The rest of Room 10A could be used as laboratory space with gloveboxes and other equipment.

6. MFC-776, Zero Power Physics Reactor

Although the Zero Power Physics Reactor (Figure A-6) initially is attractive for housing the caves because it has a large amount of available space, the security and ventilation issues make it an unrealistic option. A cost estimate has been performed for upgrading the legacy reactor ventilation for a glovebox and the estimated cost was in the range of $\$ 14 \mathrm{M}$. This upgrade cost exceeds the cost of building a new facility to house the caves. In addition, personnel working within the Zero Power Physics Reactor require a Q and HRP clearance, complicating the intended use of IMCL by foreign nationals.

7. MFC-768, Experimental Breeder Reactor II Power Plant

Because the power plant (Figure A-7) is no longer in use, the building has a large amount of available space on the main level. The second floor mezzanine would need to be removed or reconfigured as the cave ceilings. The area contains vertical steel and concrete columns that would interfere with placement of the caves.

There is a large overhead crane available within the building. The crane is mainly for use on the third floor with limited access to the main level. The power plant is heated but not air conditioned and the exterior walls do not have any insulation; therefore, an insulated shell would need to be built around the caves and their support areas to control temperature and electromagnetic interference from the metal building. The main power distribution equipment for MFC is located within the power plant; therefore, an adequate power supply is available.

The most attractive space for locating the caves on the main floor is in the southwest corner, which currently is crowded with piping and other mechanical equipment. Portions of this equipment would need to be removed. Some of this equipment contains caustics and would be considered Resource Conservation and Recovery Act hazardous waste. Nearby compressors would need to be relocated to avoid vibration interference.

The northwest area of the third floor is being used for Zeolite experiments, which could potentially impact or being impacted by the caves. 


\section{Conclusion}

Table A-1 describes the alternatives that involve modification of existing facilities, Table A-2 compares the alternatives based on performance and functionality, and Table A-3 presents a comparative evaluation of cost for the alternatives. The tables reveal significant challenges in using existing facilities for housing characterization caves. It is difficult to provide the performance and functions required in old structures built for other purposes. The expense of removing existing features and retrofitting new features to meet the mission need is, in all cases, much higher than the cost of a new facility. The best location to perform the new and changing research demanded at MFC is in a new, purpose-built IMCL. 
Table A-1. Alternative existing facility modifications to meet the Irradiated Materials Characterization Laboratory mission need.

\begin{tabular}{|c|c|c|c|c|c|c|}
\hline $\begin{array}{l}\text { PROSPECTIVE FACILITY } \\
\end{array}$ & PROGRAMMATIC ISSUES & STRUCTURAL & VENTILATION & SPACE & UTILITIES & NUCLEAR CATEGORIZATION \\
\hline MFC-799 SPF & $\begin{array}{l}\text { Designated for D\&D. Upper level where HVAC and HEPA } \\
\text { equipment is located is clean, lower level contaminated. All } \\
\text { equipment is palletized for ease of removal. This facility is also } \\
\text { an alternate for FFTF Na Processing. To take over the facility, } \\
\text { SPF would need to be taken off this alternate list (depends on if } \\
\text { Hanford decides it can perform the processing). Presents a long } \\
\text { term environmental liability. }\end{array}$ & $\begin{array}{l}\text { Slab on grade likely has potential for large } \\
\text { floor loads. } 10 T \text { crane available in main } \\
\text { space. The crane is restricted in terms of } \\
\text { degrees of freedom. Historical seismic } \\
\text { analysis may be lacking and need to be re- } \\
\text { analyzed. }\end{array}$ & $\begin{array}{l}\text { The south portion of the building is newer and } \\
\text { is well insulated and sealed. Ventilation } \\
\text { modifications would be necessary. It is not } \\
\text { practical to connect a ventilation system from } \\
\text { SPF to the stack system at SCMS because of the } \\
\text { distance ebtween the buildings and because } \\
\text { the stack is on the opposite side of SCMS. }\end{array}$ & $\begin{array}{l}\text { Area } 2 \text { is approximately } 1600 \text { sqft. One or two } \\
\text { rectangular caves could fit within this area after the } \\
\text { existing equipment undergoes D\&D. The area is too } \\
\text { small for a full set of four caves. }\end{array}$ & $\begin{array}{l}\text { Large power available } \\
\text { from nearby substation; } \\
\text { designed for high } \\
\text { amperage equipment. }\end{array}$ & $\begin{array}{l}\text { Non-nuclear. Nuclear } \\
\text { safety basis would need to } \\
\text { be developed. }\end{array}$ \\
\hline MFC-793 SCMS & $\begin{array}{l}\text { This is a RCRA permitted facility. Potentially needs permit mod } \\
\text { for changes. Currently performing Na processing within this } \\
\text { facility. Would need a programatic decision to halt } \mathrm{Na} \\
\text { processing and remove equipment. The equipment is designed } \\
\text { to be easily removed from the building. The alcohol processing } \\
\text { portion of the building is designated for D\&D. Presents a long } \\
\text { term environmental liability. }\end{array}$ & $\begin{array}{l}\text { The entire building has been disassembled, } \\
\text { moved and then reassembled. Has a } 500 \text { psf } \\
\text { floor loading limit. } 5 \text { and } 15 T \text { crane available } \\
\text { in main space. Historical seismic analysis } \\
\text { may be lacking and need to be re-analyzed. }\end{array}$ & $\begin{array}{l}\text { The building is old and is not well sealed or } \\
\text { insulated. The space is heated, but there is no } \\
\text { AC available. There is a } 2500 \text { CFM main building } \\
\text { exhaust and a } 10,000 \text { CFM exhaust for Na } \\
\text { processing vessel is available. The process } \\
\text { exhaust is } \text { EEPA-filtered and exits the facility to } \\
\text { a stack. }\end{array}$ & $\begin{array}{l}\text { Rm } 100 \text { is approximately } 2275 \text { saft. The cleaning pit in } \\
\text { the middle of the room is } 220 \text { saft and is a major } \\
\text { obstacle. Maybe two rectangular caves could fit if } \\
\text { arranged creatively around the pit once the sodium } \\
\text { processing equipment is removed. }\end{array}$ & $\begin{array}{l}\text { Large power available } \\
\text { from nearby substation; } \\
\text { designed for high } \\
\text { amperage equipment. }\end{array}$ & $\begin{array}{l}\text { Non-nuclear. Nuclear } \\
\text { safety basis would need to } \\
\text { be developed. }\end{array}$ \\
\hline MFC-720 TREAT & $\begin{array}{l}\text { If a decision is made to restart TREAT, personnel will not be } \\
\text { allowed near the facility during operation essentially } \\
\text { disqualifying it as an option. Also, the Department of Homland } \\
\text { Security has security projects currently at the facility. These } \\
\text { projects would need to be moved to accomodate IMCL type } \\
\text { project. DOE L clearance required for access. }\end{array}$ & $\begin{array}{l}\text { Slab on grade likely has potential for large } \\
\text { floor loads. Cranes available. }\end{array}$ & Ventilation modifications would be necessary. & $\begin{array}{l}\text { The area adjacent to the reactor core is } 2600 \text { saft. The } \\
\text { area has the capacity to fit all of the desired caves. The } \\
\text { laydown area (4300 sqft) also has sufficient area } \\
\text { especiallly if walls are torn down. MFC-720 is located } \\
\text { away from the main MFC campus. }\end{array}$ & $\begin{array}{l}\text { Utilities likely adequate } \\
\text { for the caves. }\end{array}$ & $\begin{array}{l}\text { HazCat } 2 \text { facility. Safety } \\
\text { basis would need } \\
\text { modification. }\end{array}$ \\
\hline MFC-765 FCF & $\begin{array}{l}\text { The mockup space would need to be moved to a new location. } \\
\text { This space is currently setup to model operations within HFEF. } \\
\text { Mock up space would require an overhead crane and an EM } \\
\text { crane. }\end{array}$ & $\begin{array}{l}\text { Slab on grade likely has potential for large } \\
\text { floor loads. Two cranes available. }\end{array}$ & $\begin{array}{l}\text { Ventilation modification would be } \\
\text { complicated. The mockup space is not self } \\
\text { contained. And the ventilation is designed for } \\
\text { the FCF cells. }\end{array}$ & $\begin{array}{l}\text { The mockup area ( } \mathrm{Rm} 28) \text { is about } 1450 \text { saft. This area } \\
\text { could potentially house all four caves. The space to the } \\
\text { sides of the caves would likely be tight and it may drive } \\
\text { making the caves smaller. }\end{array}$ & $\begin{array}{l}\text { Utilities likely adequate } \\
\text { for the caves. }\end{array}$ & \begin{tabular}{|l} 
HazCat 2 facility. Safety \\
basis would need \\
modification.
\end{tabular} \\
\hline MFC-776 ZPPR & $\begin{array}{l}\text { Q clearance and HRP needed to access facility. Homeland } \\
\text { Security is planning on using this space in the near future. }\end{array}$ & $\begin{array}{l}\text { Slab on grade likely has potential for large } \\
\text { floor loads. }\end{array}$ & $\begin{array}{l}\text { Ventilation system is in need of major upgrade. } \\
\text { Previous cost estimates for upgrading the } \\
\text { existing reactor ventilation for a glovebox } \\
\text { system were approximately \$14M. Facility } \\
\text { personnel estimate that efforts to upgrade the } \\
\text { ventilation for an IMCL type cave would be near } \\
\text { this cost. }\end{array}$ & $\begin{array}{l}\text { Rm } 101 \text { is approximately } 1800 \text { saft. The area is circular } \\
\text { and could only fit an octogonal cave configuration. }\end{array}$ & $\begin{array}{l}\text { Utilities likely adequate } \\
\text { for the caves. }\end{array}$ & $\begin{array}{l}\text { New safety basis would be } \\
\text { required. }\end{array}$ \\
\hline MFC-768 EBR Power Plant & $\begin{array}{l}\text { The main floor currently is crowded with piping and other } \\
\text { mechanical equipment. Portions of this equipment would need } \\
\text { to be removed. Some of this equipment contains caustics and } \\
\text { would be considered RCRA hazardous waste. An additional } \\
\text { concern is that the northwest area of the 3rd floor is being used } \\
\text { for Zeolite experiments. }\end{array}$ & $\begin{array}{l}\text { Slab on grade on the main level with a } 2000 \\
\text { psf floor load limit. The 2nd floor mezzanine } \\
\text { has a } 150 \text { psf floor load limit and the 3rd floor } \\
\text { slab has a } 350 \text { psf floor load limit. Large } \\
\text { overhead crane for use on the 3rd Floor, with } \\
\text { limited access to first floor. Historical seismic } \\
\text { analysis may be lacking and need to be re- } \\
\text { analyzed. }\end{array}$ & $\begin{array}{l}\text { The space is heated, however there no AC is } \\
\text { available. Ventilation system exchanges air in } \\
\text { the space. No insulation on outer walls. }\end{array}$ & $\begin{array}{l}\text { The main floor has plenty of space. The overhead is } \\
\text { low due to the 2nd floor mezzanine and many existing } \\
\text { pipes/utilities. The mezzanine would need to be } \\
\text { removed to use the space for the caves. The large open } \\
\text { area contains vertical steel and concrete members that } \\
\text { would potentially interfere with placement of the } \\
\text { caves. The location of these members would need to } \\
\text { be integrated into the configuration of the caves. } \\
\text { There are vibrational and electromagnetic } \\
\text { interferences in the area. Compressors currently in use } \\
\text { would need to be relocated away from the area. }\end{array}$ & $\begin{array}{l}\text { Main power distribution } \\
\text { (13.8kV) for MFC located } \\
\text { on the 3rd floor. }\end{array}$ & $\begin{array}{l}\text { Non-nuclear/Non- } \\
\text { radiological. Nuclear safety } \\
\text { basis would need to be } \\
\text { developed. }\end{array}$ \\
\hline
\end{tabular}


Table A-2. Performance/functionality comparison of alternatives.

\begin{tabular}{|c|c|c|c|c|c|c|c|c|c|}
\hline \multirow[b]{2}{*}{ CRITERIA \# } & \multirow[b]{2}{*}{ WEIGHTING } & \multirow[b]{2}{*}{ PERFORMANCE/FUNCTIONALITY CRITERIA } & \multicolumn{6}{|c|}{ FACILITY } & \multirow[b]{2}{*}{ COMMENTS } \\
\hline & & & $\begin{array}{l}799 \mathrm{SPF} / \\
793 \mathrm{SCMS}\end{array}$ & 720 TREAT & $765 \mathrm{FCF}$ & 776 ZPPR & $\begin{array}{c}768 \text { Power } \\
\text { Plant }\end{array}$ & IMCL & \\
\hline 1 & 4 & Room for Sample Cave & 5 & 7 & 1 & 1 & 7 & 10 & 1 \\
\hline 2 & 8 & Impact on Ongoing Operations/Programs & 3 & 1 & 2 & 3 & 8 & 10 & 2,3 \\
\hline 3 & 2 & Ease of Facility Access & 7 & 1 & 5 & 4 & 5 & 9 & 4 \\
\hline 4 & 6 & Inter-facility Transfer Efficiency & 4 & 1 & 2 & 1 & 2 & 8 & $5,6,7$ \\
\hline 5 & 4 & Intra-facility Transfer Efficiency & 3 & 10 & 3 & 8 & 8 & 10 & $8,9,10$ \\
\hline 6 & 8 & Operations/Maintenance Gallery Space & 1 & 10 & 3 & 2 & 5 & 9 & \\
\hline 7 & 6 & Future Expansion & 3 & 8 & 5 & 5 & 3 & 10 & 11,12 \\
\hline 8 & 5 & Non-nuclear Support Space & 9 & 10 & 2 & 4 & 9 & 8 & 13 \\
\hline 9 & 7 & Access Requirements / Security & 10 & 2 & 4 & 1 & 10 & 10 & \\
\hline 10 & 10 & Vibration / EMI Issues & 5 & 5 & 3 & 5 & 1 & 10 & 14 \\
\hline \multicolumn{3}{|r|}{ WEIGHTED AVERAGE SCORE (MAX SCORE = 6) } & 2.9 & 3.3 & 1.8 & 2 & 3.3 & 5.7 & \\
\hline
\end{tabular}

\section{COMMENTS:}

1. The proximity of the sample cave to the instrument caves is considered in Criteria \#5.

2. Mainly pertains to programs in the existing facilities displaced or impacted.

3. For $799 / 793$ consideration is for Na-processing and environmental liability .

4. Includes campus/foot-traffic and co-located activities, especially distance from HFEF.

5. Mainly pertains to inter-facility RABBIT, but also includes availability of equipment door

6. For 793/799, RABBIT would need to go to two buildings.

7. For 765 and 768, RABBIT would travel through congested areas.

8. Includes RABBIT and direct insertion of samples to instrument caves.

9. For 776 , sample cave location is unknown.

10. For 768 , direct insertion would be inhibited by structural columns

11. Includes expansion within existing facility $(720,768)$ or new facility $(799 / 793,765,776$ IMCL).

12. For 799/793 and 765, may depend on D\&D of adjacent facilities.

13. Assumes sharing space with existing operations is not viable.

14. Vibration pads will be cut into all foundations.
NOTES:

Four caves is the target number of caves Scoring is on a 1 to 10 scale 
Table A-3. Cost comparison of alternatives.

\begin{tabular}{|c|c|c|c|c|c|c|c|c|}
\hline \multirow{2}{*}{ COST ID } & \multirow{2}{*}{ COST ELEMENT } & \multicolumn{6}{|c|}{ FACILITY } & \multirow{2}{*}{ COMMENTS } \\
\hline & & 799 SPF / 793 SCMS & 720 TREAT & 765 FCF & 776 ZPPR & 768 Power Plant & IMCL & \\
\hline 1 & Demolition & 3 & 2 & 2 & 1 & 3 & $\mathrm{~N} / \mathrm{A}$ & \\
\hline 2 & Civil/Structural & 3 & 2 & 3 & 2 & 3 & 1 & A \\
\hline 3 & Caves - Concrete/Metal & 3 & 1 & 3 & 1 & 3 & 1 & B \\
\hline 4 & Ventilation & 3 & 2 & 2 & 3 & 3 & 1 & $\mathrm{C}$ \\
\hline 5 & Stack & 3 & 2 & 1 & 2 & 2 & 1 & $\mathrm{D}$ \\
\hline 6 & Thermal/Moisture Protection (building shell) & 1 & 1 & 1 & 1 & 2 & 1 & $\mathrm{C}, \mathrm{F}$ \\
\hline 7 & Mechanical & 3 & 2 & 2 & 2 & 2 & 1 & C, G \\
\hline 8 & Electrical & 3 & 2 & 2 & 2 & 2 & 1 & C, G \\
\hline 9 & Communications & 3 & 2 & 2 & 2 & 3 & 1 & C, G \\
\hline 10 & Relocation of Ongoing Programs/Operations & 2 & 2 & 3 & 1 & 3 & 1 & $\mathrm{E}$ \\
\hline 11 & Inter-facility RABBIT & 3 & 3 & 2 & 3 & 2 & 1 & $\mathrm{H}$ \\
\hline 12 & Vibration / EMI Solutions & 2 & 2 & 3 & 2 & 3 & 1 & \\
\hline 13 & Safety Basis Development & 1 & 3 & 3 & 3 & 1 & 1 & \\
\hline & COMPARATIVE COST & 2.5 & 2 & 2.2 & 1.9 & 2.5 & 1 & \\
\hline
\end{tabular}

Key

$1=$ Similar cost to IMCL

2 = Significantly more expensive than IMCL

$3=$ Dramatically more expensive than IMCL
Note: for this analysis, cost elements are not weighted by their comparative size, and cost scores are not directly proportional to estimated costs. Numbers between 1 and 2 in the "Comparative Cost" row should be interpreted as "significantly" more expensive than IMCL and numbers between 2 and 3 should be interpreted as "dramatically" more expensive than IMCL.
COMMENTS:
A. Includes site preparation and concrete work to improve floor loading within existing facilities and additional seismic analysis. Older buildings will be more expensive than newer buildings.
B. For 799/793, 765, and 768, caves and support systems would be more expensive because of the varied cave configuration and because they are not located adjacent to each other. A RABBIT system could be retrofitted either overhead or below ground during installation of vibration pads and structural upgrades to the floor.
C. Having to modify existing support systems increases costs dramatically.
D. For 799/793, two new stacks may be needed for these two facilities; other facilities require one or no new stacks.
E. Relocate compressors in 768. For 765, cost to build new mockup facility would be in addition to this evaluation. Assume relocation of Homeland Security in 720 would not require a new facility. New programs have not moved into to 776 yet, so no relocation is required.
F. Existing structures will require similar costs to the IMCL shell, for example, new roof or enhanced insulation. 768 requires a building within a building for temperature control.
G. Bathrooms and other mechanical systems will require upgrades. Routing piping and conduit in an existing structure is difficult. H. Based on proximity to HFEF. 

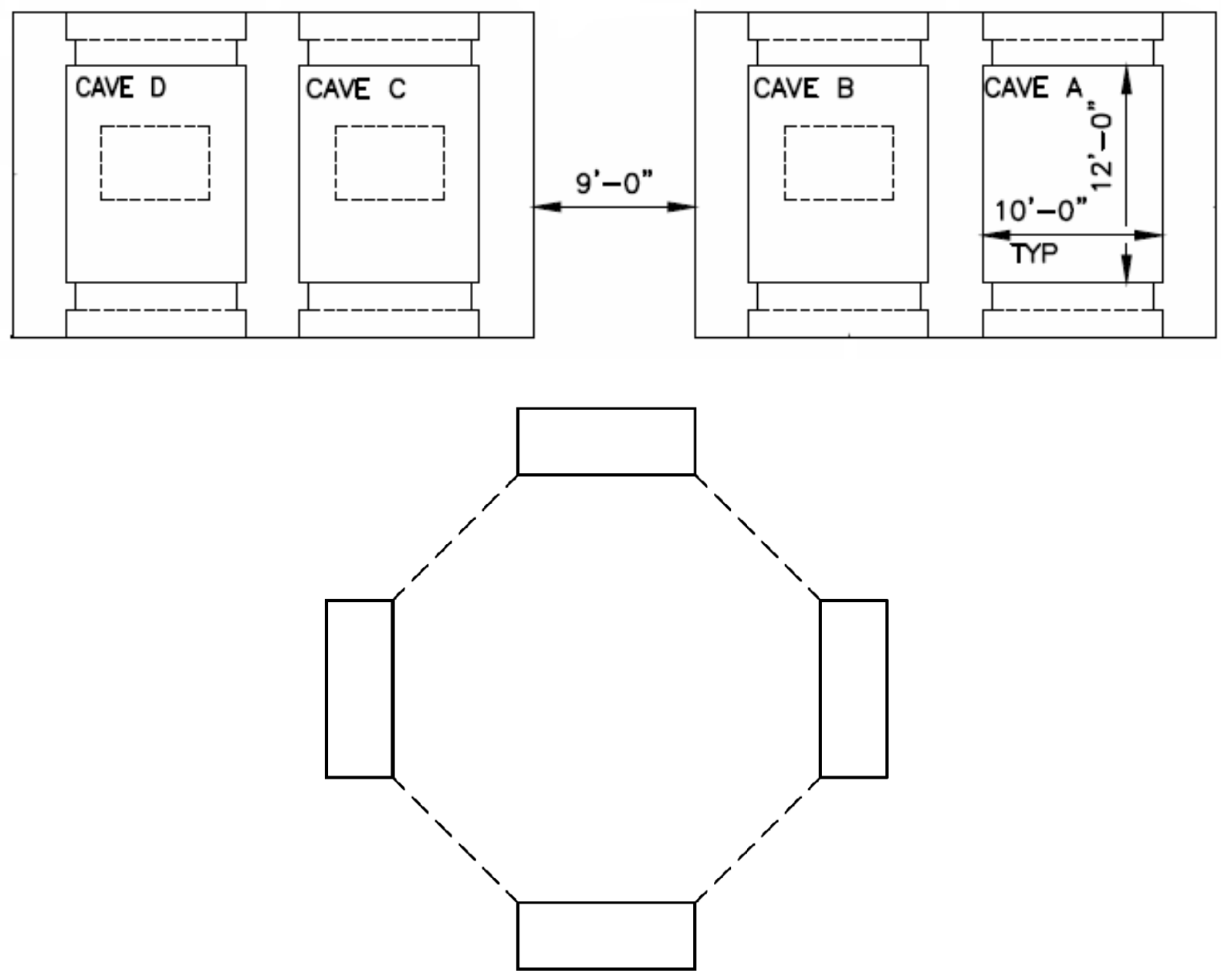

Figure A-1. Potential cave layouts. 


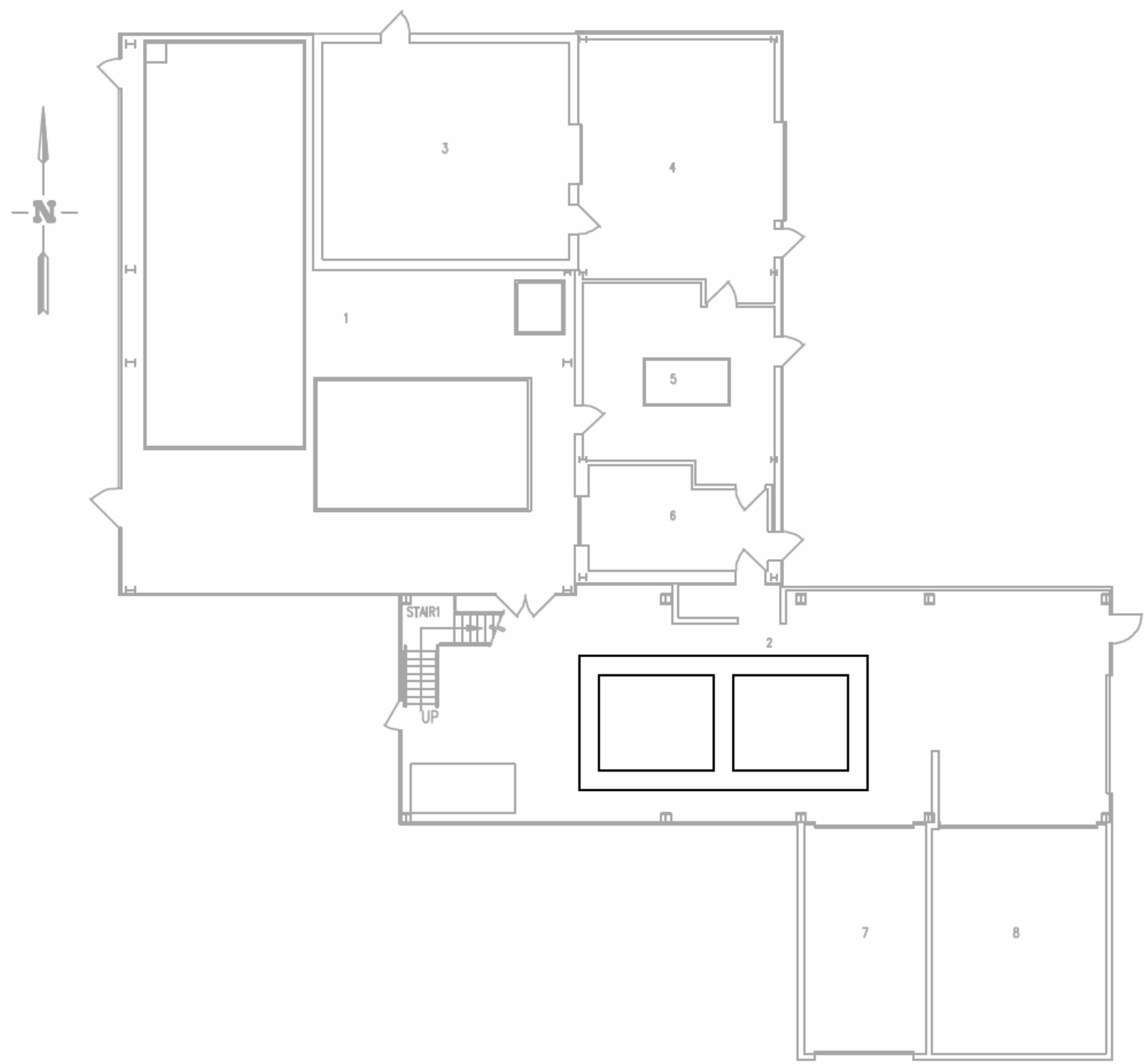

Figure A-2. MFC-799, Sodium Processing Facility, floor plan with potential cave location. 


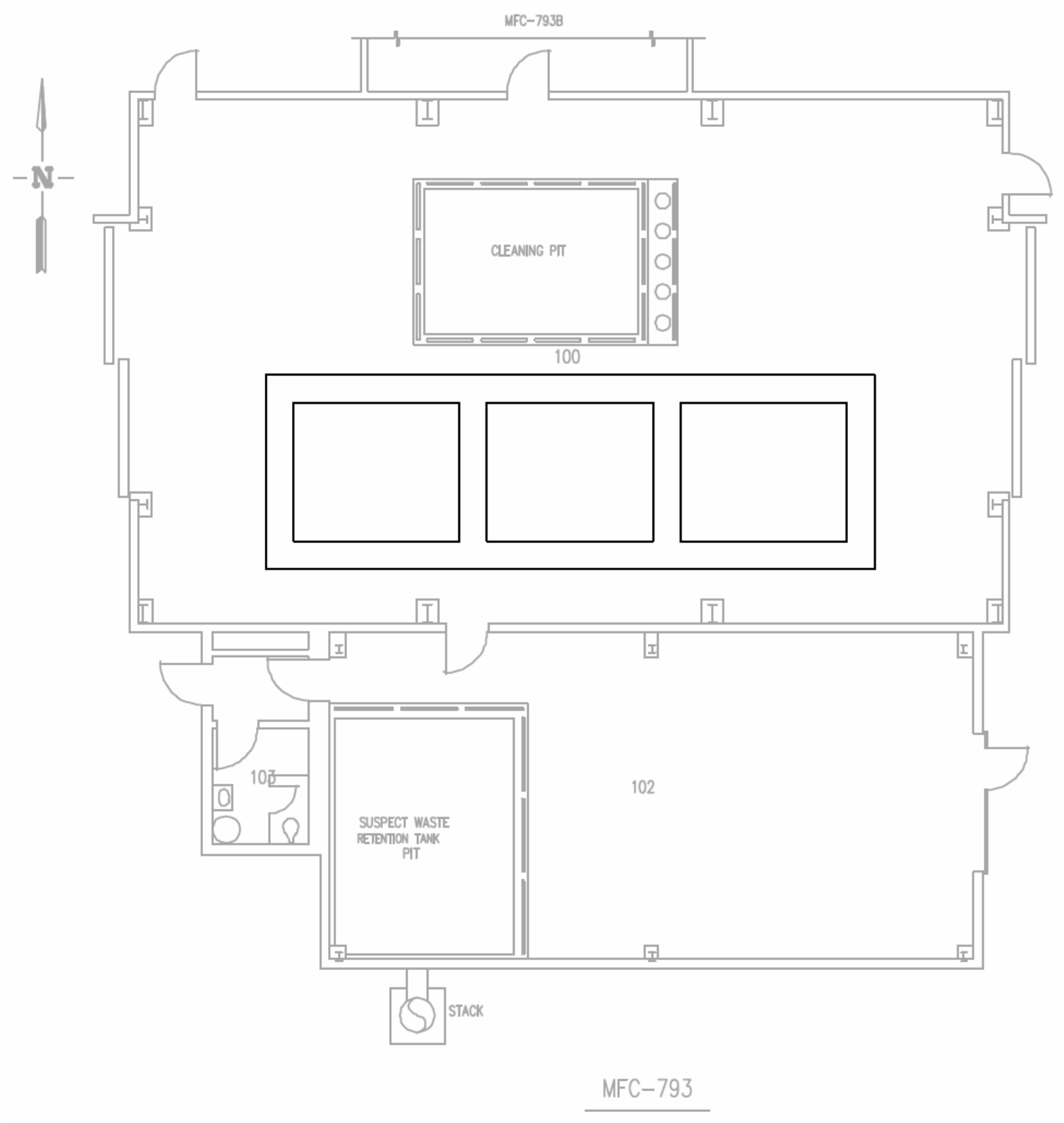

Figure A-3. MFC-793, Sodium Components Maintenance Shop, floor plan with potential cave location. 


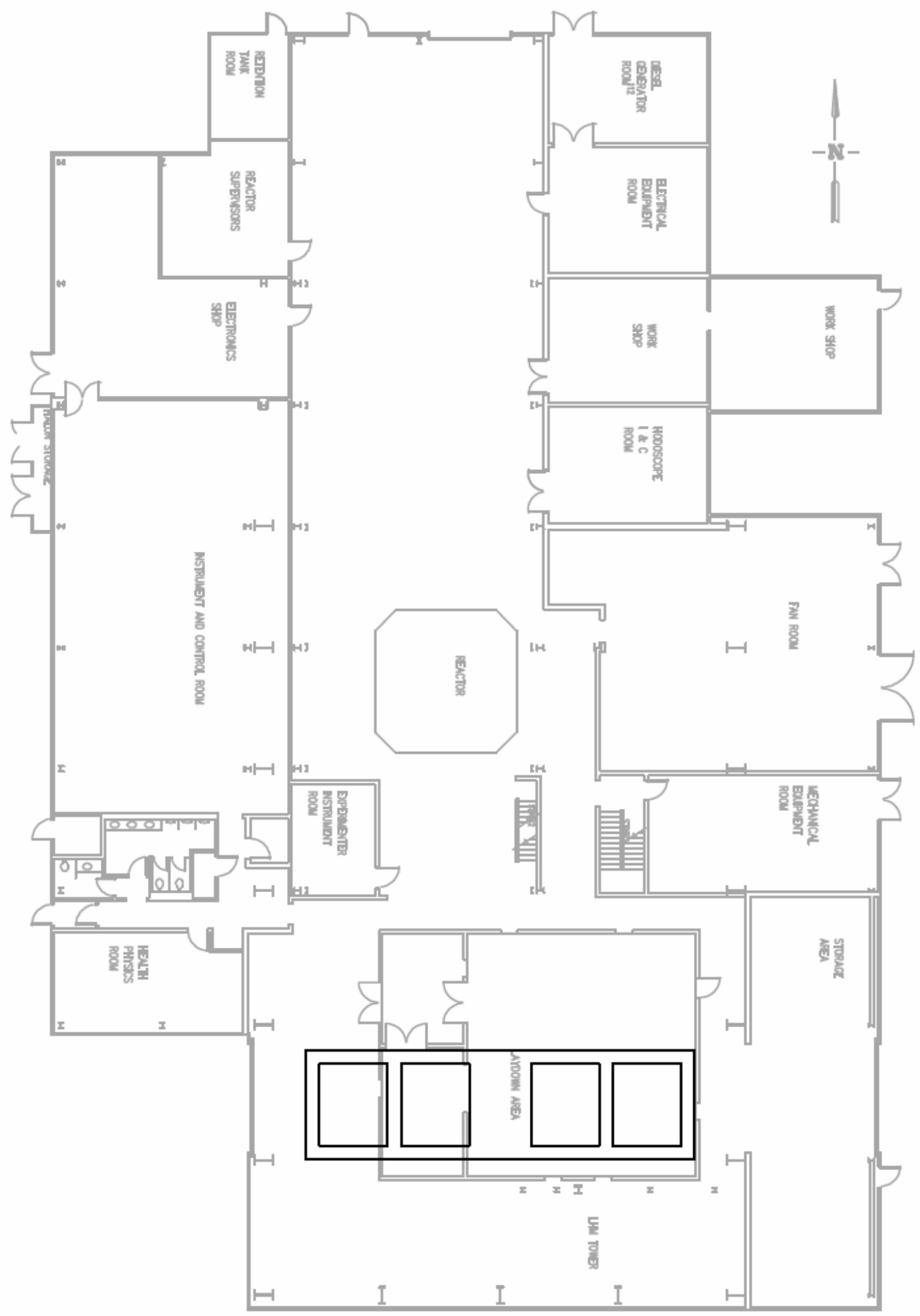

Figure A-4. MFC-720, Transient Reactor Experiment and Test Facility, floor plan with potential cave location. 


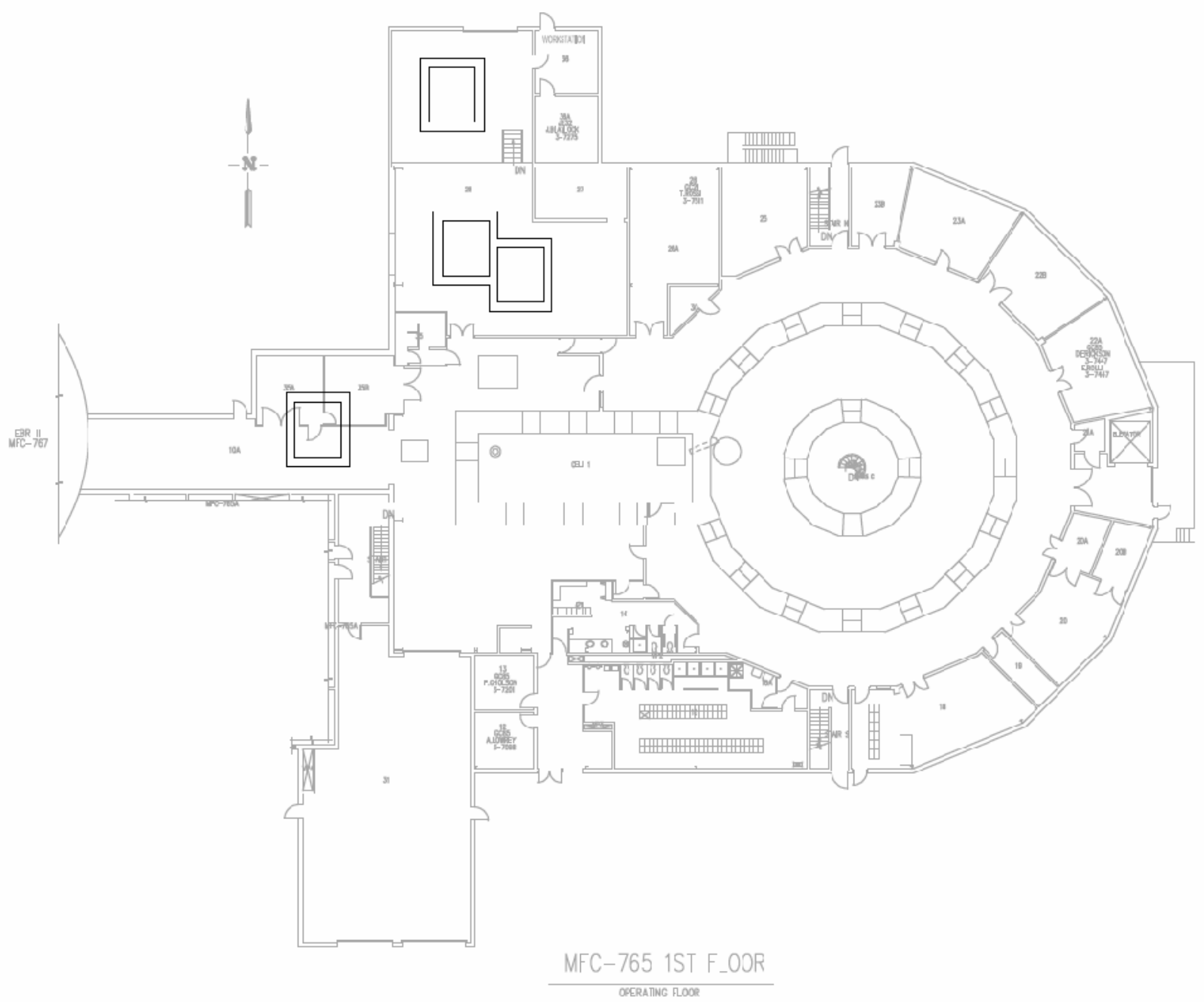

Figure A-5. MFC-765, Fuel Conditioning Facility, floor plan with potential cave location. 


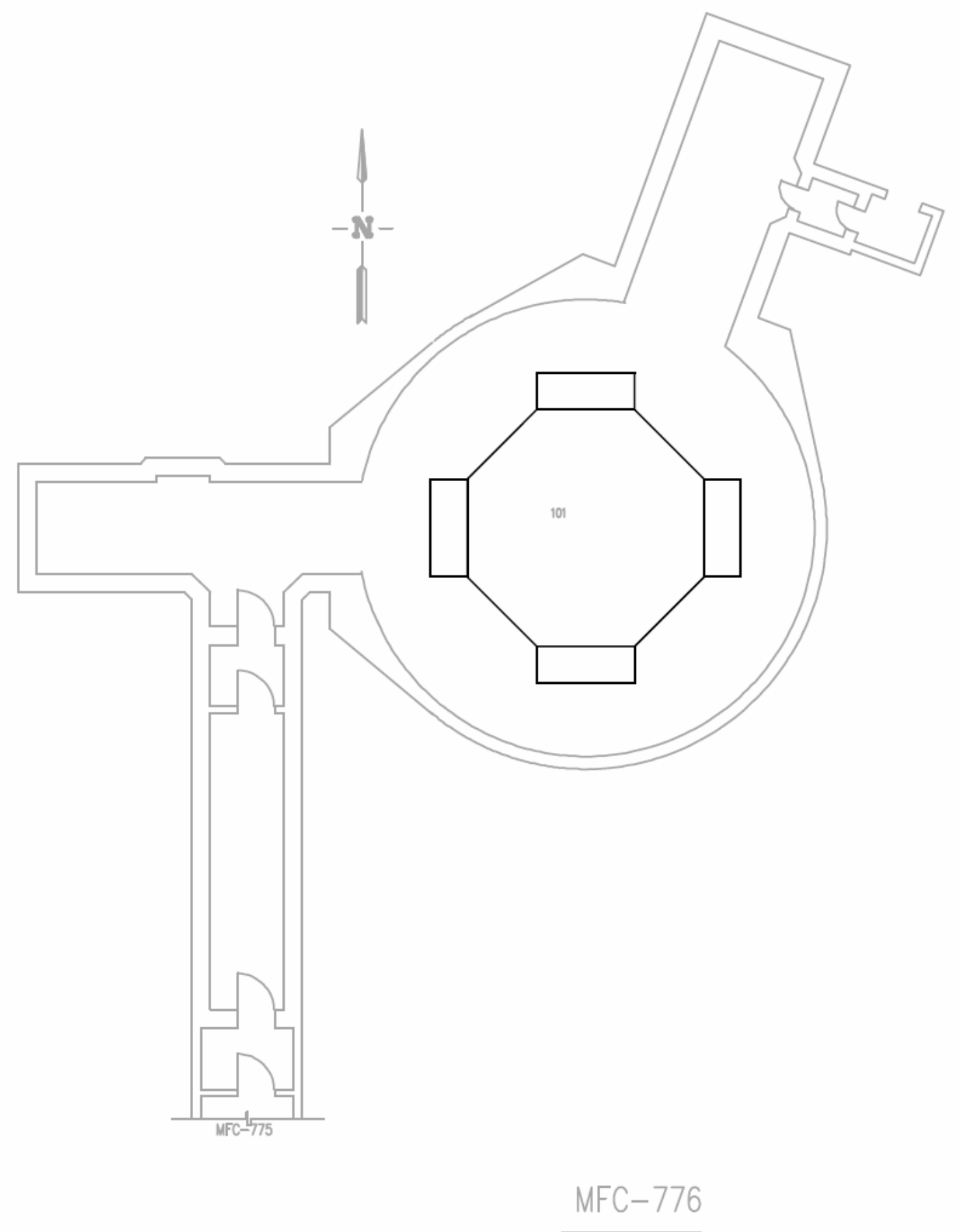

Figure A-6. MFC-776, Zero Power Physics Reactor, floor plan with potential cave location. 


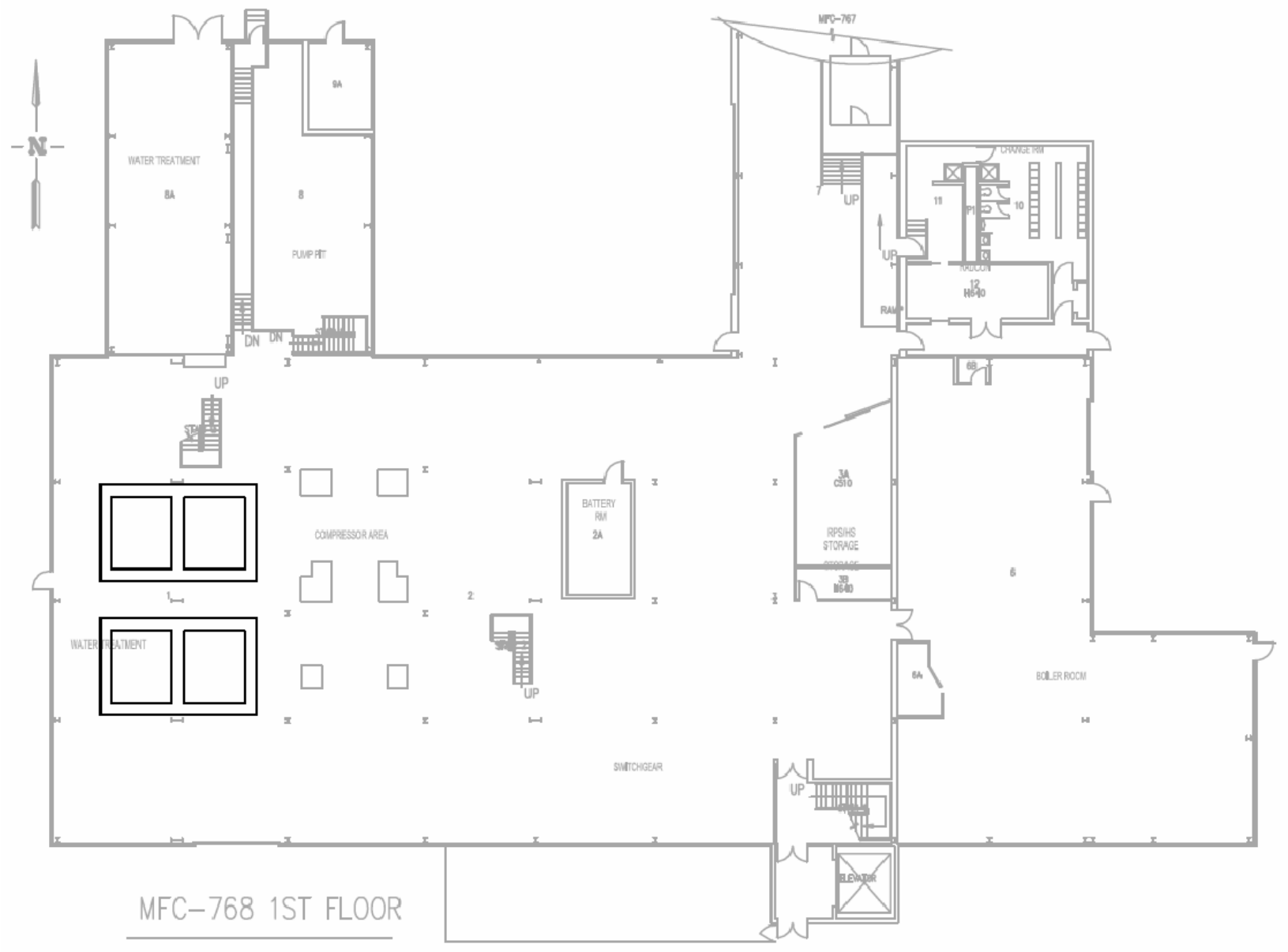

Figure A-7. MFC-768, Experimental Breeder Reactor-II Power Plant, floor plan with potential cave location. 
Appendix B

\section{LEED Project Checklist}




\section{Appendix B \\ LEED Project Checklist}

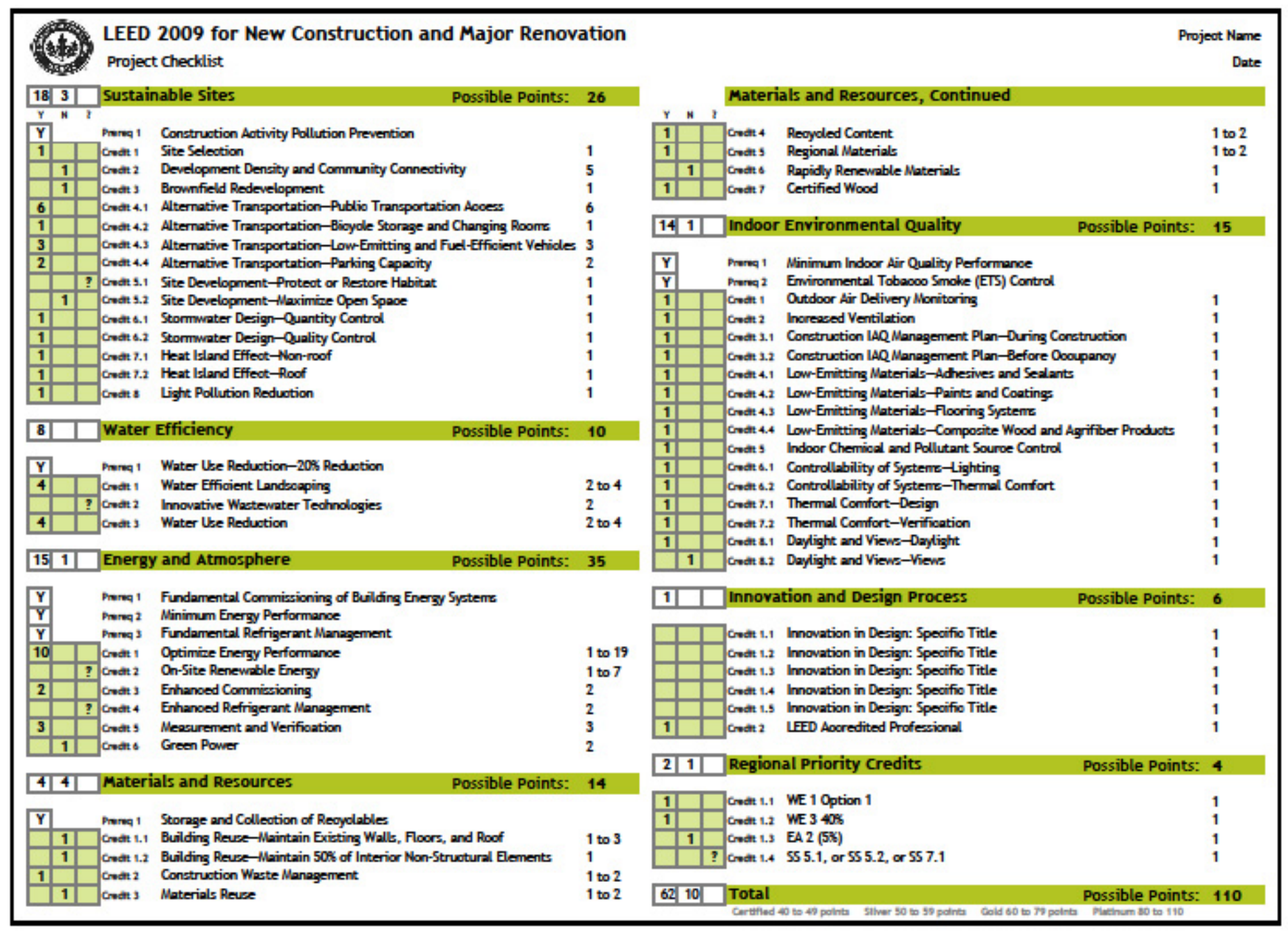




\section{Appendix C}

\section{Colin Gordon and Associates IMCL Site Study}




\section{Appendix C \\ Colin Gordon and Associates IMCL Site Study}




\title{
C O L I N G ORDON \\ ASSOCIATES
}

\section{Idaho National Laboratory - IMCL Site Study}

\author{
Battelle Energy Alliance, LLC
}

CG\&A Project No. 10007

Revision 1

\section{Best Viewed in Color}

\author{
Prepared by: $\quad$ Blong Xiong \\ Colin Gordon \& Associates \\ 150 North Hill Drive, Suite 15 \\ Brisbane, CA 94005 \\ +1 (415) 570-0350
}

March 9, 2010 


\section{Introduction and Executive Summary}

A site survey was carried out on February 23, 2010 evaluate the vibration and EMI (AC magnetic field) conditions at the future site of the Irradiated Materials Characterization Lab (IMCL) at the Idaho National Laboratory (INL) Materials and Fuels Complex. The site is currently a graded "green field" site used as a scrap yard. The results showed that the ambient vibration levels were very low and capable of meeting the stringent VC-E criterion (and the NIST-A criterion above $2 \mathrm{~Hz}$ ). The EMI levels were also very low.

\section{Criteria}

We will discuss the vibration results relative to the generic vibration criterion (VC) curves as described in Appendix A and relative to the criteria for typical future installed instrumentation. Examples of these which have available criteria are as follows:

\section{FEI 3D FEG}

Vibration - see data plots

EMI - $\leq 300 \mathrm{nT}(3 \mathrm{mG})$ at mains frequency, $\leq 40 \mathrm{nT}(0.4 \mathrm{mG})$ all other frequencies

FEI Titan 80-300

Vibration - see data plots

EMI - $\leq 30 \mathrm{nT}(0.3 \mathrm{mG})$ at mains frequency

Cameca SX100 R

Vibration - $\leq 3 \mu \mathrm{m}$ pk-pk below $2 \mathrm{~Hz}, \leq 500 \mu \mathrm{m} / \mathrm{s}^{2}$ above $2 \mathrm{~Hz}, 1 / 3$ Octave Bands EMI $-\leq 300 \mathrm{nT}(3 \mathrm{mG})$ at mains frequency, $\leq 10 \mathrm{nT}(0.1 \mathrm{mG})$ all other frequencies

Bruker D8 XRD

Vibration $-0.15 \mathrm{~mm}$ up to $20 \mathrm{~Hz}$, assuming 1/3 Octave Bands (well above VC-A)

Other potential equipment mentioned but do not have criteria available include the Cameca IMS 7f-R Shielded SIMS and the LEAP 3000X HR.

\section{Site Descriptions}

As mentioned in the introduction, the site is currently a green field site. Vibration measurements were carried out at the locations indicated in Figure 1. EMI measurements were carried out at Locations 1 and 5. Note that the future building is superimposed onto the existing site in this illustration. 
Figure 1: IMCL Measurement Locations

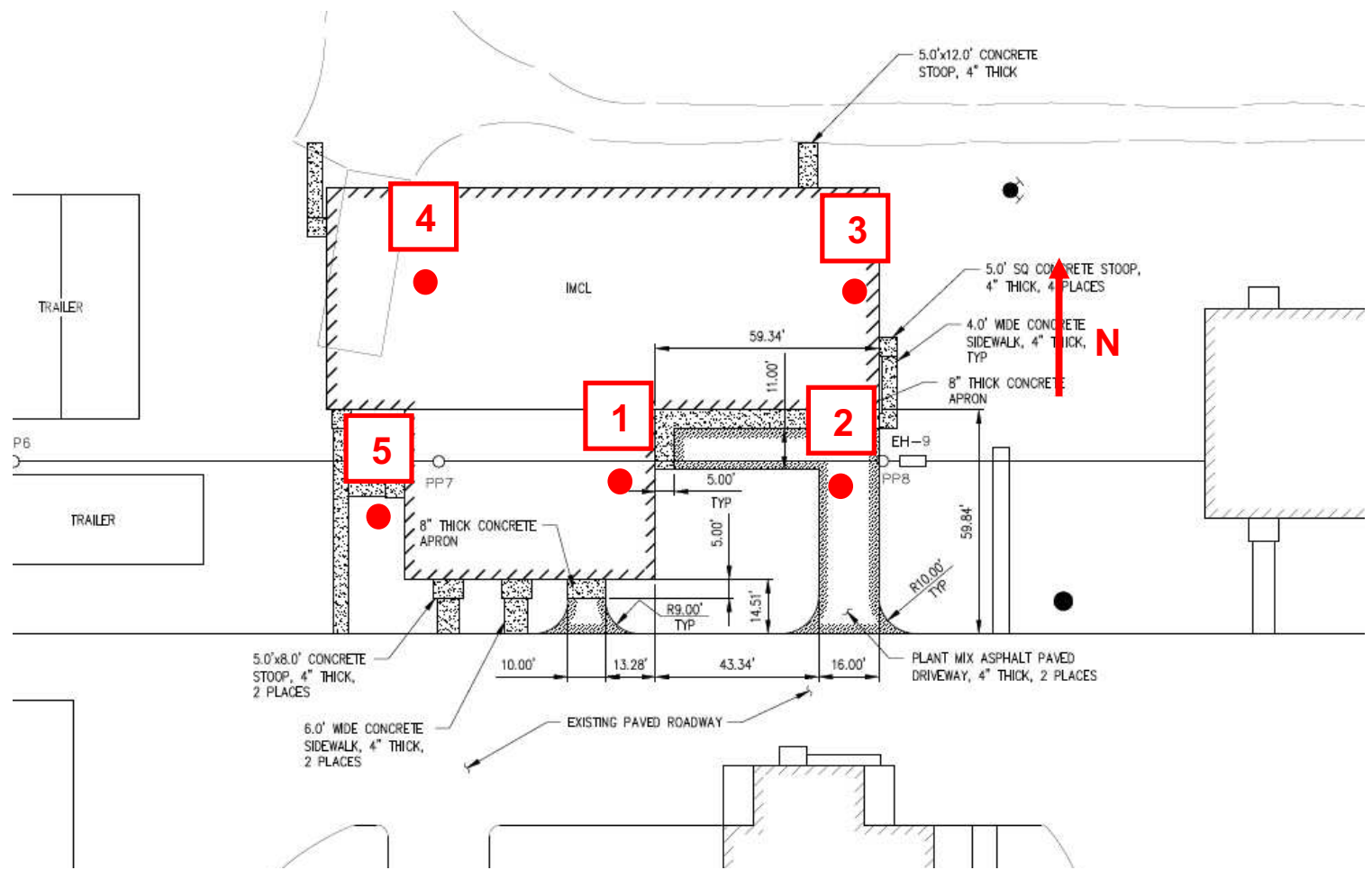

\section{Measurement Methodologies \& Instrumentation}

This study was carried out with the following set of equipment:

Accelerometer - Wilcoxon 731A, SN 3587

Charge Amplifier - Wilcoxon P31, SN 2060

Signal Analyzer - Rion SA-77, SN 10151050

Signal Analyzer - Dataphysics Quattro 4 Channel Analyzer, SN21020

Magnetometer - Bartington Mag-03MC100, SN 1283

Power Supply Unit - Bartington Mag-03PSU, SN 767

together with the associated calibration systems, cables, connectors, etc. The annual calibration of the measurement instruments uses reference standards traceable to the US National Institute of Standards and Technology (NIST).

\subsection{Vibration Measurement Methodology}

Vibration measurements were carried out with the Wilcoxon 731A and P31 accelerometer/amplifier system hooked up to a Rion SA-77 signal analyzer. Vibration data were collected in velocity spectra format using a Hanning Windowing function and $400 \mathrm{FFT}$ lines in the frequency range up to $100 \mathrm{~Hz}$. Typically we quantify the vibration velocity at a single location on the basis of the rms linear average (energy average) of multiple sequential samples acquired over an appropriate period of time, which is 
typically around 60 top 90 seconds. This is an adequate statistic for environments that are statistically "stationary," dominated by steady-state random processes. In cases where a location is impacted by short-term transient events, such as vehicle traffic, it is necessary to use the "maximum RMS" (on some signal analyzers called "peak hold") measurement methodology to characterize the vibration. We noted that there is no regular traffic in and around the area so the "maximum RMS" vibration was not analyzed.

\subsection{EMI Measurement Methodology}

EMI measurements were carried out with the Bartington Mag-03MC100 tri-axial magnetometer hooked up to the Quattro 4 channel analyzer. Measurements were taken in time domain with a $256 \mathrm{~Hz}$ sampling frequency in the frequency range up to $100 \mathrm{~Hz}$. Data are presented as peak to peak nano-Tesla (nT).

\section{Vibration Results}

\section{Ambient Vibration Data}

The ambient vibration in the vertical direction is summarized against the generic vibration criterion curves in Figure 2. Note that the levels are fairly consistent between the locations. Overall, the levels easily meet the VC-E $(3.125 \mu \mathrm{m} / \mathrm{s})$ criterion and would meet the NIST-A requirement at frequencies above $2 \mathrm{~Hz}$. This data is again plotted in Figure 3; however this time compared to the vertical requirements of the FEI Titan 80300, FEI 3D FEG, and Cameca SX-1000R tools. We can see that the criteria is essentially met for each tool. There was one location exceedance of the Cameca spec at $31.5 \mathrm{~Hz}$. This however should not cause alarm since it is only one location, and the presence of the new building will likely attenuate some of the ambient vibration at this frequency. The horizontal vibration results are summarized against the generic criterion curves in Figure 4. The vibration levels in these directions are also very low and are comparable to the vertical vibration. Figure 5 compares the horizontal vibration against the tool criteria. Again we see that these vibration levels currently satisfy the available tool criteria. Overall, these results indicate that the site is capable of meeting the vibration requirements for some of the most stringent research and lab equipment. 
Figure 2: INL IMCL Site Ambient Vertical Vibration

a) Narrowband Data (Bandwidth $=0.375 \mathrm{~Hz}$ )

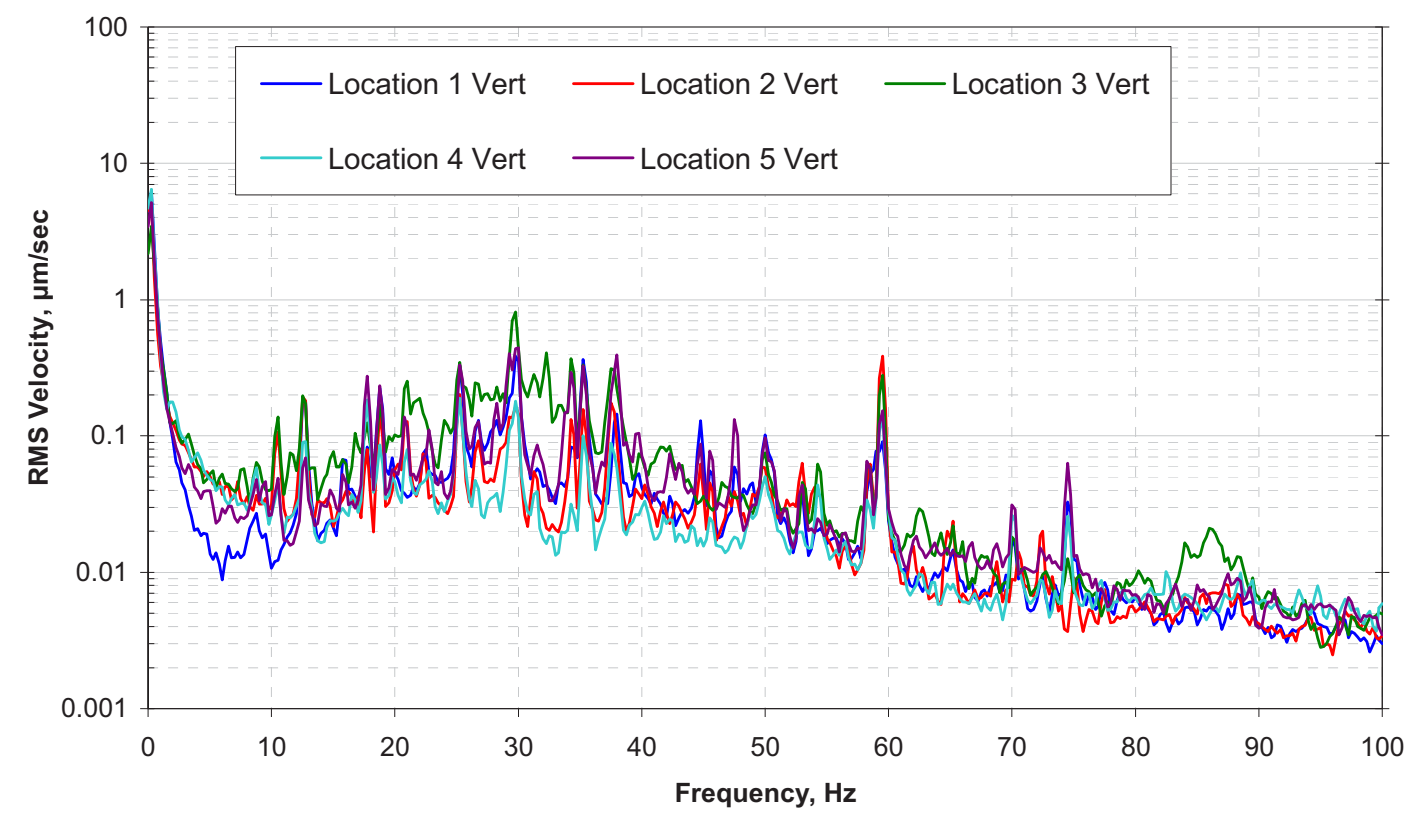

b) One-Third Octave Band Data

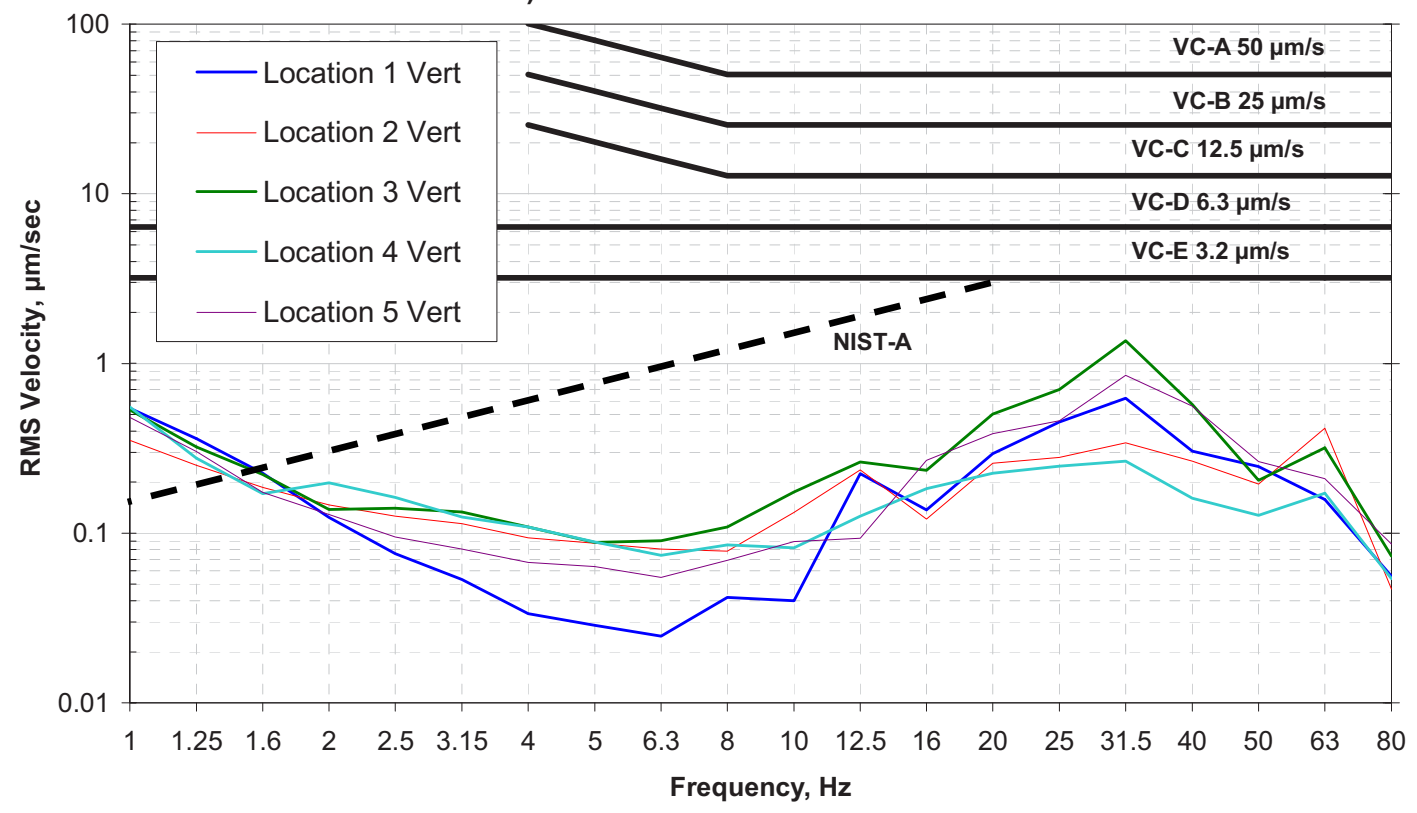


Figure 3: INL IMCL Site Ambient Horizontal Vibration vs. Tool Specs

b) One-Third Octave Band Data

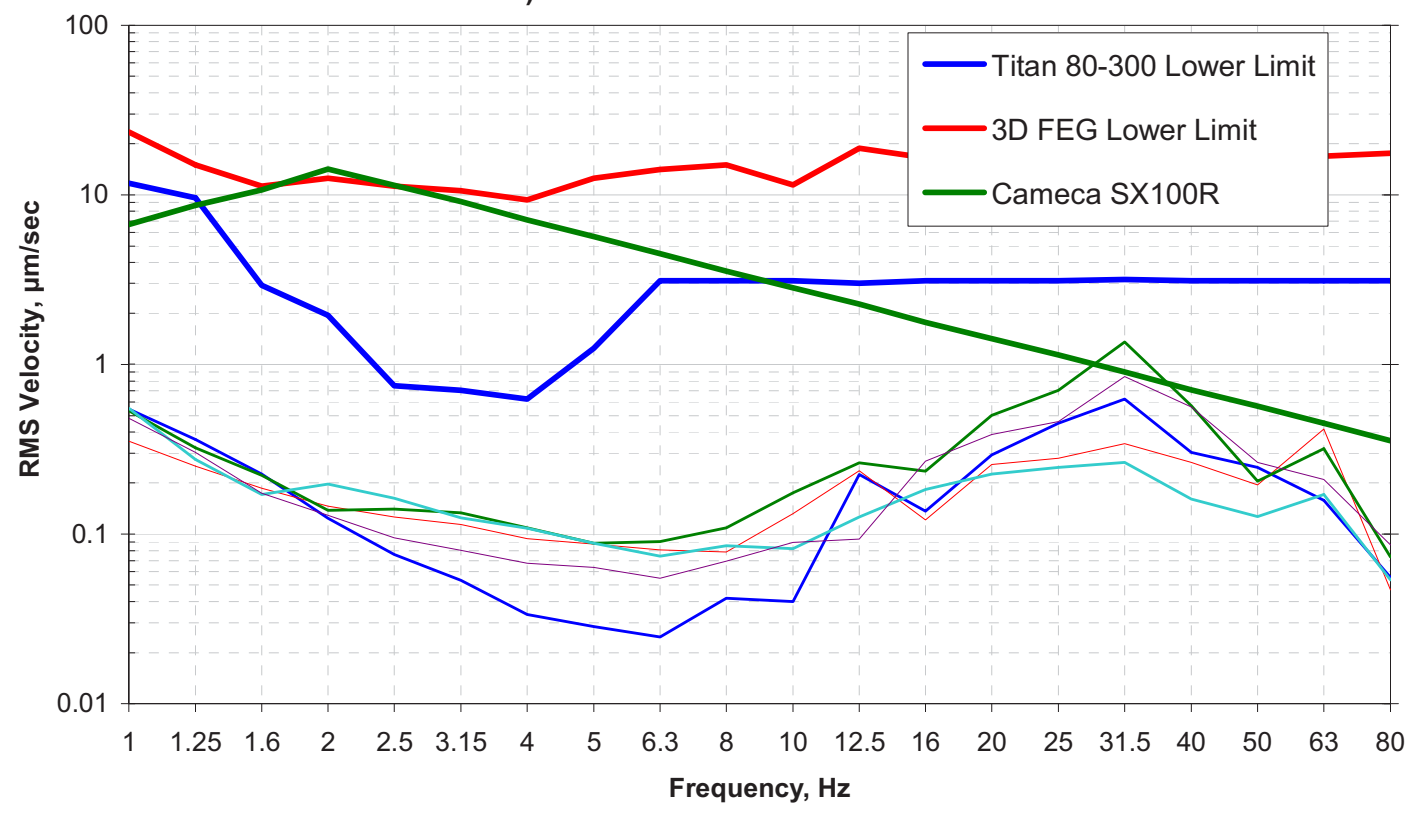




\section{Figure 4: INL IMCL Site Ambient Horizontal Vibration}

a) Narrowband Data (Bandwidth $=0.375 \mathrm{~Hz}$ )

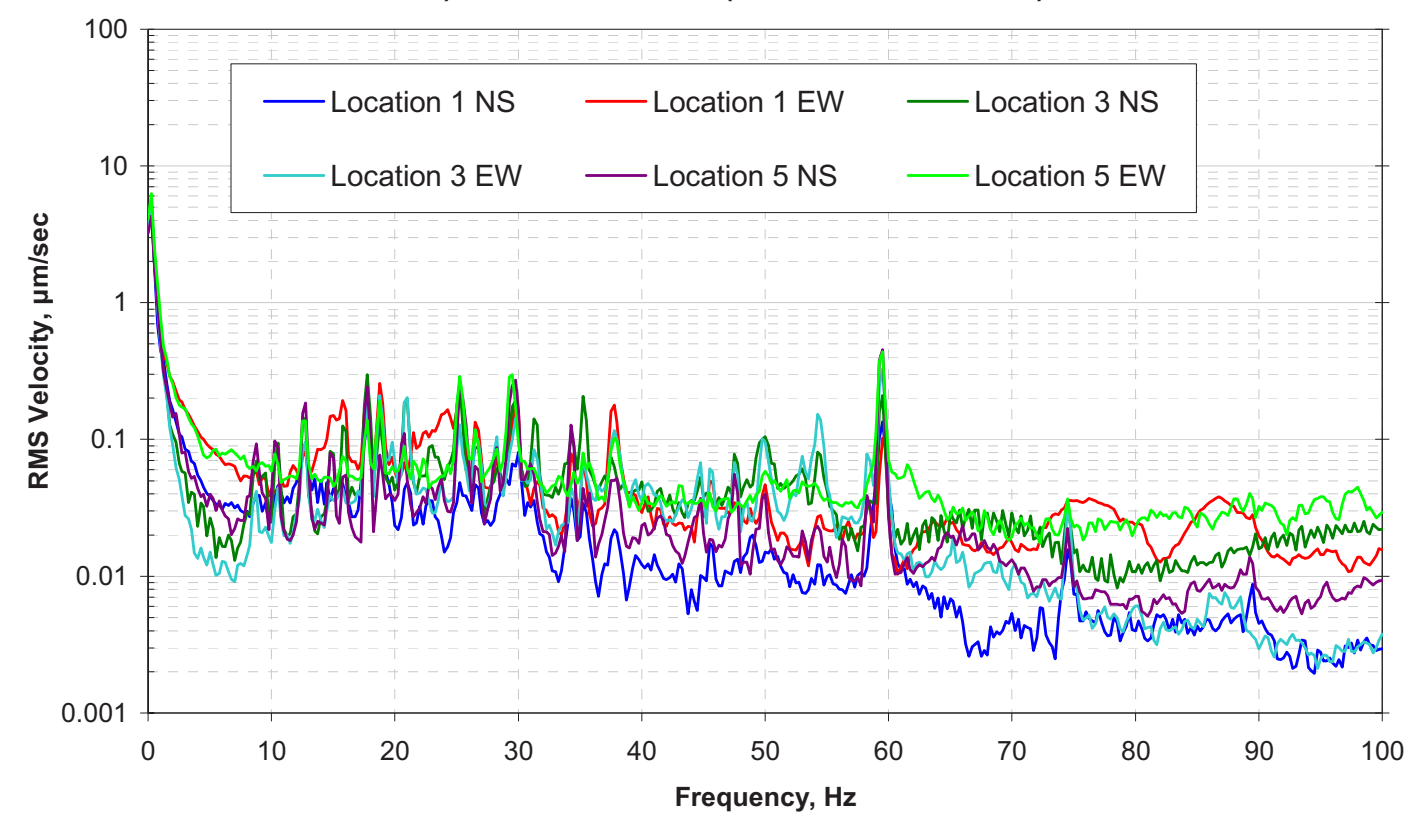

b) One-Third Octave Band Data

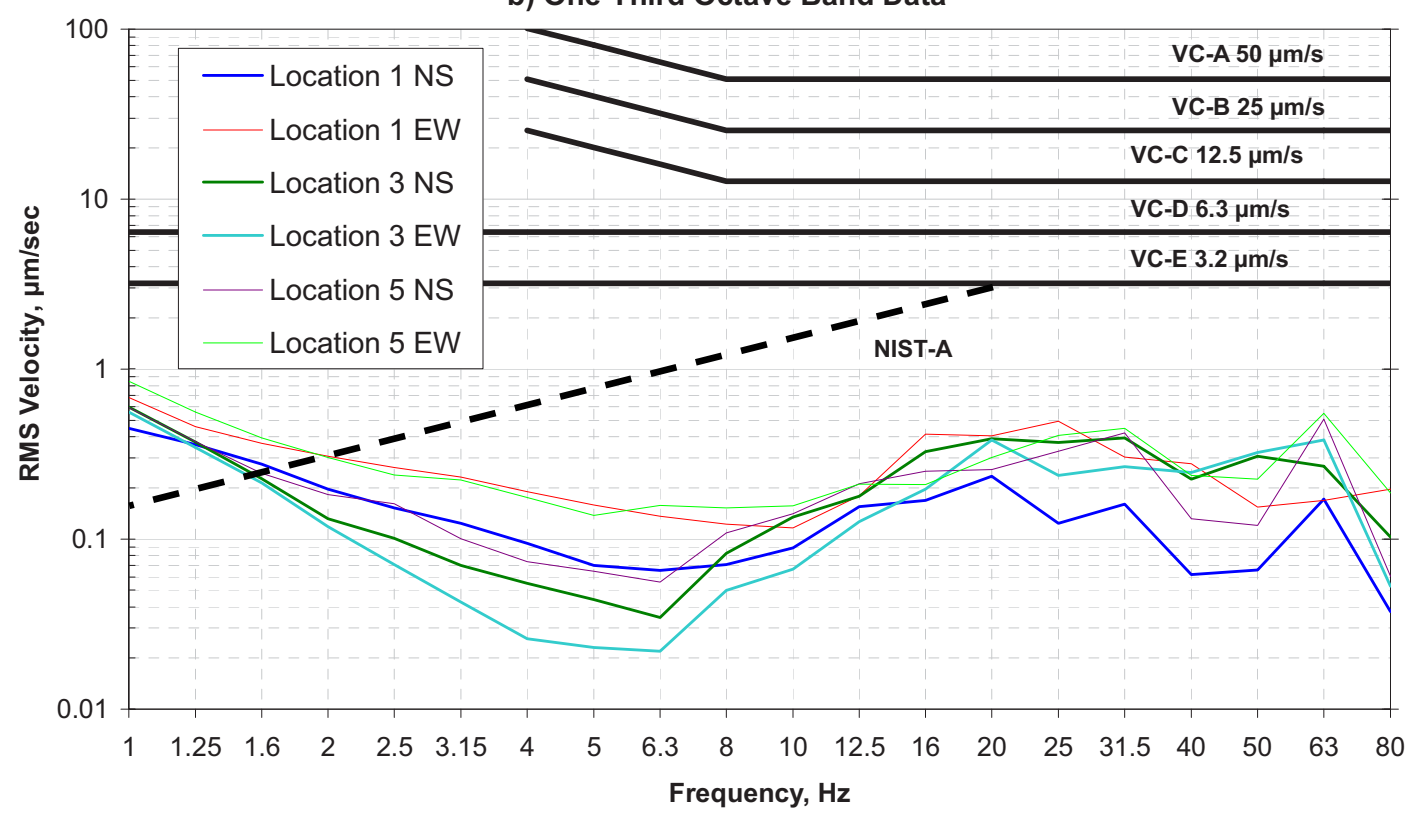


Figure 5: INL IMCL Site Ambient Horizontal Vibration vs. Tool Specs

b) One-Third Octave Band Data

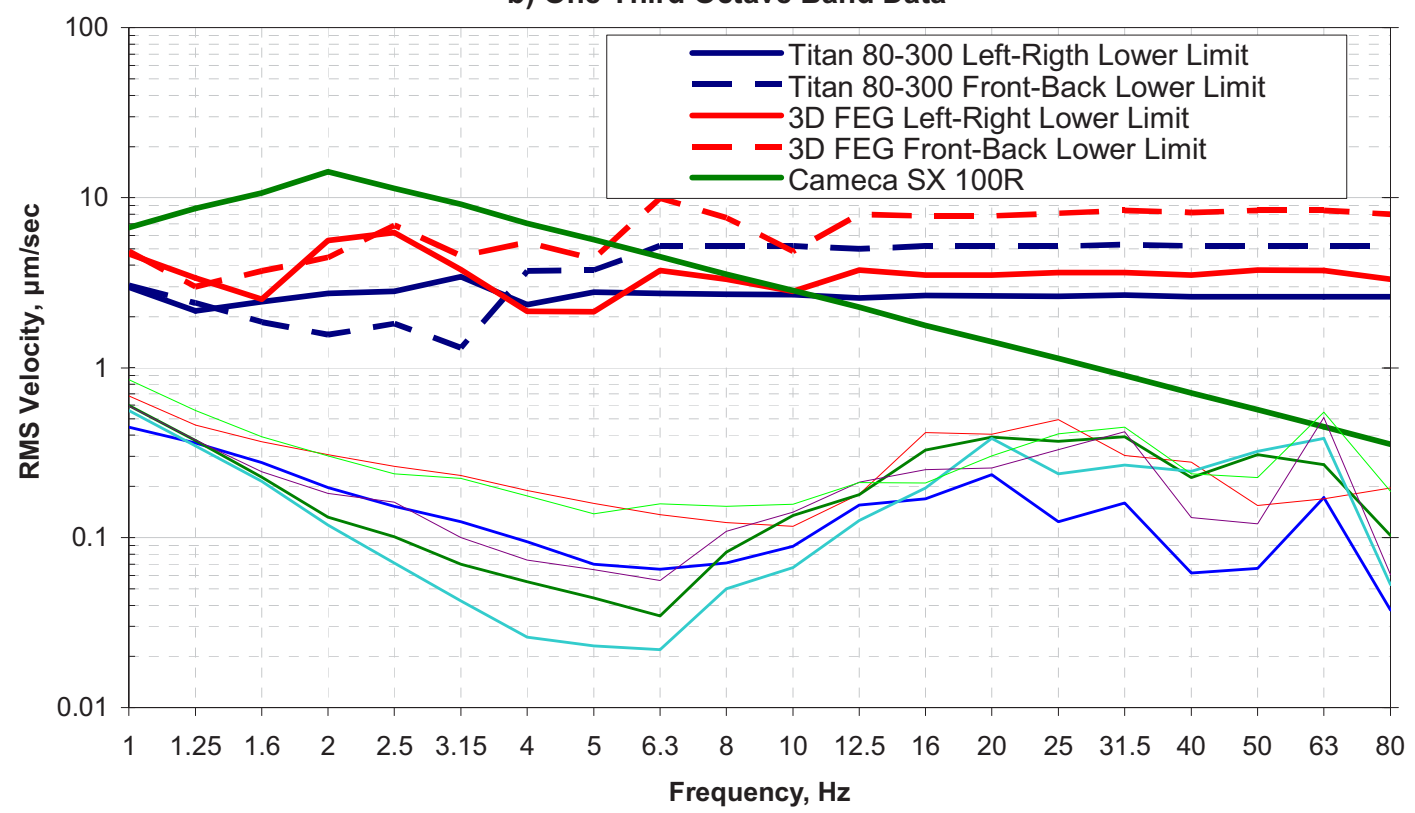

The EMI (AC magnetic field) measurement results are presented in Table 1. As one can see, the $60 \mathrm{~Hz}$ mains frequency values measured were well below the $300 \mathrm{nT}$ requirement for the Cameca SX100 R and FEI 3D FEG. Furthermore, the values would even satisfy the $30 \mathrm{nT}$ requirement for the Titan 80-300 electron microscope. At all other frequencies, the nominal AC values up to $100 \mathrm{~Hz}$ were seen to be even lower and would satisfy both the SX100R and 3D FEG requirements for that frequency range.

Table 1: EMI Results for IMLC Site Locations 1 and 5

\begin{tabular}{|l|c|c|c|c|}
\cline { 2 - 4 } \multicolumn{1}{c|}{} & \multicolumn{3}{c|}{$60 \mathrm{~Hz}(\mathrm{nT}), \mathrm{pk}-\mathrm{pk}$} & \multicolumn{1}{c}{} \\
\hline & Vertical & $\mathrm{NS}$ & $\mathrm{EW}$ & SRSS \\
\hline Location 1 & 1.2202 & 0.3794 & 0.4273 & 1.3474 \\
\hline Location 5 & 1.0156 & 0.1739 & 0.3273 & 1.0811 \\
\hline
\end{tabular}

*SRSS = vector sum

\begin{tabular}{|l|c|c|c|c|}
\cline { 2 - 4 } \multicolumn{1}{c|}{} & \multicolumn{2}{c|}{ Avg of All Other Frequencies (nT), pk-pk } & \multicolumn{1}{c}{} \\
\hline & Vertical & NS & EW & SRSS \\
\hline Location 1 & 0.0644 & 0.1329 & 0.4185 & 0.4438 \\
\hline Location 5 & 0.1214 & 0.0596 & 0.0659 & 0.1504 \\
\hline
\end{tabular}

${ }^{\star}$ SRSS $=$ vector sum

\section{Conclusions}

The ambient vibration levels measured at the site are very low and easily meet the VC-E criterion. This is not surprising given that there were no obvious sources of vibration 
nearby such as mechanical equipment or vehicular traffic. The EMI levels at the site were also very low and can be attributed to the lack of direct sources nearby. Overall, these results show that the site provides a good baseline for a building that could provide for a very low vibration and low EMI environment. Care will be needed however in the design and construction of the building structure and foundation, mechanical, and electrical services in order to maintain these conditions in the operating building.

Note that layout of future site roads with respect to the vibration-sensitive areas will also be critical to minimize impact from vehicles. A condition that could not be evaluated during this study is the potential for impact from trucks delivering samples to the IMCL. It is understood however that experiments could possibly be scheduled around these events, which may occur once or twice a week, if they prove to be disruptive.

Though noise measurements were not carried out, the site can easily be described as fairly quiet. This is again due to the lack of sources in the area. We do not expect the ambient background noise to be an issue for the lab spaces inside the IMCL given that some of the experiments will be carried out within 3' thick concrete enclosures, and in addition the building façade and roof can be designed to minimize external noise impacts, if this is deemed to be important. Control of noise generated by the new mechanical and HVAC systems introduced with the lab building will be most critical. 


\section{APPENDIX A}

\section{GENERIC DESIGN CRITERIA FOR VIBRATION-SENSITIVE EQUIPMENT AND PROCESSES \\ Colin Gordon \& Associates}

This appendix presents vibration criteria that have been used quite extensively for several years, particularly by the microelectronics and optoelectronics industries and research communities.

Two families of generic criteria are discussed here: (1) the VC criteria developed in the early 1980s by Eric Ungar and Colin Gordon ; and (2) the NIST-A criterion developed in the early 1990s for the Advanced Measurement Laboratory at the U.S. National Institute of Standards and Technology (NIST). The VC criteria were originally developed for use in the semiconductor industry, but have found application in a wide variety of technological applications. The NIST-A criterion was developed for metrology, but has gained popularity within the nanotechnology community. ${ }^{\dagger}$

The VC criteria take the form of a set of one-third octave band velocity spectra labeled vibration criterion curves VC-A through VC-G, as developed by Gordon and Ungar, modified several times during the intervening years, and currently published in an IEST Recommended Practice. ${ }^{\ddagger}$ These are shown in Figure A.1, together with the International Standards Organization (ISO) guidelines for the effects of vibration on people in buildings. ${ }^{\S}$ The criteria apply to vibration as measured in the vertical and two orthogonal horizontal directions, and are applied to each direction separately.

For environments that are continuous and steady-state in time, the criteria apply to the "linear average" of data samples acquired over an adequate time period. In instances where the environment is impacted by occasional disturbances such as vehicular movements, "stage" movements (in tools), passing trains, etc., these may be evaluated in the "peak hold" or "maximum RMS" mode of the measuring system. If the disturbing event is long enough (i.e., "Quasi-static", or steady-state during the averaging time) the linear average mode should be used. The importance attributed to these occasional events will depend upon the frequency of occurrence and other parameters relating to the vibration-sensitive process.

\footnotetext{
* Eric E. Ungar and Colin G. Gordon, "Vibration Challenges in Microelectronics Manufacturing," Shock and Vibration Bulletin, 53(I):51-58 (May 1983), or Gordon, C. G., and Ungar, E. E., "Vibration Criteria for Microelectronics Manufacturing Equipment," Proceedings of Inter-Noise 83, pp. 487-490 (July 1983). † H. Amick, M. Gendreau, and C. G. Gordon, "Facility Vibration Issues for Nanotechnology Research," Proc. Symp. on Nano Device Technology 2002, May 2-3, 2002, National Chiao-Tung University, Hsinchu, Taiwan.

"Institute of Environmental Sciences and Technology, "Considerations in Cleanroom Design," RPCC012.2, 2005.

$\S$ International Standards Organization, ISO 2631 "Mechanical vibration and shock - Evaluation of human exposure to whole-body vibration, Parts 1 and 2." Part 1 was updated 15 July 1997 and Part 2 was updated 1 April 2003. 
For environments involving large areas, such as an entire cleanroom, a single location is probably not representative of the whole. The ambient vibrations of a large area may be characterized by a spectrum representing the mean plus one standard deviation spectrum, $A_{\text {mean }}$ sig, of a collection of spectra obtained at a statistically significant number of locations randomly distributed throughout the cleanroom or other area of interest. The $A_{\text {mean }}$ and $A_{\text {sig }}$ spectra are defined for a collection of linear spectra $X_{i}$ as

$$
\begin{aligned}
& \log \left(A_{\text {mean }}\right)=\text { Average }\left(\log \left(X_{i}\right)\right) \\
& \log \left(A_{\text {sig }}\right)=\operatorname{StdDev}\left(\log \left(X_{i}\right)\right)
\end{aligned}
$$

The statistics are calculated for each frequency. The two spectra are combined in $l o g$ space to obtain $A_{\text {mean }+ \text { sig, }}$, defined as ${ }^{* *}$

$$
\log \left(A_{\text {mean }+ \text { sig }}\right)=\log \left(A_{\text {mean }}\right)+\log \left(A_{\text {sig }}\right)
$$

When presenting data in a report, the data for a single direction (e.g., vertical) may be summarized in a plot that shows four spectra: $A_{\text {min }}, A_{\text {mean }}, A_{\text {mean }+ \text { sig }}$, and $A_{\text {max }}$. The reader can then easily see the range of the data, the statistically meaningful representations, and the spectrum used to characterize the space as a whole, $A_{\text {mean }}$ sig. In order to compare the performance of the entire space at two different times, the $A_{\text {mean }}$ sig spectra from each set of measurements may be used.

The use of $A_{\text {mean }}$ sig as a means for characterizing a large area infers that the data approximate a Gaussian distribution at each frequency. This is not always the case, because the mechanical "load" (i.e., the dynamic forces traveling into the floor from mechanical equipment, piping, and ducting) may not always be distributed uniformly about the space being evaluated. If it were truly Gaussian, then one could assume that at any location within the area being evaluated, there was an $84 \%$ probability that the vibrations at that location would be equal to or less than $A_{\text {mean }}$ sig. Even if the data are not truly Gaussian, it may be argued that $A_{\text {mean }}$ sig provides a more reliable estimate of the majority of the data than either $A_{\max }$ or $A_{\text {mean }}$.

The application of these criteria to people and vibration-sensitive equipment is described in Table A.1. The criteria do not necessarily apply to experimental systems used in laboratory research. Such systems often have not received the benefits of dynamic modeling and vibration isolation available to the equipment manufacturer, or may be oneof-a-kind.

The main elements of the criteria are as follows:

1) The vibration is expressed in terms of its root-mean-square (rms) velocity (as opposed to displacement or acceleration). It has been found in various studies that while

\footnotetext{
** Carrying out statistical operations on levels expressed in decibels produces the same results as operations in log space. The latter is simply a more general format for definition. COLIN GORDON \& ASSOCIATES SPECIALIZING IN ACOUSTIC AND VIBRATION SOLUTIONS 150 NORTH HILL DRIVE, SUITE 15, BRISBANE CA 94005 USA TEL +1-415-570-0350 FAX +1-415-570-0351 http://www.colingordon.com
} 
different items of equipment (and people) may exhibit maximum sensitivity at different frequencies (corresponding to internal resonances), often these points of maximum sensitivity lie on a curve of constant velocity. ${ }^{\dagger \dagger}$

2) The use of a proportional bandwidth (the bandwidth of the one-third octave is twenty-three percent of the band center frequency) as opposed to a fixed bandwidth is justified on the basis of a conservative view of the internal damping of typical equipment components. Experience shows that in most environments where adequate layout and isolation of electrical and mechanical equipment has been provided, the vibration is dominated by broadband (random) energy rather than tonal (periodic) energy.

3) The fact that some of the criterion curves allow for greater vibration velocity for frequencies below $8 \mathrm{~Hz}$ reflects experience that this frequency range, in most instances, lies below the lowest resonance frequency of the equipment components to which these curves apply. Relative motions between the components are, therefore, harder to excite and the sensitivity to vibration is reduced. The curves more stringent than $\mathrm{VC}-\mathrm{C}$ do not relax the requirements at frequencies below $8 \mathrm{~Hz}$, and the curves extend down to $1 \mathrm{~Hz}$. This change was based upon the requirements of equipment with internal pneumatic vibration isolation, which in many cases shifted the frequency of greatest vibration sensitivity from greater than $8 \mathrm{~Hz}$ down to the range of 1 to $4 \mathrm{~Hz}$.

4) For a floor or site to comply with a particular equipment category, the measured onethird octave band velocity spectrum must lie below the appropriate criterion curve of Figure A.1. It is generally accepted that vibration measurements are accurate and repeatable only within about 1 or 2 decibels $(12 \%$ or $26 \%)$, so an overly strict interpretation of a comparison with the criteria is not encouraged. (For instance, a measured value of $51 \mu \mathrm{m} / \mathrm{s}$ versus one of $49 \mu \mathrm{m} / \mathrm{s}$, when being compared to a criterion of $50 \mu \mathrm{m} / \mathrm{s}$, lies within the range of inaccuracy — less than 1 decibel — with respect to the criterion, and it may be argued that both of them meet the criterion, from a measurement accuracy perspective.)

The equipment criterion curves have been developed on the basis of data on individual items of equipment and from data obtained from measurements made in facilities before and after vibration-related problems were solved. The curves are generic in the sense that they are intended to apply to broadly defined classes of equipment and processes. They are intended to apply to the more sensitive equipment within each category that is defined.

\footnotetext{
${ }^{\dagger}$ Amick, H., "On Generic Vibration Criteria for Advanced Technology Facilities: with a Tutorial on Vibration Data Representation," J. Institute of Environmental Sciences, pp. 35-44, (Sept/Oct, 1997).

$\$$ E. E. Ungar, D. H. Sturz, and H. Amick, "Vibration Control Design of High Technology Facilities," Sound and Vibration (Jul. 1990). 
The criteria assume that equipment will be supported on benches or pedestals that are rigidly constructed and damped so that amplifications due to resonances are limited to a small value or located at non-critical frequencies. The criteria take into account the fact that certain types of equipment (such as stepper scanners) are supplied by the manufacturer with built-in vibration isolation.

The NIST-A criterion is identical to VC-E at frequencies above $20 \mathrm{~Hz}$, but maintains a constant rms displacement amplitude at lesser frequencies. This is to accommodate some of the ultra-high-precision metrology, probe, and lithography equipment being used in nanotechnology. This is a very difficult criterion to meet at some sites with significant low-frequency vibration content.

It is important to note that these criteria are for guidance only. The "detail sizes" given in Table A.1 appear to represent experience at the time of writing. They reflect the fact that the quality of design and of built-in isolation in most equipment tends to improve as dimensional requirements become more stringent. In some instances the criteria may be overly conservative because of the high quality of built-in isolation.

Facility vibrations do not necessarily remain constant over extended periods of time. Vibrations measured during construction may not reflect the contribution of the mechanical systems in their operational state at building completion. Likewise, vibrations at a few months beyond completion may include contributions from userinstalled equipment, and this contribution could change over time as layout is varied. (This variation has been called "maturation," and must be considered a normal part of the aging process. ${ }^{\S \S}$ ) It is important that a facility survey be carried out at a time appropriate for characterization of the operational state of interest. For example, one would not want to characterize the "as built" state using measurements made either during construction or at one year after startup.

In most instances it is recommended that the advice of a vibration consultant be sought in selecting a design standard.

\footnotetext{
$\S \S$ M. Gendreau and H. Amick, "'Maturation' of the Vibration and Noise Environments in Semiconductor Production Facilities," Proc. ESTECH 2004, 50 ${ }^{\text {th }}$ Annual Technical Meeting, Institute of Environmental Sciences and Technology (IEST), Las Vegas, Nevada, April 28, 2004

${ }^{* * *}$ H. Amick, M. Gendreau, and T. Xu, "On the Appropriate Timing for Facility Vibration Surveys," Semiconductor Fabtech, No. 25, March 2005, Cleanroom Section. 


\section{Table A.1: Application and interpretation of the generic vibration criterion (VC) curves \\ (as shown in Figure A.1)}

\begin{tabular}{|c|c|c|c|}
\hline Criterion Curve & $\begin{array}{l}\text { Amplitude } \\
\mu \mathrm{m} / \mathrm{s}(\mu \mathrm{in} / \mathrm{s})\end{array}$ & $\begin{array}{c}\text { Detail size }^{2} \\
\mu \mathrm{m}\end{array}$ & Description of use \\
\hline Workshop (ISO) & $800(32000)$ & $\mathrm{N} / \mathrm{A}$ & $\begin{array}{l}\text { Distinctly perceptible vibration. Appropriate to workshops and } \\
\text { nonsensitive areas. }\end{array}$ \\
\hline Office (ISO) & $400(16000)$ & $\mathrm{N} / \mathrm{A}$ & $\begin{array}{l}\text { Perceptible vibration. Appropriate to offices and nonsensitive } \\
\text { areas. }\end{array}$ \\
\hline Residential day (ISO) & $200(8000)$ & 75 & $\begin{array}{l}\text { Barely perceptible vibration. Appropriate to sleep areas in } \\
\text { most instances. Usually adequate for computer equipment, } \\
\text { hospital recovery rooms, semiconductor probe test equipment, } \\
\text { and microscopes less than } 40 \mathrm{x} \text {. }\end{array}$ \\
\hline Operating theatre (ISO) & $100(4000)$ & 25 & $\begin{array}{l}\text { Vibration not perceptible. Suitable in most instances for } \\
\text { surgical suites, microscopes to } 100 \mathrm{x} \text { and for other equipment } \\
\text { of low sensitivity. }\end{array}$ \\
\hline VC-A & $50(2000)$ & 8 & $\begin{array}{l}\text { Adequate in most instances for optical microscopes to } 400 \mathrm{x}, \\
\text { microbalances, optical balances, proximity and projection } \\
\text { aligners, mass spectrometers other than MALDI and } \\
\text { quadrupole or high-resolution, conventional } \\
\text { spectrophotometers, etc. }\end{array}$ \\
\hline VC-B & $25(1000)$ & 3 & $\begin{array}{l}\text { Appropriate for inspection and lithography equipment } \\
\text { (including steppers) to } 3 \mu \mathrm{m} \text { line widths, microtomes and } \\
\text { cryotomes for } 5-10 \text { micron slices, most tissue and cell culture, } \\
\text { except as noted below. }\end{array}$ \\
\hline VC-C & $12.5(500)$ & $1-3$ & $\begin{array}{l}\text { Appropriate standard for optical microscopes to } 1000 \mathrm{x} \\
\text { lithography and inspection equipment (including moderately } \\
\text { sensitive electron microscopes) to } 1 \mu \mathrm{m} \text { detail size, TFT-LCD } \\
\text { stepper/scanner processes, digital imaging and/or } \\
\text { fluorescence with optical microscope, high-precision balances } \\
\text { measuring quantities less than } 1 \mathrm{mg} \text {, MALDI mass } \\
\text { spectrometer, nano-drop spectrophotometers, microtomes and } \\
\text { cryotomes for slices < } 5 \text { microns, tissue and cell culture of the } \\
\text { following types: hanging drop, unstirred layers, embryonic } \\
\text { stem cells, weakly adherent cells, very long-term cultures, } \\
\text { chemotaxis, invasion assays. }\end{array}$ \\
\hline VC-D & $6.25(250)$ & $0.1-0.3$ & $\begin{array}{l}\text { Suitable in most instances for demanding equipment, including } \\
\text { many electron microscopes (SEMs and TEMs) and E-Beam } \\
\text { systems, microinjection, micromanipulation, electrophysiology, } \\
\text { confocal microscopy, quadrupole and other high-resolution } \\
\text { mass spectrometers. }\end{array}$ \\
\hline VC-E & $3.12(125)$ & $<0.1$ & $\begin{array}{l}\text { A challenging criterion to achieve. Assumed to be adequate } \\
\text { for the most demanding of sensitive systems including long } \\
\text { path, laser-based, small target systems, E-Beam lithography } \\
\text { systems working at nanometer scales, and other systems } \\
\text { requiring extraordinary dynamic stability. }\end{array}$ \\
\hline VC-F & $1.56(62.5)$ & $\mathrm{N} / \mathrm{A}$ & $\begin{array}{l}\text { Appropriate for extremely quiet research spaces; generally } \\
\text { difficult to achieve in most instances, especially cleanrooms. } \\
\text { Not recommended for use as a design criterion, only for } \\
\text { evaluation. }\end{array}$ \\
\hline VC-G & $0.78(31.3)$ & $\mathrm{N} / \mathrm{A}$ & $\begin{array}{l}\text { Appropriate for extremely quiet research spaces; generally } \\
\text { difficult to achieve in most instances, especially cleanrooms. } \\
\text { Not recommended for use as a design criterion, only for } \\
\text { evaluation. }\end{array}$ \\
\hline
\end{tabular}

${ }^{1}$ As measured in one-third octave bands of frequency over the frequency range 8 to $80 \mathrm{~Hz}$ (VC-A and VC-B) or 1 to $80 \mathrm{~Hz}$ (VC-C through VC-G).

${ }^{2}$ The detail size refers to line width in the case of microelectronics fabrication, the particle (cell) size in the case of medical and pharmaceutical research, etc. It is not relevant to imaging associated with probe technologies, AFMs, and nanotechnology.

The information given in this table is for guidance only. In most instances, it is recommended that the advice of someone knowledgeable about applications and vibration requirements of the equipment and processes be sought. 
Figure A.1. Generic Vibration Criterion (VC) Curves for vibration-sensitive equipment - Showing also the ISO Guidelines for People in Buildings (see Table A.1 for description of equipment and uses.)

[From IEST RP-012.2 (2005)]

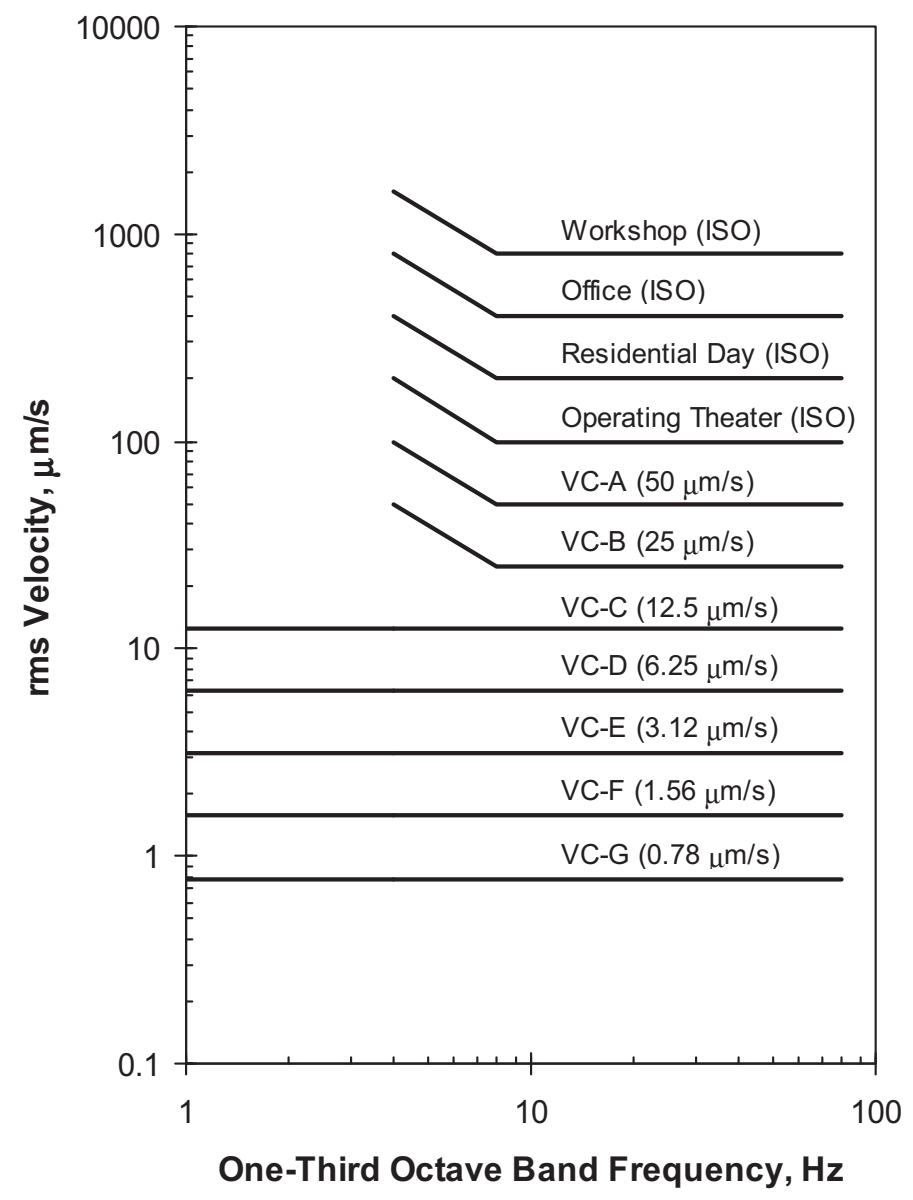

Table A.2: Numerical definition of criterion curves shown in Figure A.1

\begin{tabular}{|c|l|}
\hline Criterion & \multicolumn{1}{|c|}{ Definition } \\
\hline VC-A & $260 \mu \mathrm{g}$ between $4 \mathrm{~Hz}$ and $8 \mathrm{~Hz} ; 50 \mu \mathrm{m} / \mathrm{s}(2000 \mu \mathrm{in} / \mathrm{s})$ between $8 \mathrm{~Hz}$ and $80 \mathrm{~Hz}$ \\
\hline VC-B & $130 \mu \mathrm{g}$ between $4 \mathrm{~Hz}$ and $8 \mathrm{~Hz} ; 25 \mu \mathrm{m} / \mathrm{s}(1000 \mu \mathrm{in} / \mathrm{s})$ between 8 and $80 \mathrm{~Hz}$ \\
\hline VC-C & $12.5 \mu \mathrm{m} / \mathrm{s}(500 \mu \mathrm{in} / \mathrm{s})$ between 1 and $80 \mathrm{~Hz}$ \\
\hline VC-D & $6.25 \mu \mathrm{m} / \mathrm{s}(250 \mu \mathrm{in} / \mathrm{s})$ between 1 and $80 \mathrm{~Hz}$ \\
\hline VC-E & $3.1 \mu \mathrm{m} / \mathrm{s}(125 \mu \mathrm{in} / \mathrm{s})$ between 1 and $80 \mathrm{~Hz}$ \\
\hline VC-F & $1.6 \mu \mathrm{m} / \mathrm{s}(62.5 \mu \mathrm{in} / \mathrm{s})$ between 1 and $80 \mathrm{~Hz}$ \\
\hline VC-G & $0.78 \mu \mathrm{m} / \mathrm{s}(31.3 \mu \mathrm{in} / \mathrm{s})$ between 1 and $80 \mathrm{~Hz}$ \\
\hline
\end{tabular}


Figure A.2. Generic Vibration Criterion (NIST-A) Curve for critical areas In nanotechnology facilities - Showing also several of the $\mathrm{VC}$ criteria for reference

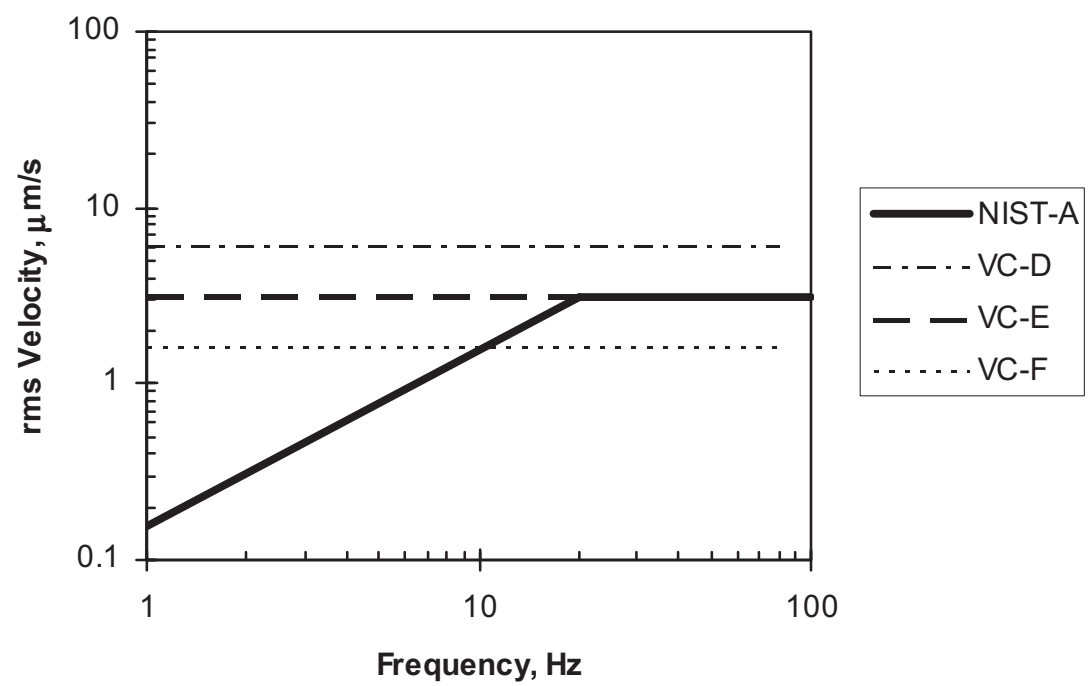

Table A.3: Numerical definition of criterion curves shown in Figure A.2

\begin{tabular}{|c|l|}
\hline Criterion & \multicolumn{1}{|c|}{ Definition } \\
\hline NIST-A & $\begin{array}{l}0.025 \mu \mathrm{m} \text { or } 25 \mathrm{~nm}(1 \mu \mathrm{in}) \text { between } 1 \mathrm{and} 20 \mathrm{~Hz} ; 3.1 \mu \mathrm{m} / \mathrm{s}(125 \mu \mathrm{in} / \mathrm{s}) \text { between } 20 \text { and } \\
100 \mathrm{~Hz}\end{array}$ \\
\hline VC-D & $6.25 \mu \mathrm{m} / \mathrm{s}(250 \mu \mathrm{in} / \mathrm{s})$ between 1 and $80 \mathrm{~Hz}$ \\
\hline VC-E & $3.1 \mu \mathrm{m} / \mathrm{s}(125 \mu \mathrm{in} / \mathrm{s})$ between 1 and $80 \mathrm{~Hz}$ \\
\hline VC-F & $1.6 \mu \mathrm{m} / \mathrm{s}(62.5 \mu \mathrm{in} / \mathrm{s})$ between 1 and $80 \mathrm{~Hz}$ \\
\hline
\end{tabular}


Appendix D

\section{Conceptual Design Drawings}




\section{Appendix D \\ Conceptual Design Drawings}




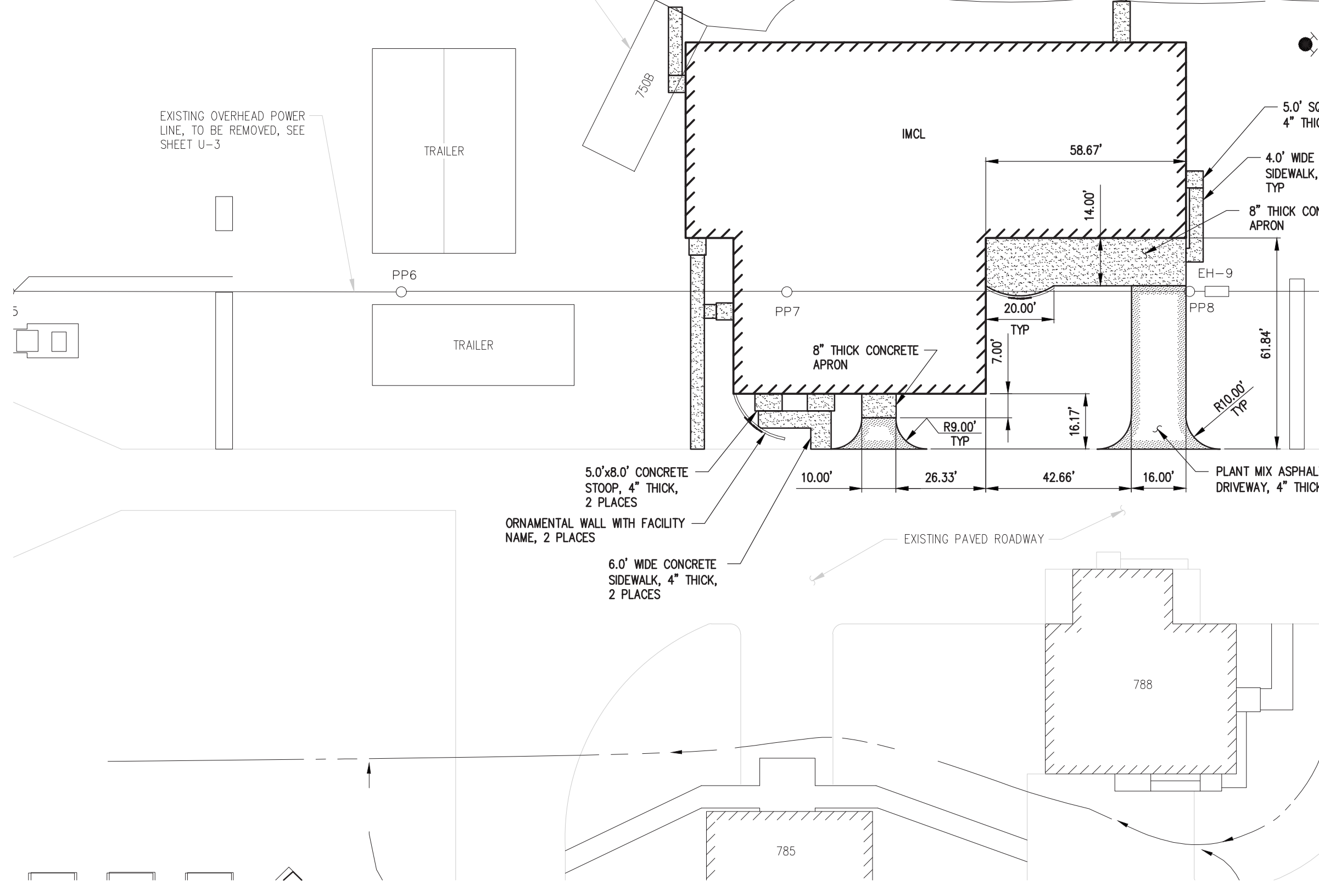

NOTE

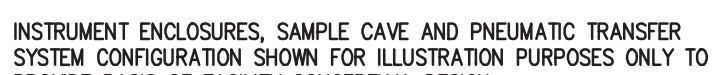

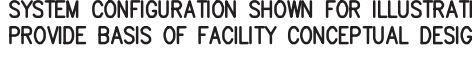

RELEASED FOR RECORD ONLY DO NOT FABRICATE

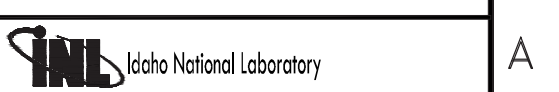

\begin{tabular}{|c|c|c|}
\hline $\begin{array}{l}\text { FOOR DRAWGG MOEX XEE DRAMNG NO. } \\
768366\end{array}$ & 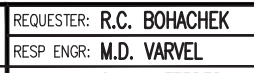 & 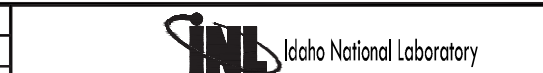 \\
\hline \multirow{4}{*}{ 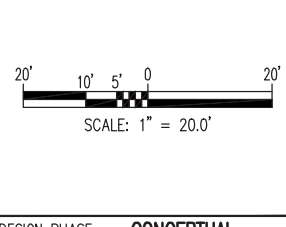 } & 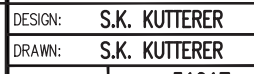 & \\
\hline & 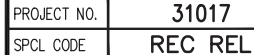 & CHARACECRRIATION LABORATTOYY (IICL) \\
\hline & 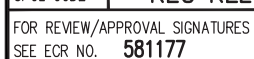 & SITE PLAN \\
\hline & $6-3-10$ & 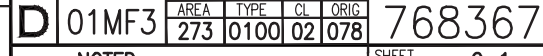 \\
\hline
\end{tabular}




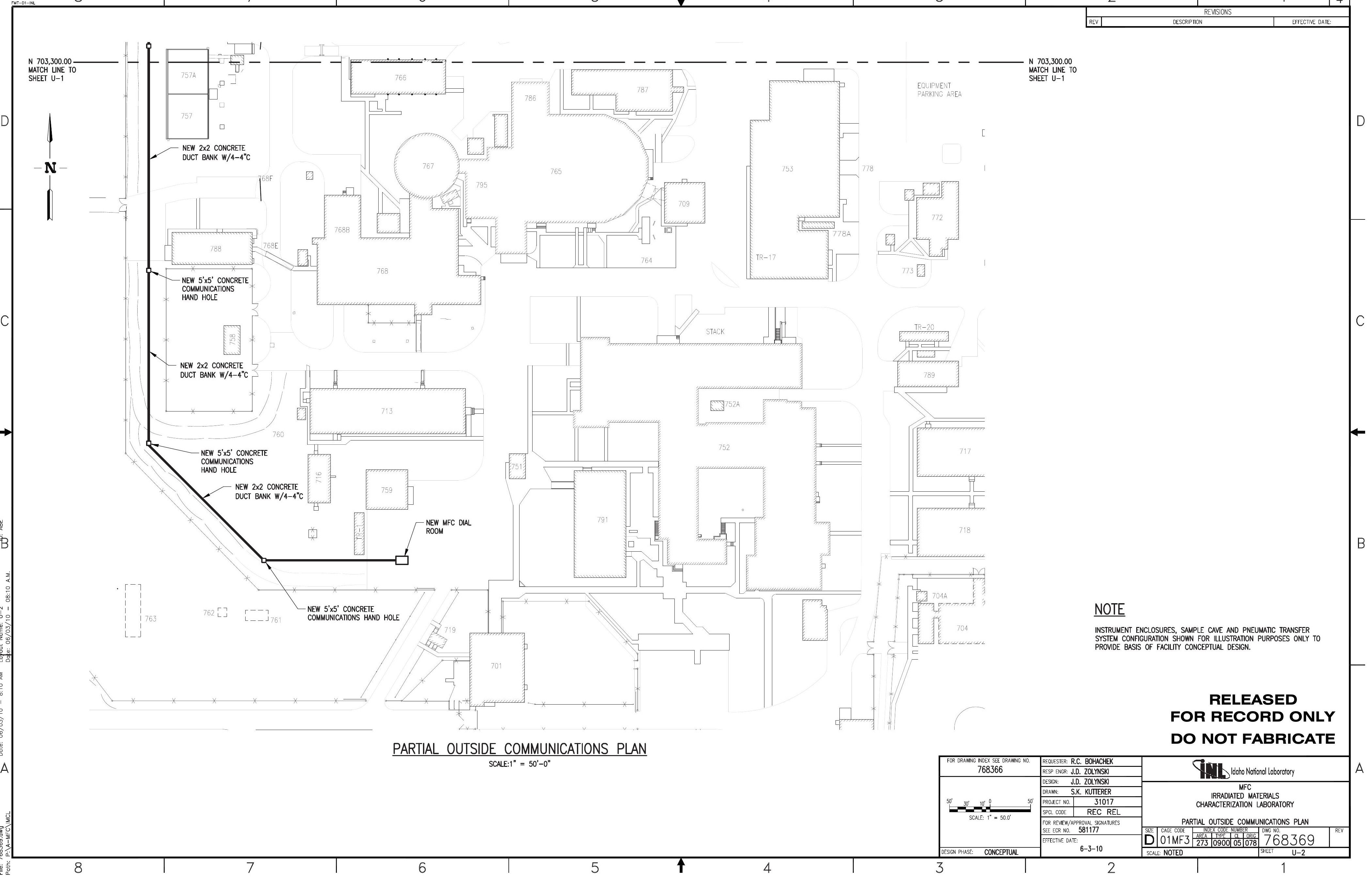




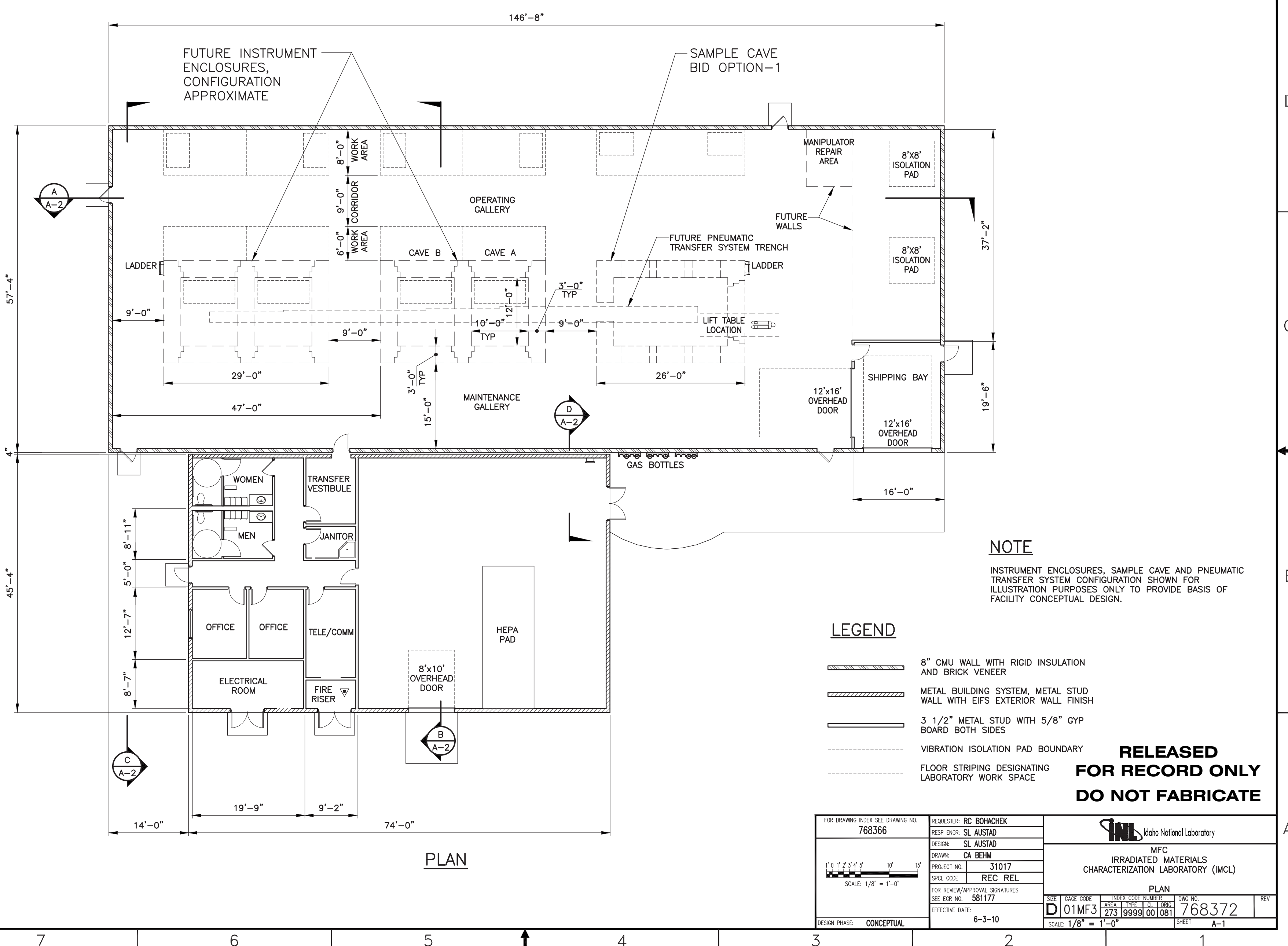



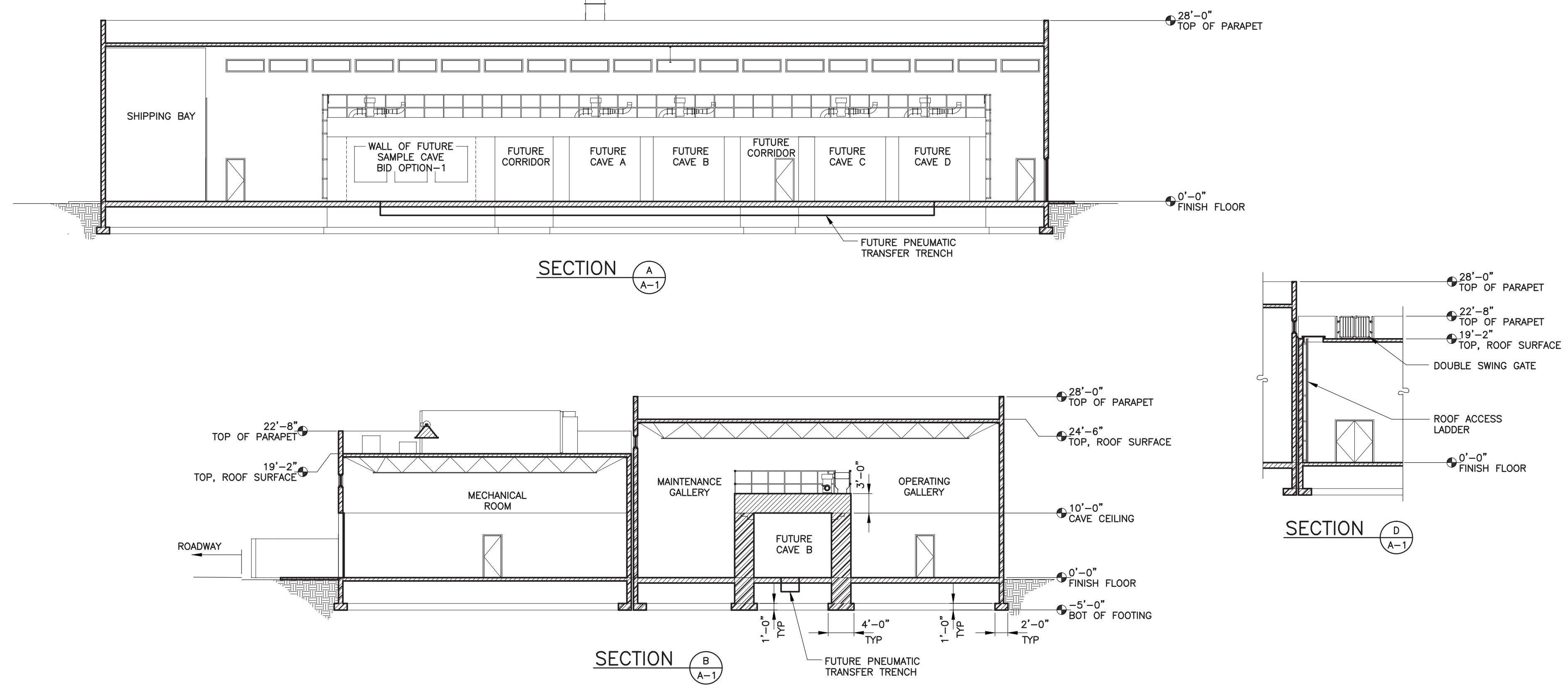

$\mathbb{Q M C}$ FINISH FLOOR
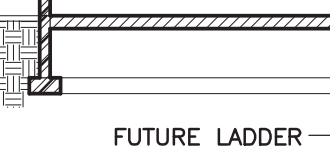
EXTERIOR WALL TO-
FUTURE CAVE D

SECTION

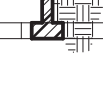
(C)
NOTE

INSTRUMENT ENCLOSURES, SAMPLE CAVE AND PNEUMATIC ILLUSTRATION PURPOSES ONAY TO PROVIDE BASIS OF

SECTION D

\begin{tabular}{|c|c|c|}
\hline & & DO NOT FABRICATE \\
\hline $\begin{array}{l}\text { FOR DRAWGG WOEX SEE DRAMIG NO. } \\
768366\end{array}$ & $\begin{array}{l}\text { REOUESERR: RC BOHACCHEK } \\
\text { RESP ENGR: SL AUSTAD }\end{array}$ & STI Idoho National laboratiory \\
\hline 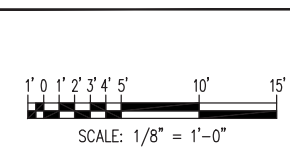 & 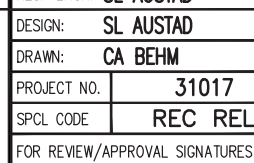 & $\begin{array}{l}\text { MFFC } \\
\text { IRRADIAED MAERALS } \\
\text { CHARACTERIZATON LABORAORY (IMCL) } \\
\text { SECTIONS }\end{array}$ \\
\hline & 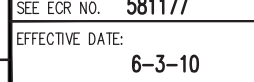 & 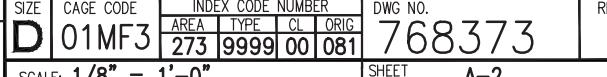 \\
\hline
\end{tabular}




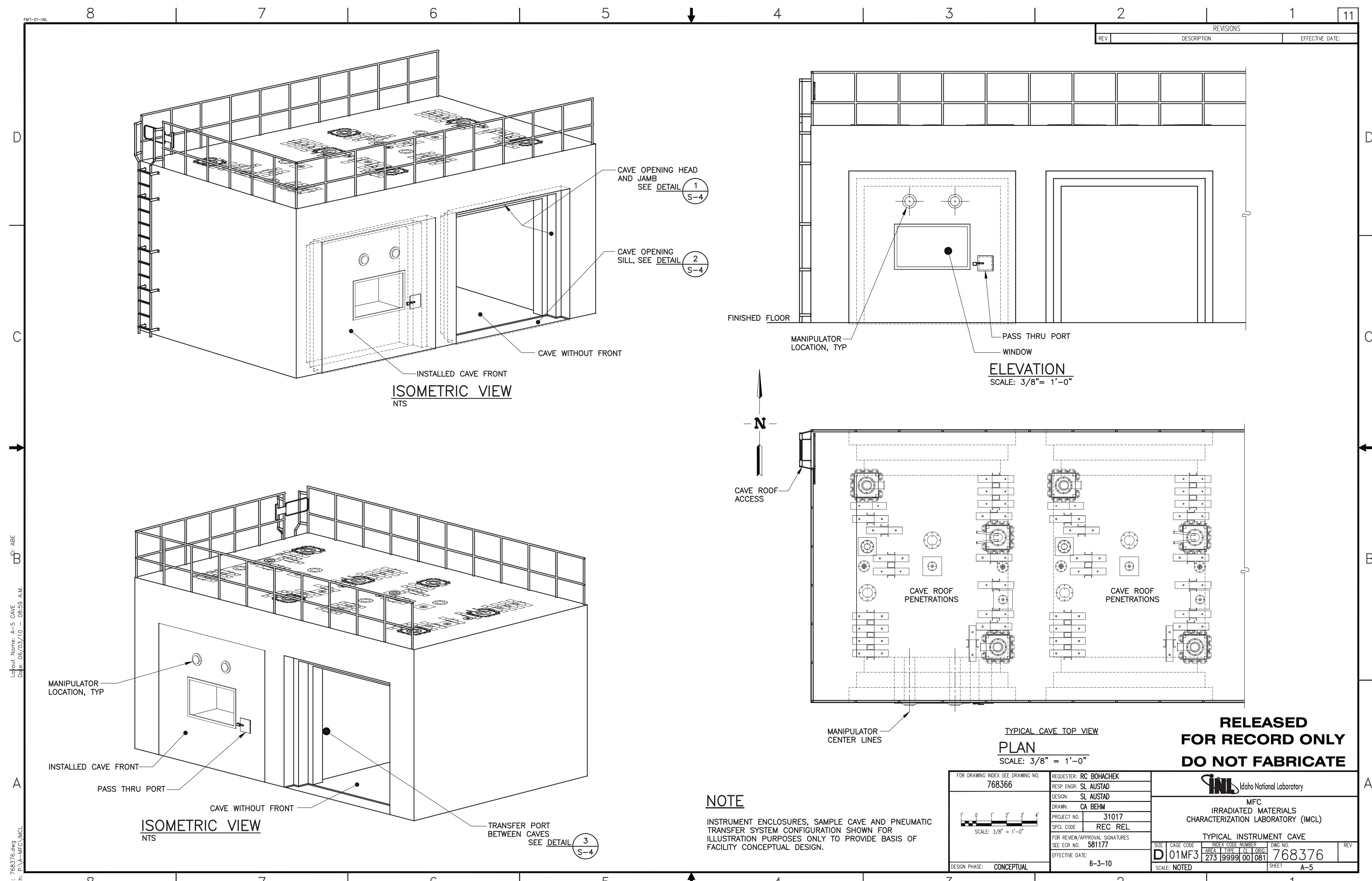




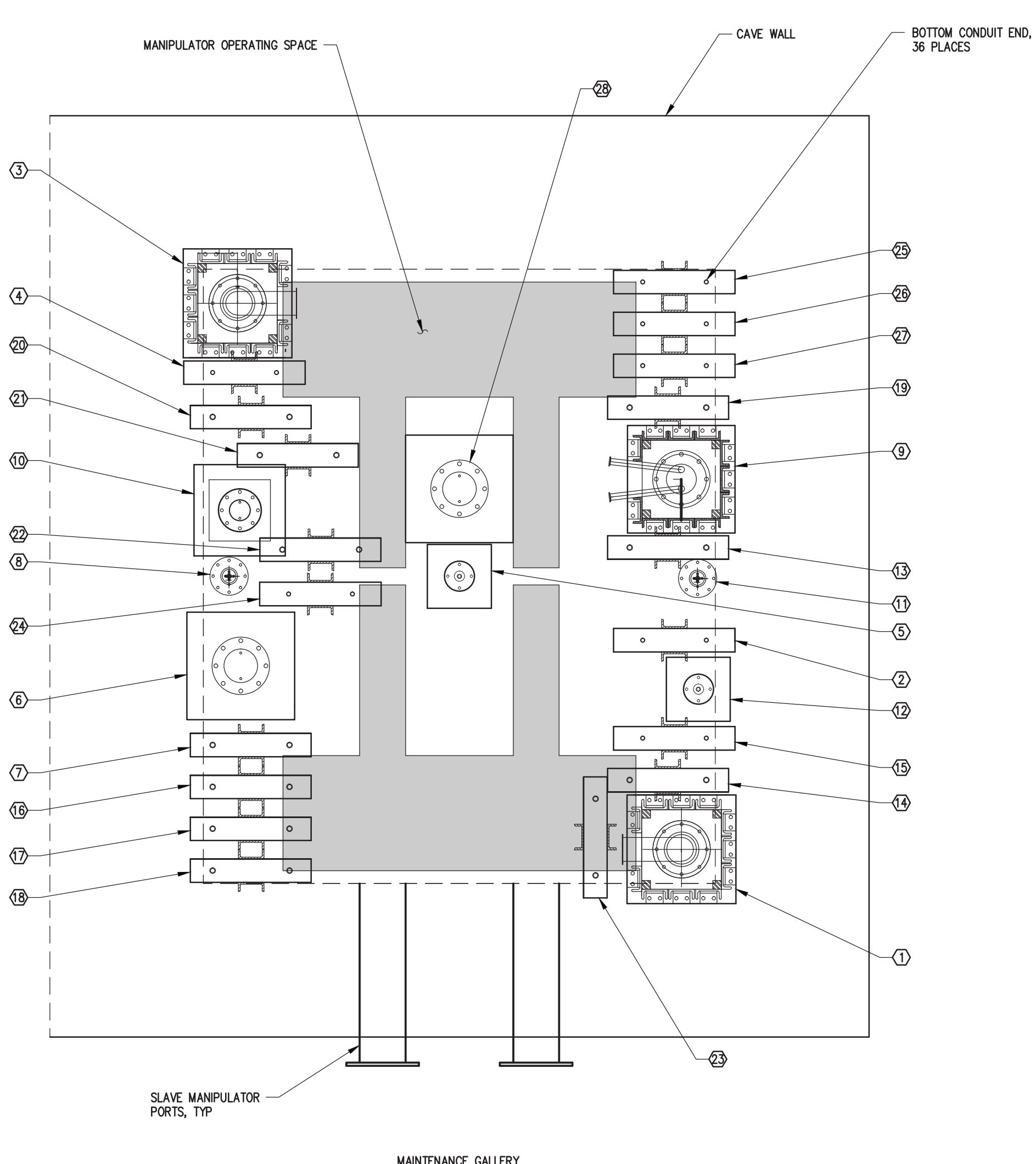

\begin{tabular}{|c|c|c|c|}
\hline \multicolumn{4}{|c|}{$凶$ KEY NOTES } \\
\hline KENNOTE & EMEED SIZE & INSERT SIIE & USE OR DESCRPTION \\
\hline & $8 \mathrm{INCH}$ & 5 IN. OD DUCT & \begin{tabular}{|l|l|l|l|l} 
AR SUPPLY DUCT \\
\end{tabular} \\
\hline 2 & DIRECT EMBED & 34 INCH RGIID CONDUTT-GALV. & ELECTRCAL-CONTROL -AR SUPPLY DUCT DAMPER ACTUATORS \\
\hline 3 & $8 \mathrm{INCH}$ & 5 IN. OD DUCT & SUSPECT EXHAUST DUCT \\
\hline 4 & DIRECT EMBED & 3/4 INCH RIGID CONDUIT - GALV. & ELECTRCALL-CONTROL - SUSPECT EXHAUST DUCT DAMPER ACTUATORS \\
\hline 5 & 2-1/21/1 1NCH & IIN. SCH. 40 CS PIPE & FIRE SPRINKLLR \\
\hline 6 & $8 \mathrm{INCH}$ & 3 3N. SCH.40 PPE & 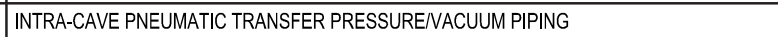 \\
\hline 7 & \begin{tabular}{|l|l|l|l|l|l|l} 
DRECT EMBED \\
\end{tabular} & 1 INCH RGID CONDUTT & $\begin{array}{l}\text { ELECTRCALL-CONTROL- ELECTRCALACAUATOR ON } 3 \text { INCH PRESSUVENACUUM BALL } \\
\text { VALVE AND ON } 3 \text { IN. TRANSERER TUBE BALL VALVE }\end{array}$ \\
\hline 8 & 4 4 INCH & 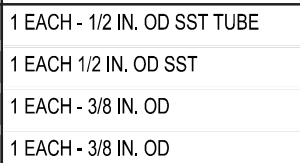 & $\begin{array}{l}\text { FACLLTT DFFERENTAL PRESSURE SENSE TUBE FOR CAVE PRESSURE REEENCE } \\
\text { COMPRESSED AR SUPPLY FOR DUCT DAMPER ACTUATORS } \\
\text { SPARE } \\
\text { SPARE }\end{array}$ \\
\hline 9 & $8 \mathrm{INCH}$ & $\begin{array}{l}1 \text { EACH-1-1/2IN. OD SST TUBE } \\
1 \text { EACH - 1-1/2 N. OD SST TUBE }\end{array}$ & \begin{tabular}{|l|l|} 
INERT ENCLOSURE GAS SUPPLY \\
INERT ENCLOSURE GAS RETURN
\end{tabular} \\
\hline 10 & $5 \mathrm{INCH}$ & BLANK & SPARE \\
\hline 11 & $4 \mathrm{INCH}$ & BLANK & SPARE \\
\hline 12 & 2-1/21/NCH & BLANK & SPARE \\
\hline 13 & DIRECT EMBED & 1 INCH RGID CONDUIT & ELECTRCAL -POWER - LIGHTING GENERAL LAVE \\
\hline 14 & DIRECT EMBED & 1 INCH RGID CONDUIT & ELECTRCALL-POWER - LLGHTING RESEARCH INSTRUMENT \\
\hline 15 & DIRECT EMBED & $3 / 4$ INCH RIGID CONDUIT - GALV. & ELECTRCAL-RECEPTACLES AT WORKSTATION \\
\hline 16 & DIRECT EMBED & 1 INCH RGID CONDUTT & ELECTRCAL-POWER- RESEARCH INSTRUMENT \\
\hline 17 & DIRECT EMBED & 1 INCHRIGID CONDUIT & ELECTRCAL-POWER-RESEARCH INSTRUMENT \\
\hline 18 & DIRECT EMBED & 1 INCH RGID CONDUIT & ELECTRCAL- CONTROL - PHOTODETECTORS ON PNEUMATC TRANSFER TUBNG \\
\hline 19 & DIRECT EMBED & 1 INCH RGID CONDUIT & ELECTRCAL-CONTROL-FRRE DETECTION CABBE OR ALARM \\
\hline 20 & DIRECT EMBED & 1 INCHRIGID CONDUIT & ELECTRCAL-SPARE \\
\hline 21 & DIRECT EMBED & 1 INCH RIGID CONDUIT & ELECTRICAL-SPARE \\
\hline 22 & DIRECT EMBED & 1 INCH RIGID CONDUIT & ELECTRICAL-SPARE \\
\hline 23 & DIRECT EMBED & 1 INCH RIGID CONDUIT & ELECTRICAL-SPARE \\
\hline 24 & DIRECT EMBED & 3/4 INCH RIGID CONDUIT - GALV. & ELECTRICAL-SPARE \\
\hline 25 & DIRECT EMBED & 3/4 INCH RIGID CONDUIT - GALV. & ELECTRICAL-SPARE \\
\hline 26 & DIRECT EMBED & 3/4 INCH RIGID CONDUIT - GALV. & ELECTRICAL-SPARE \\
\hline 27 & DIRECT EMBED & 314 INCH RIGID CONDUIT - GALV. & ELECTRICAL-SPARE \\
\hline 28 & $8 \mathrm{INCH}$ & BLANK & \begin{tabular}{|l|} 
SPARE \\
\end{tabular} \\
\hline
\end{tabular}

NOTE

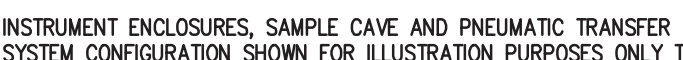

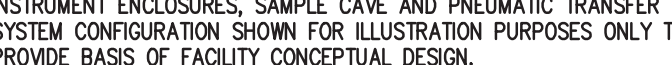

RELEASED FOR RECORD ONLY DO NOT FABRICATE

INSTRUMENT CAVE CEILING PENETRATIONS PLAN

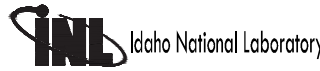

\begin{tabular}{|c|c|c|}
\hline 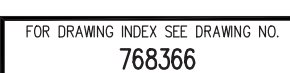 & 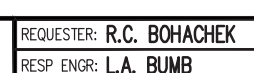 & 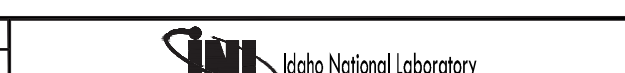 \\
\hline \multirow{4}{*}{$=-0 \quad 1-6^{\circ}$} & 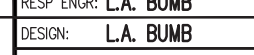 & \\
\hline & 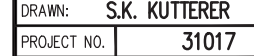 & 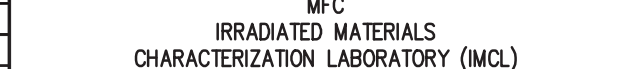 \\
\hline & 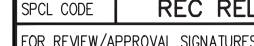 & insकाया \\
\hline & SEE ECQ NO. 588177 & 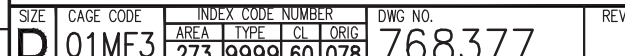 \\
\hline DESGGN PHASE: CONCEPTUAI & 6-3-10 & 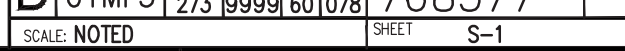 \\
\hline
\end{tabular}




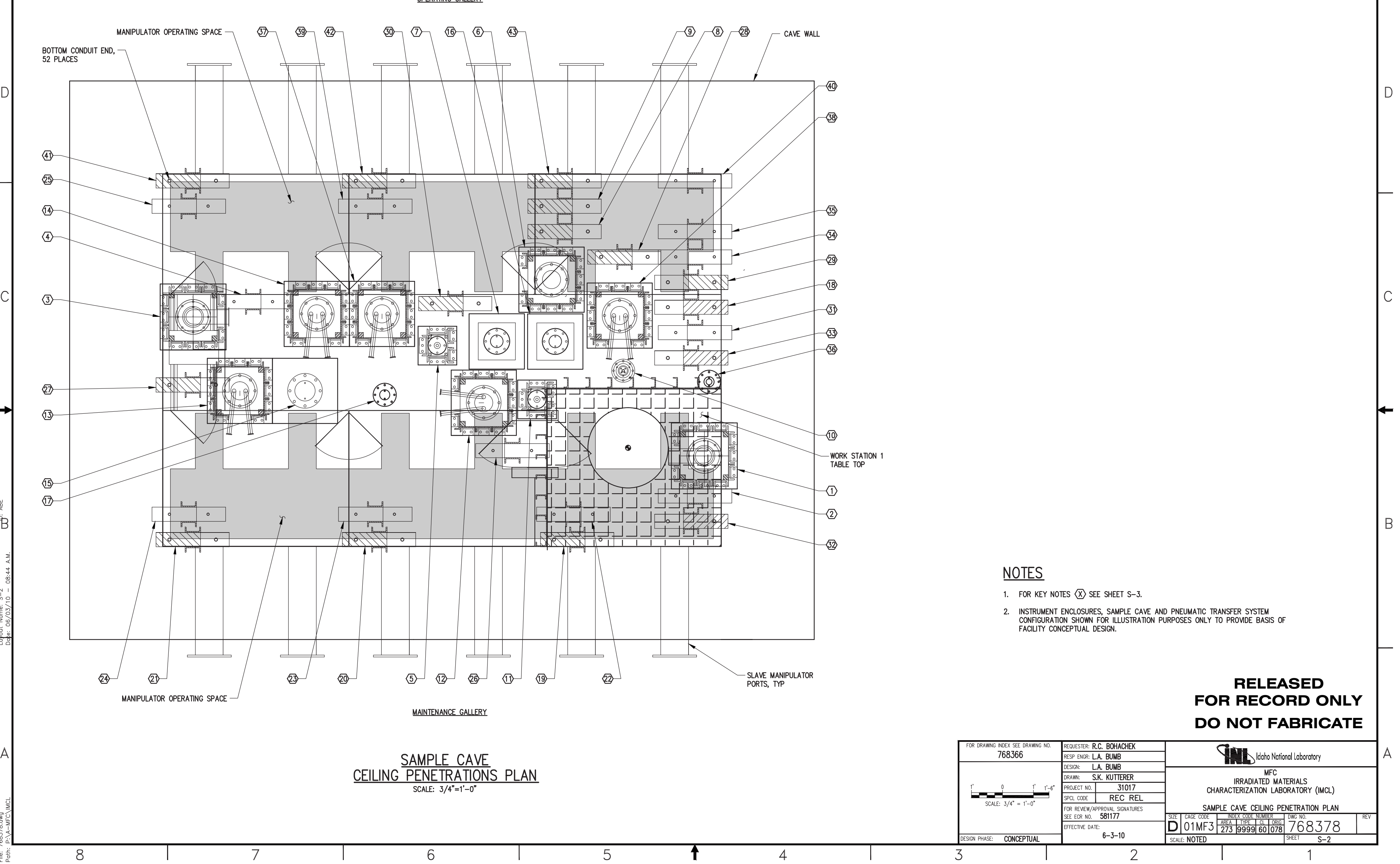




\begin{tabular}{|c|c|c|c|}
\hline \multicolumn{4}{|c|}{$凶$ KEY NOTES } \\
\hline KKYYNOTE & EMBED SIZE & INSERT OR PLUG SIZE & USE OR DESCRPTION \\
\hline & $8 \mathrm{INCH}$ & 5 IN. OD DUCT & AR SUPPLY DUCT \\
\hline & DIRECT EMBED & 3/4 INCH RGID CONDUIT-GALV. & ELECTRICAL-CONTROL-AR SUPPLY DUCT DAMPER ACTUATORS \\
\hline & 8 INCH & 5 IN. OD DUCT & SUSPECT EXHAUST DUCT \\
\hline & DIRECT EMBED & 3/4 INCH RGID CONDUIT - GALV. & ELECTRICAL -CONTROL - SUSPECT EXHAUST DUCT DAMPER ACTUATORS \\
\hline & 2-1/21/1NCH & 1 IN. - SCH. 40 CS PPE & FIRE SPRINKLER \\
\hline & 8 INCH & $\begin{array}{l}31 \mathrm{~N} . \text {. SCH.40 PPE } \\
\text { BAKK }\end{array}$ & 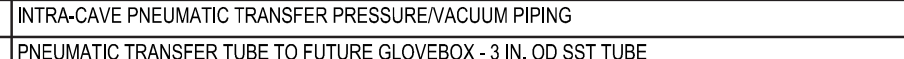 \\
\hline$\frac{1}{8}$ & $\begin{array}{l}5 \text { INCH } \\
\text { DRECT EMBED }\end{array}$ & $\frac{\text { BAANK }}{1 \text { INCH RIGID CONDUIT }}$ & 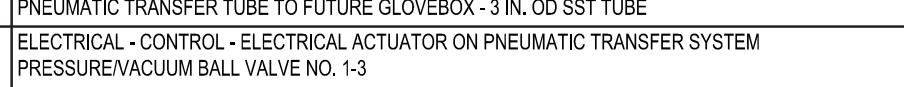 \\
\hline & \begin{tabular}{|l|l|l} 
DRECT EMBED \\
\end{tabular} & 1 INCH RIGID CONDUIT & $\begin{array}{l}\text { ELECTRRCALL-CONTROLL-ELECTRICAL ACTUATOR ON PNEUMATCC TRANSFER PRESSURENACUUM } \\
\text { BALL YALVV NO.46 }\end{array}$ \\
\hline 10 & $4 \mathrm{INCH}$ & \begin{tabular}{|l} 
EACH-1/2 IN. OD SST TUBE \\
1 EACH 1/2N. OD SST \\
1 EACH-38 IN. OD \\
1 EACH-38 IN. OD
\end{tabular} & $\begin{array}{l}\text { FACLLITY DIFFERETTAL PRESSURE SENSE TUUE FOR CAVE PRESSURE REEREENCE } \\
\text { COMPRESSED AR SUPPLY FOR DUCT DAMPER ACTUATORS } \\
\text { SPARE } \\
\text { SPARE }\end{array}$ \\
\hline 11 & $2 \cdot 12121 \mathrm{NCH}$ & 334 IN. SCH. 40 CS PPE & TRANSFER LOCK GAS SUPPLY AND VACUUM DUAL LSE \\
\hline 12 & $8 \mathrm{INCH}$ & 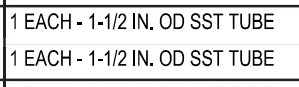 & \begin{tabular}{|l|} 
NERT ENCLOSURE NO. 1 GAS SUPPIY \\
|NERT ENCLOSURE NO. 1 GAS RETURN \\
\end{tabular} \\
\hline 13 & $8 \mathrm{INCH}$ & $\begin{array}{l}\text { EACH-1-1/2 N N OO SST TUBE } \\
\text { 1EACH-1-1/2 N . OO SST TUBE }\end{array}$ & \begin{tabular}{|l} 
NERT ENCLOSURE NO 2 GAS SUPPLY \\
NERT ENCLOSURE NO 2 2 GS RETURN
\end{tabular} \\
\hline 14 & $8 \mathrm{INCH}$ & $\begin{array}{l}1 \text { EACH-1-1/2 N. OD SST TUBE } \\
1 \text { EACH - 1-1/2 N. OD SST TUBE }\end{array}$ & \begin{tabular}{|l} 
INERT ENCLOSURE NO. 3 GAS SUPPLY \\
INERT ENCLOSURE NO. 3 GAS RETURN
\end{tabular} \\
\hline & $8 \mathrm{INCH}^{-1}$ & BLANK & SPARE \\
\hline & $5 \mathrm{INCH}$ & BLANK & SPARE \\
\hline & $\begin{array}{lll}4 \text { INCH } \\
\text { PCFT }\end{array}$ & BLANK & SPARE \\
\hline & $\begin{array}{l}\text { DREET MEBED } \\
\text { DRECT EMBED }\end{array}$ & $\frac{1 \text { INCH RIIII CONDUUT }}{1 \text { 1NCH HGD CONDUT }}$ & 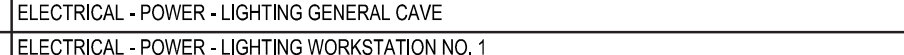 \\
\hline & 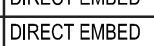 & 1 INCH RIGID CONDUIT & ELECTRICALL LLGHTING WORKSTATON2 \\
\hline & \begin{tabular}{|l|l|l} 
DRECT EMBED \\
\end{tabular} & 1INCHRIIID CONDUIT & ELECTRICALL LLGHTING WORKSTATION NO. 3 \\
\hline & 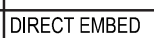 & 34 INCHRGID CONDUT-GALV. & ELECTRICAL-RECEPTACLES AT WORKSTATION NO 1 \\
\hline & DREET EMBED & 34 ICHRGII CONDUTT-GALV. & ELECTRICAL-RECEPTACLES AT WORKSTATION NO 2 \\
\hline & \begin{tabular}{|l|l|l} 
DRECT EMBED \\
\end{tabular} & $3 / 4$ INCH RGID CONDUT-GALV. & ELECTRICAL-RECEPTACLES AT WORKSTATION NO. 3 \\
\hline & 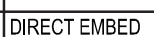 & 3 34 INCH RGID CONDUT-GALV. & ELECTRICLL-RECEPTACLES AT WORKSTATION N0.4 \\
\hline 26 & DIRECT EMBED & 3/4 INCH RIGID CONDUIT - GALV. & ELECTRICAL - CONTROL - LIMT SWTCHES ON TRANSEER LOCK \\
\hline 27 & DIRECT EMBED & 1 INCH RIGID CONDUIT & ELECTRICAL - POWER- TRANSFER CART BETWEEN FRONT AND BACK WORKSTATIONS \\
\hline 28 & DIRECT EMBED & 1 INCH RIGI CONDUIT & ELECTRICAL-CONTROL -PHOTODETECTORS ON PNEUMATIC TRANSERR TUBNG - TUBES 1-4 \\
\hline 29 & DIRECT EMBED & 1 INCH RIGID CONDUIT & ELECTRICAL-CONTROL-PHOTOOETECTORS ON PNEUMATIC TRANSEER TUBING - TUBES 5-7 \\
\hline 30 & DRECT EMBED & 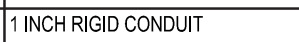 & 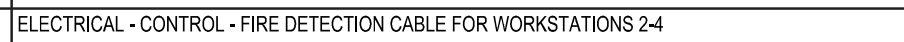 \\
\hline & \begin{tabular}{|l|l|l} 
DRECT EMBED \\
\end{tabular} & 3/4 INCH RIGID CONDUIT - GALV. & ELECTRIICAL - CONTROL - FIRE DETECTION CABLE FOR SMOKE DETECTOR IN GENERAL CAVE \\
\hline & DRECT EMBED & 1 11NCHRGGD CONDUTT & EEECTRCALL-HOIST AT WORKSTATOON NO. 1 \\
\hline & 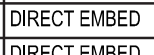 & 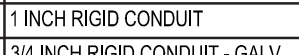 & ELECTRCAL PAARE \\
\hline & DRRCT EMBED & 344 INCH RGID CONDUTT-GALV. & 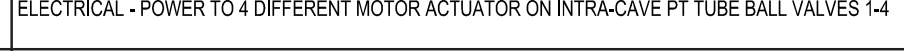 \\
\hline 35 & DRECT EMBED & 3/4 INCH RGID CONDUIT - GALV. & ELECTRCALL-POWER T O 3 OFFERENT MOTOR ACTUATOR ON INTRA-CAVE PT TUBE BALL VALVES 5.7 \\
\hline & $4 \mathbb{1 N C H}$ & 2 INCH SCH. 40 PIPE-GALV & 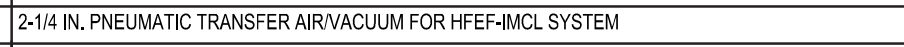 \\
\hline & $8 \mathrm{INCH}$ & $\begin{array}{l}1 \text { EACH-1-1/2 IN. OD SST TUBE } \\
\text { 1 EACH-1-1/2N OD SST TUBE }\end{array}$ & \begin{tabular}{|l|l|} 
NERT ENCLOSURE NO 4 4 GAS SUPPLY \\
NERT ENCLOSURE NO 4 GAS RETURN
\end{tabular} \\
\hline 38 & $8 \mathrm{INCH}$ & $\begin{array}{l}1 \text { EACH-1-1/2 IN. OD SST TUBE } \\
\text { 1 EACH-1-1/2 N OD SST TUBE }\end{array}$ & \begin{tabular}{|l|} 
INERT ENCLOSURE NO. 5 GAS SUPPLY \\
INERT ENCLOSURE NO. 5 GAS RETURN
\end{tabular} \\
\hline 39 & DIRECT EMBED & 3/4 INCH RIGID CONDUIT - GALV. & ELECTRICAL-RECEPTACLES AT WORKSTATION NO. 5 \\
\hline & DRECT EMBEDD & 3/4 INCH RIGID CONDUIT - GALV. & ELECTRICAL-RECEPTACLES AT WORKSTATION NO. 6 \\
\hline 41 & DIRECT EMBED & 1 INCH RIGID CONDUIT & ELECTRICAL-LGHTING WORKSTATION4 \\
\hline 42 & DRECT EMBED & 1 IINCHRGID CONDUTT & ELECTRICALL LIGHTTNG WORKSTATION NO. 5 \\
\hline & DRECT EMBED & $\begin{array}{l}\text { INCH RIGID CONDUIT } \\
\end{array}$ & ELECTRICALLLLGHTING WORKSTATION NO. 6 \\
\hline
\end{tabular}

NOTE

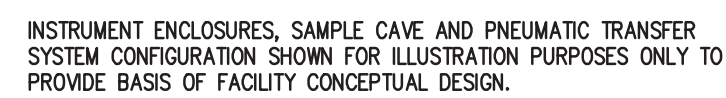

RELEASED FOR RECORD ONLY DO NOT FABRICATE

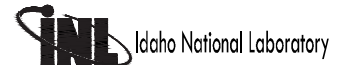

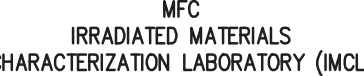

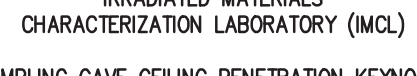

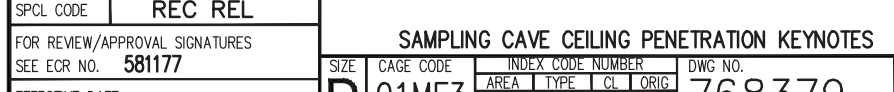

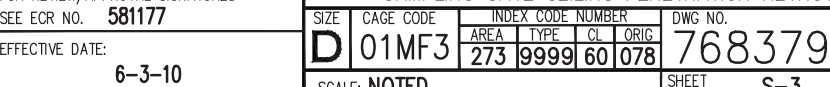




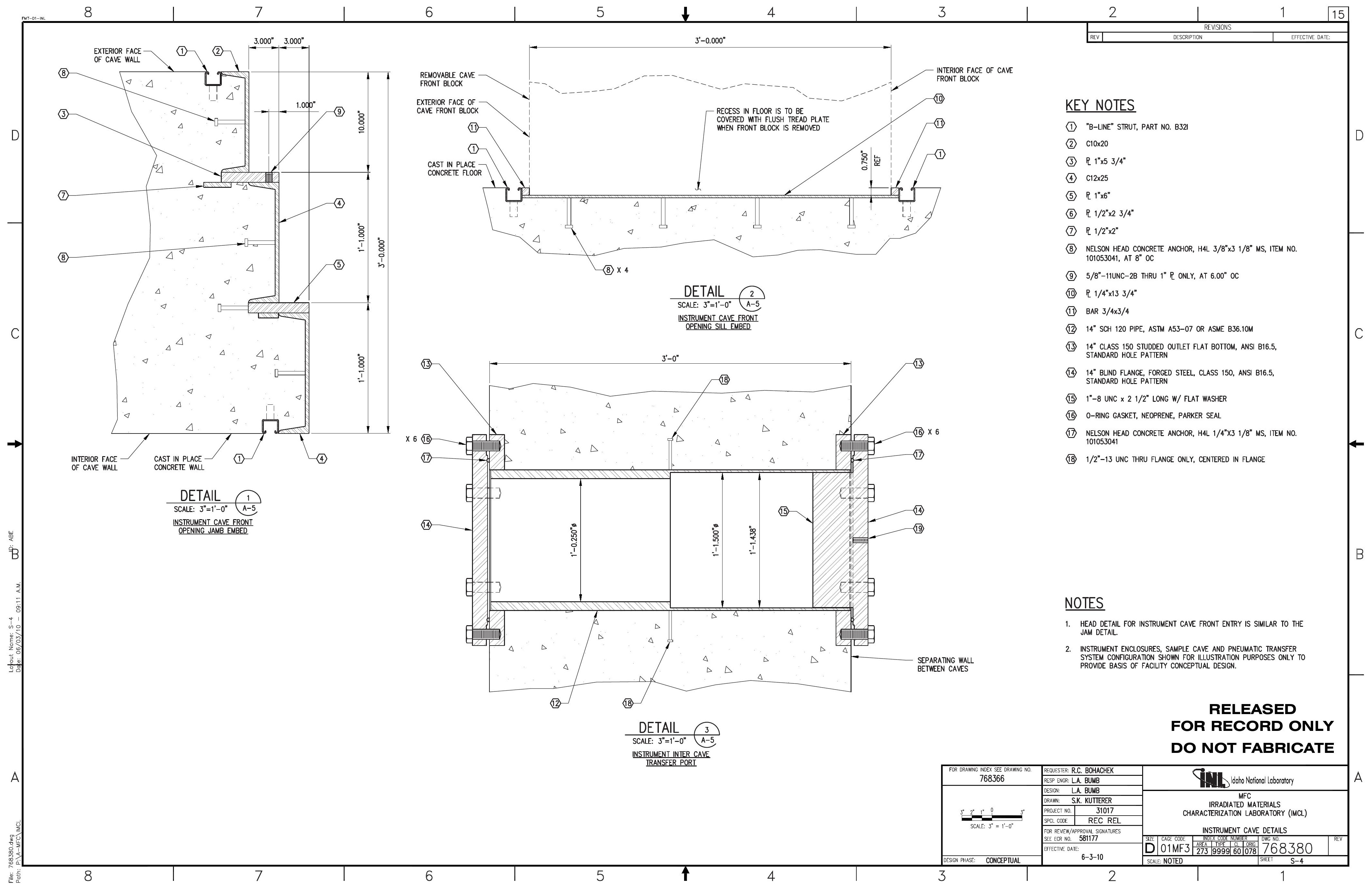




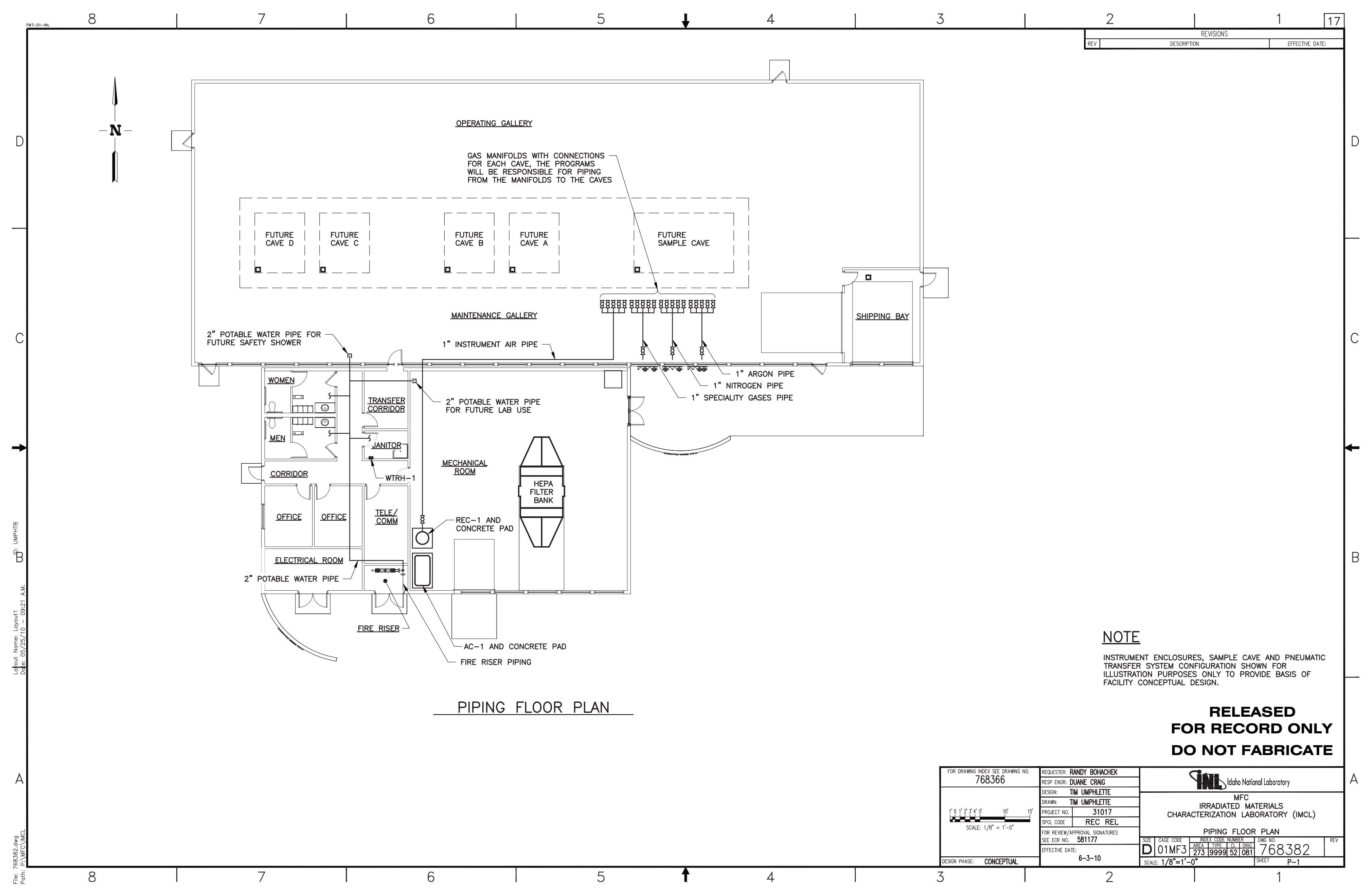



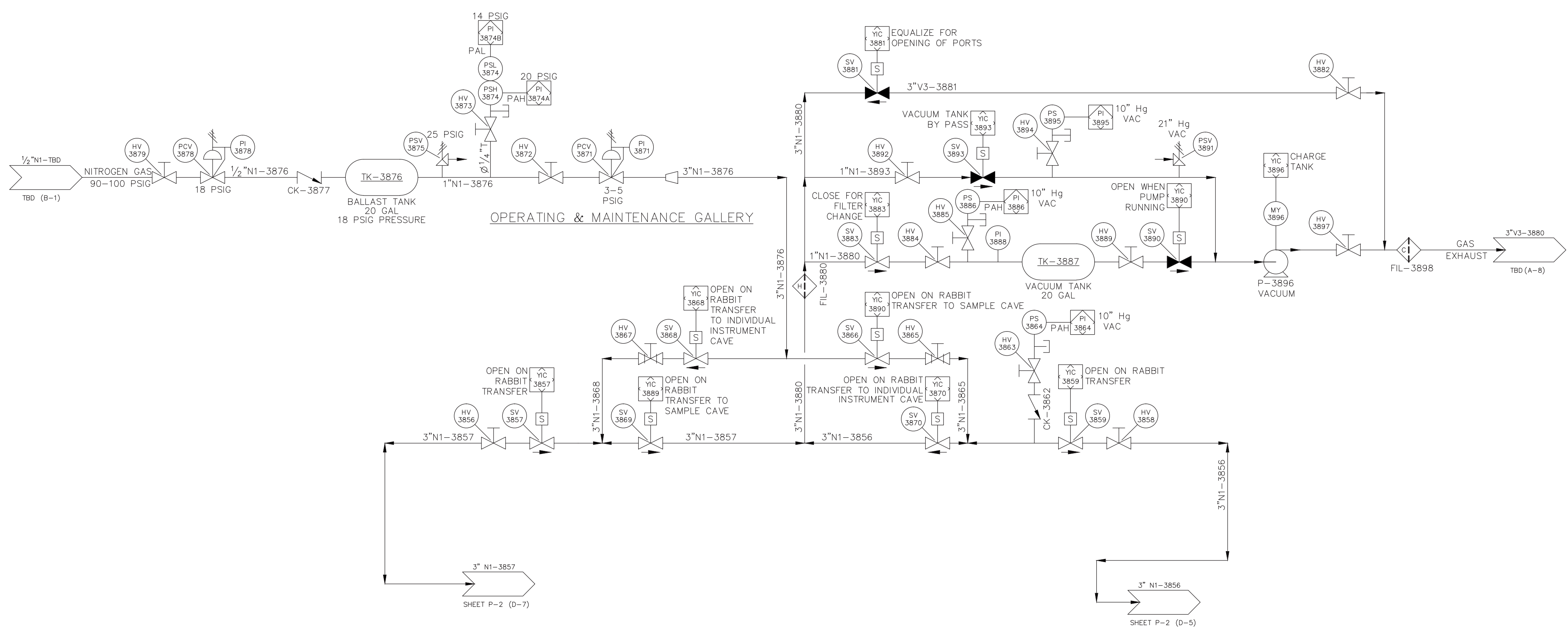

NOTES:

1. ARROWS ( - ) BELOW SOLENOID VALVES INDICATE VALVE BODY FLOW ORIENTATION.

2. INSTRUMENT ENCLOSURES, SAMPLE CAVE AND PNEUMATIC TRANSFER SYSTEM
CONFIGURATION SHOWN FOR ILLUSTRATION PURPOSES ONLY TO PROMDE BASIS OF

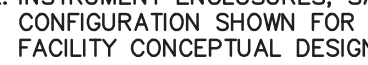

RELEASED

FOR RECORD ONLY

DO NOT FABRICATE

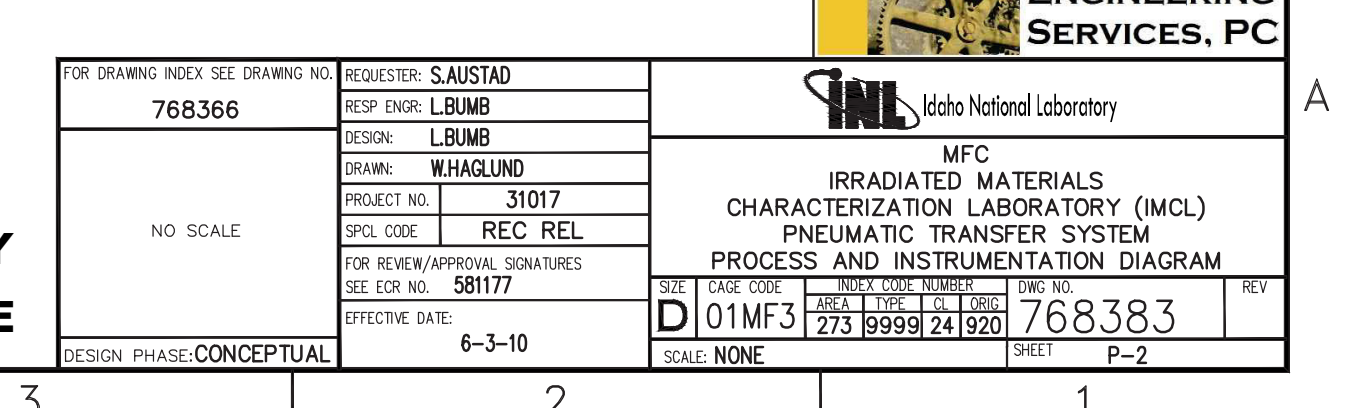




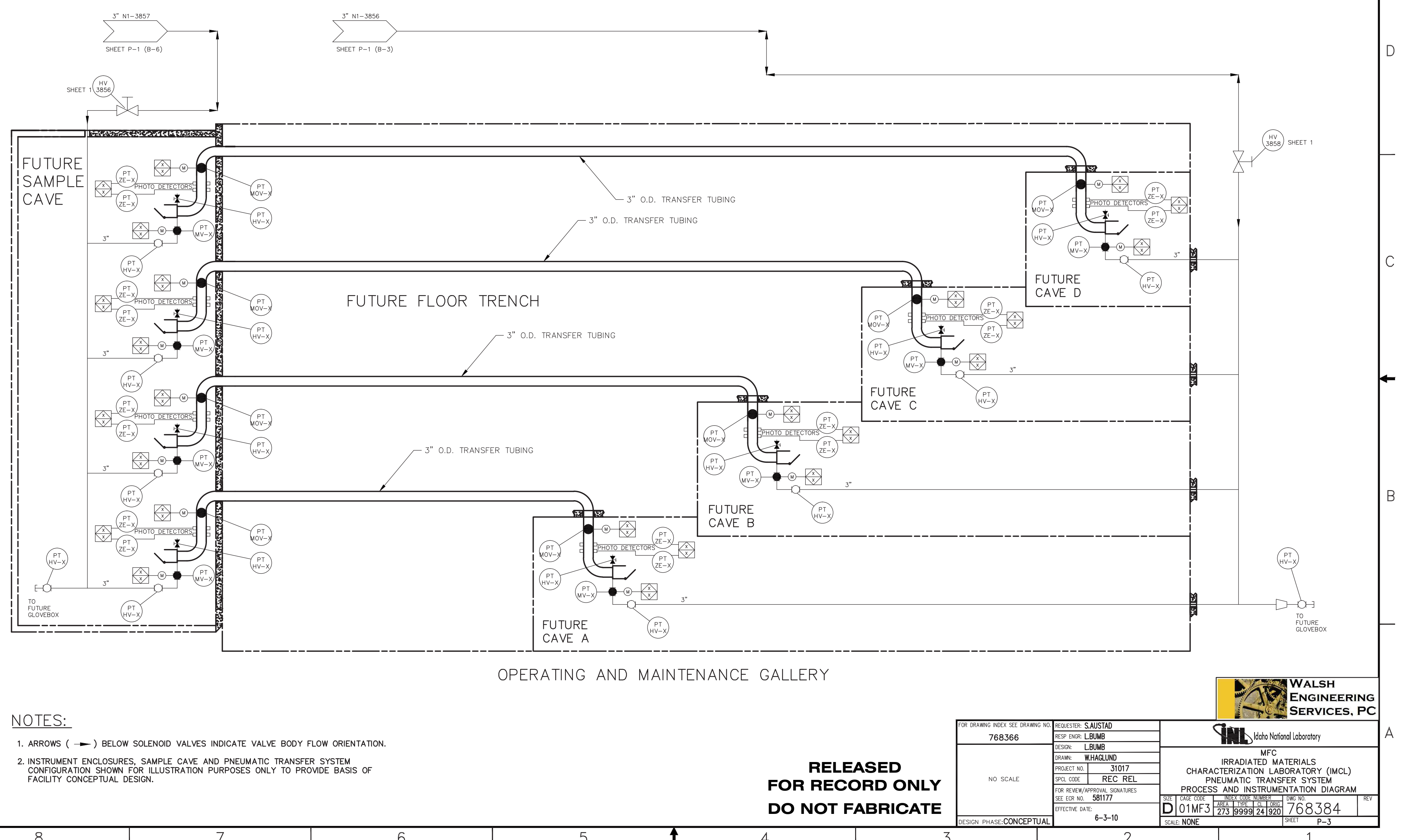




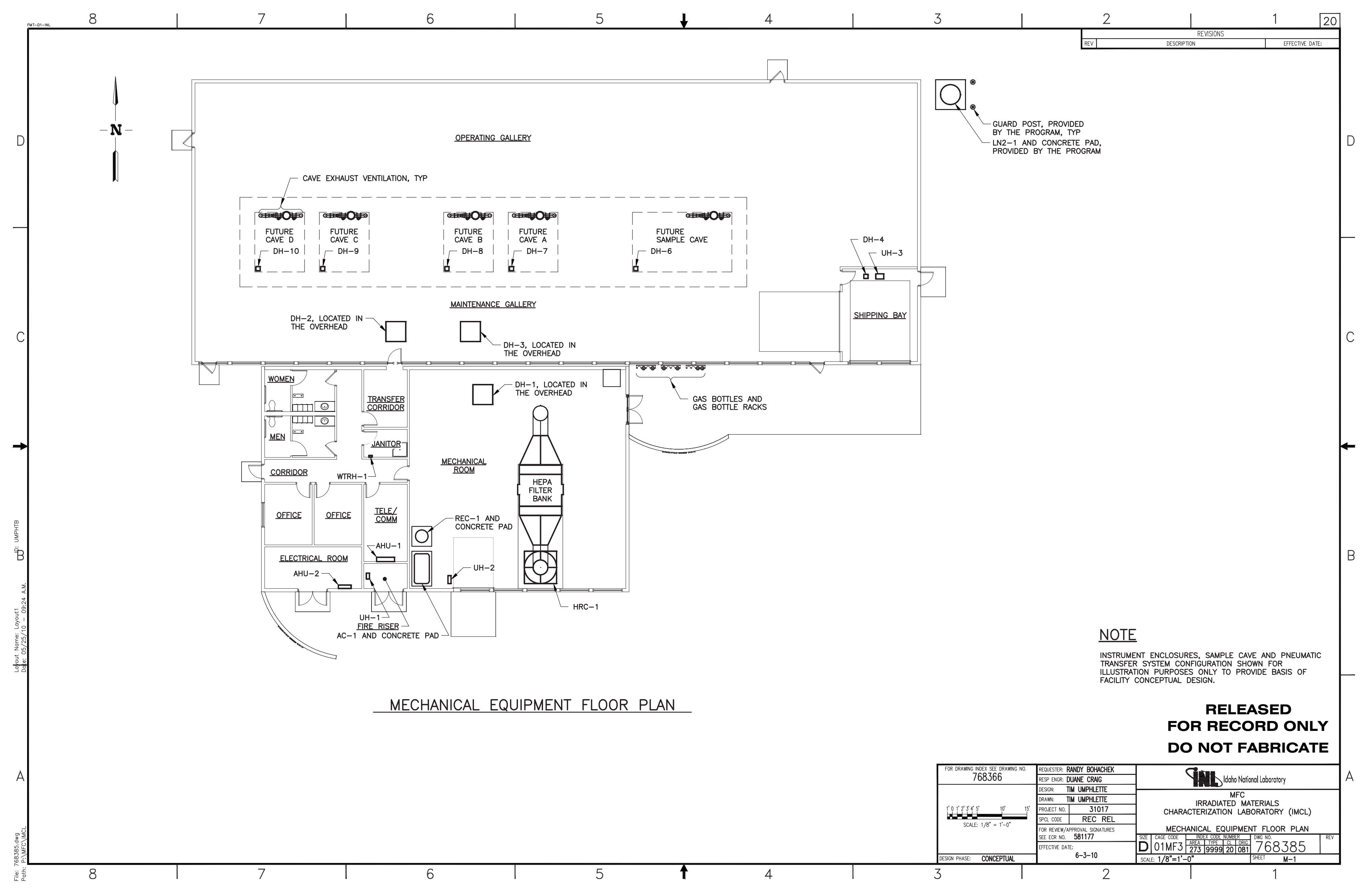




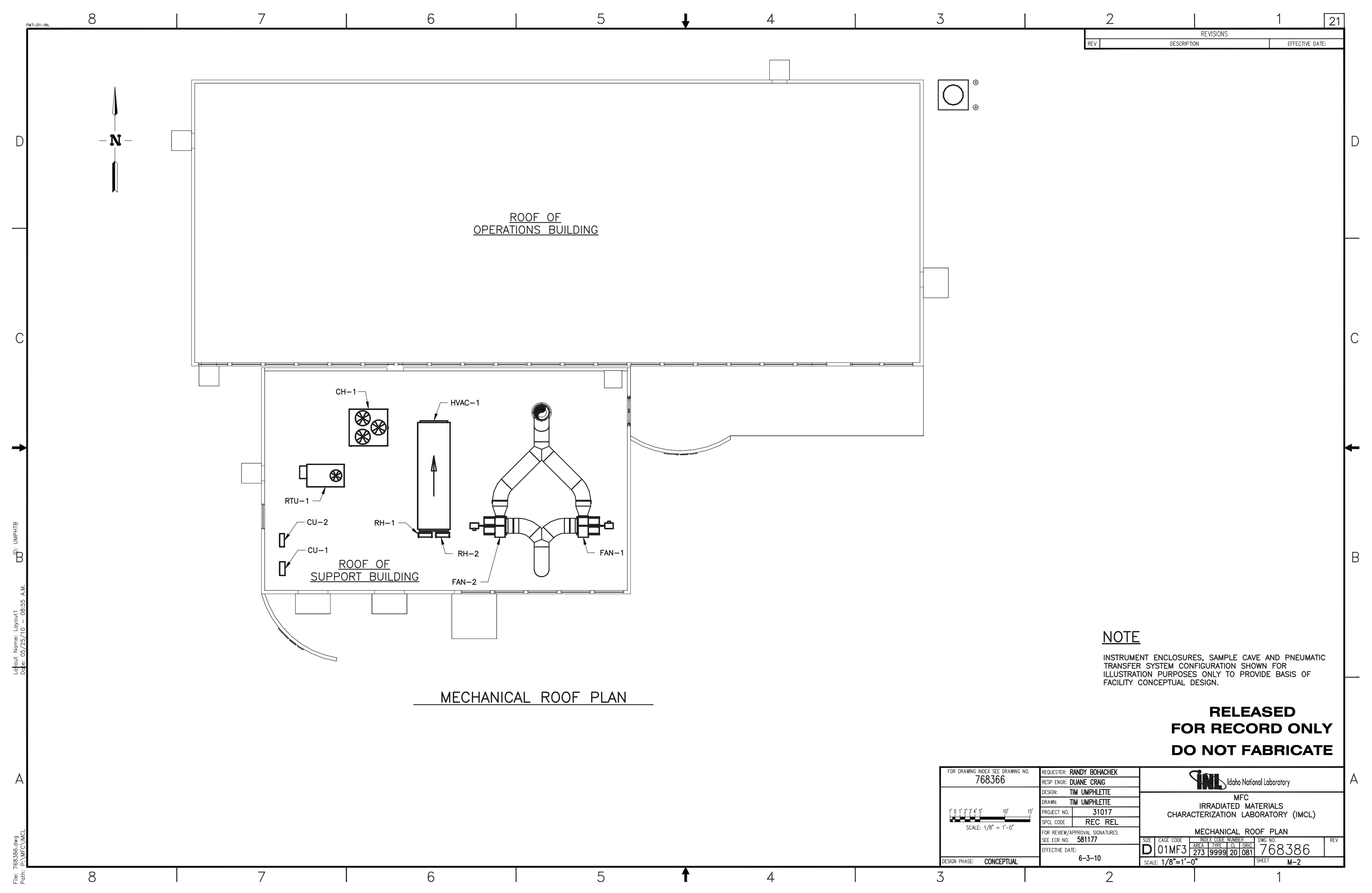




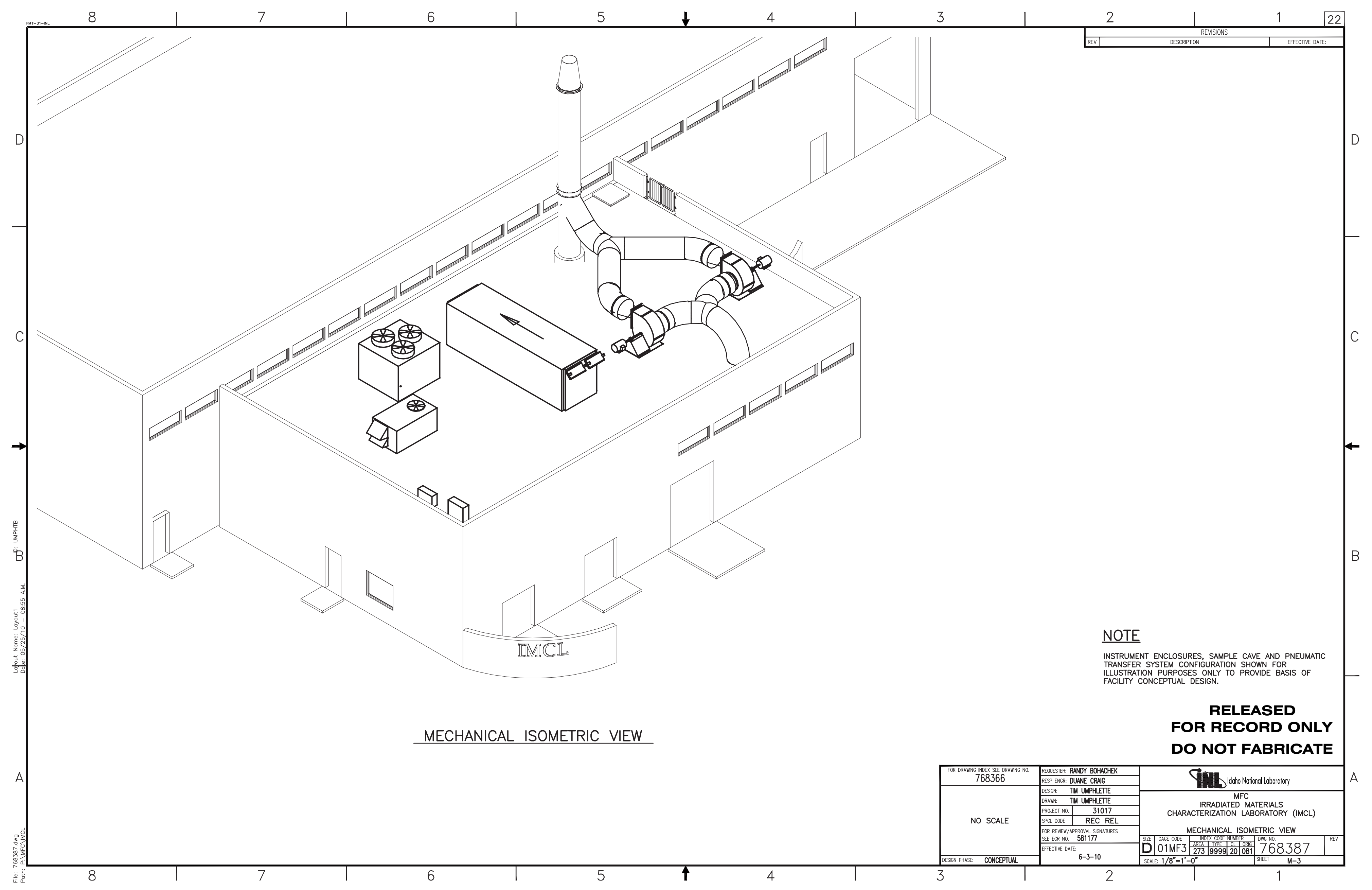




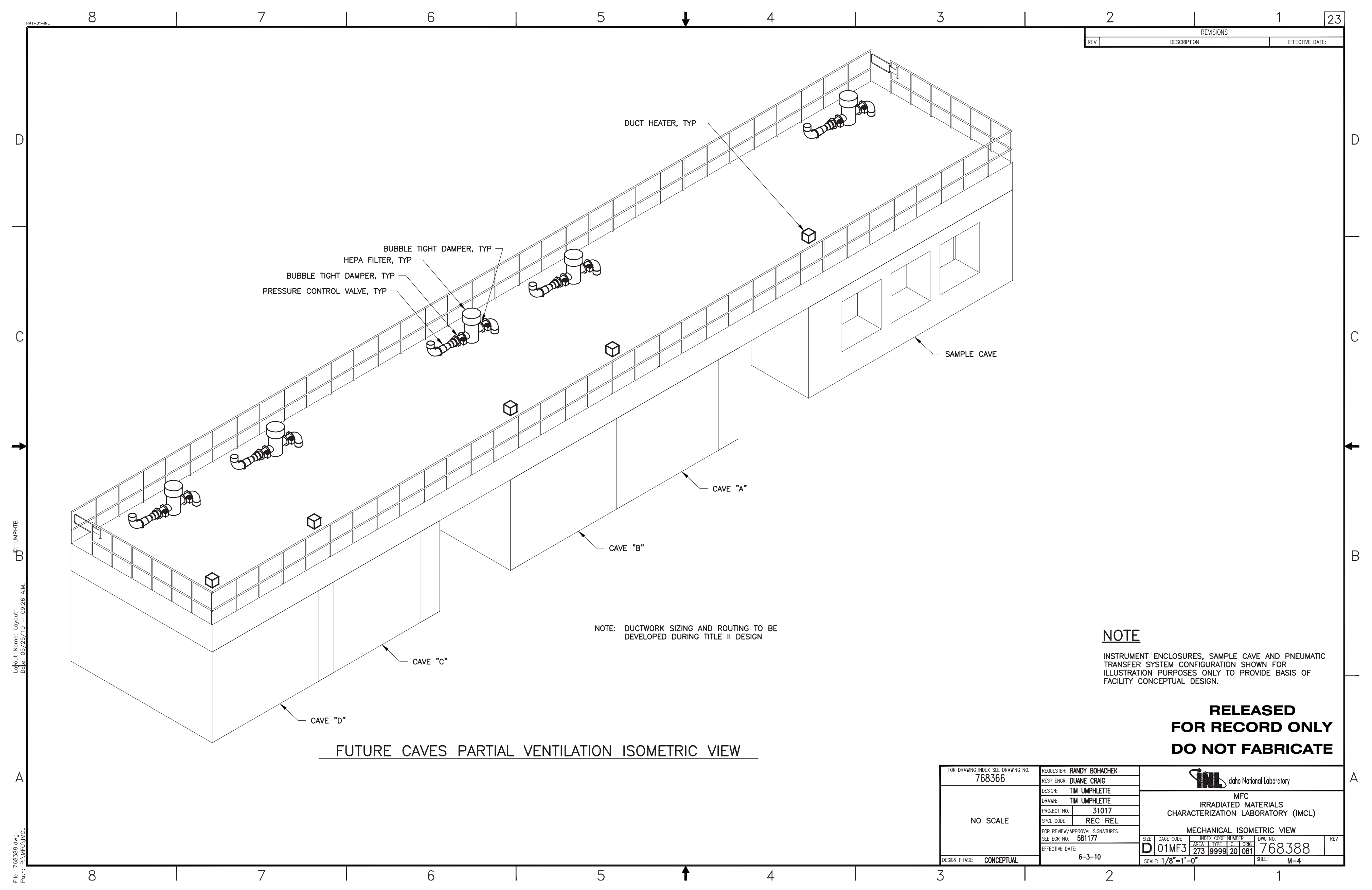




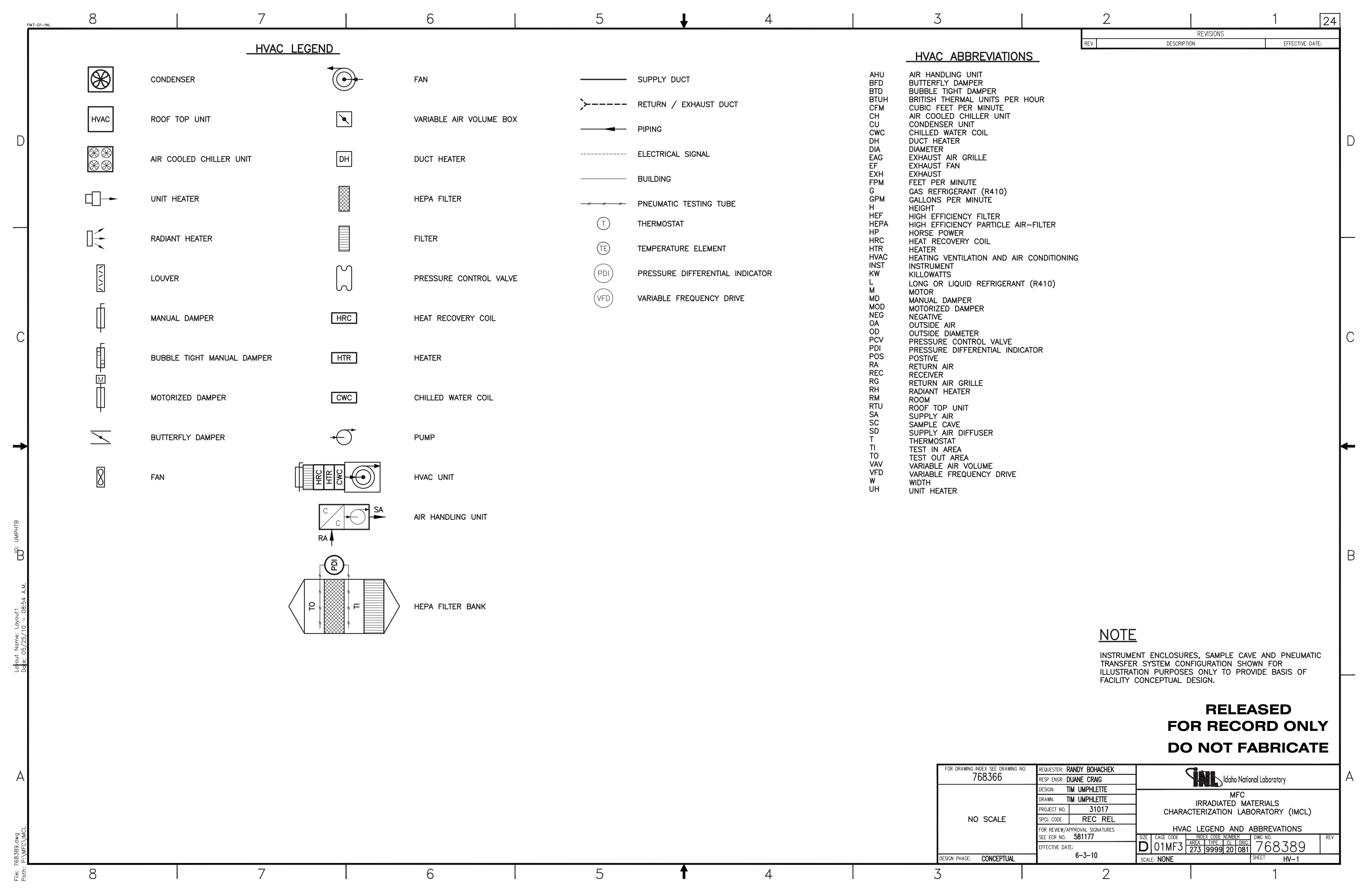




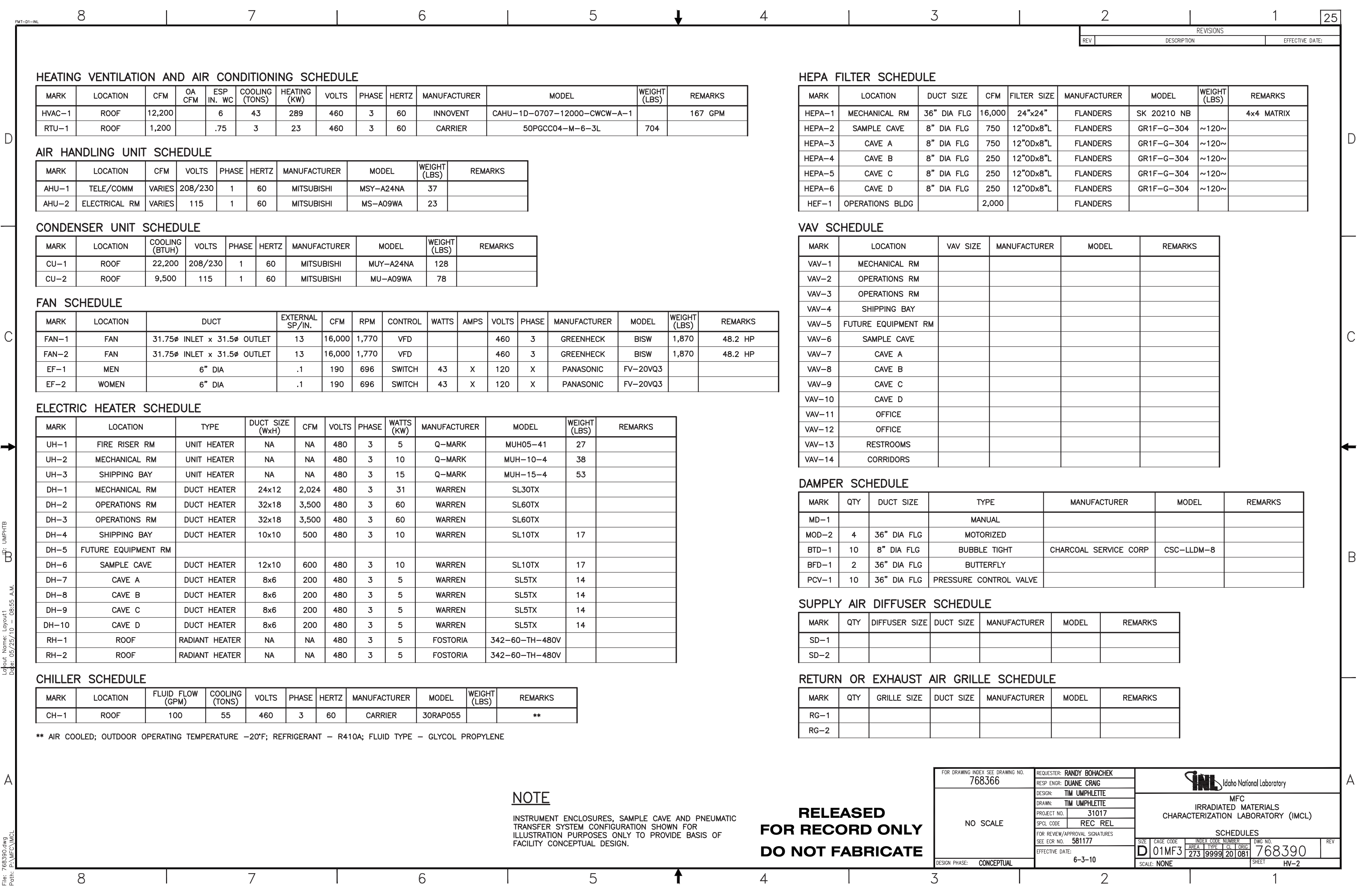




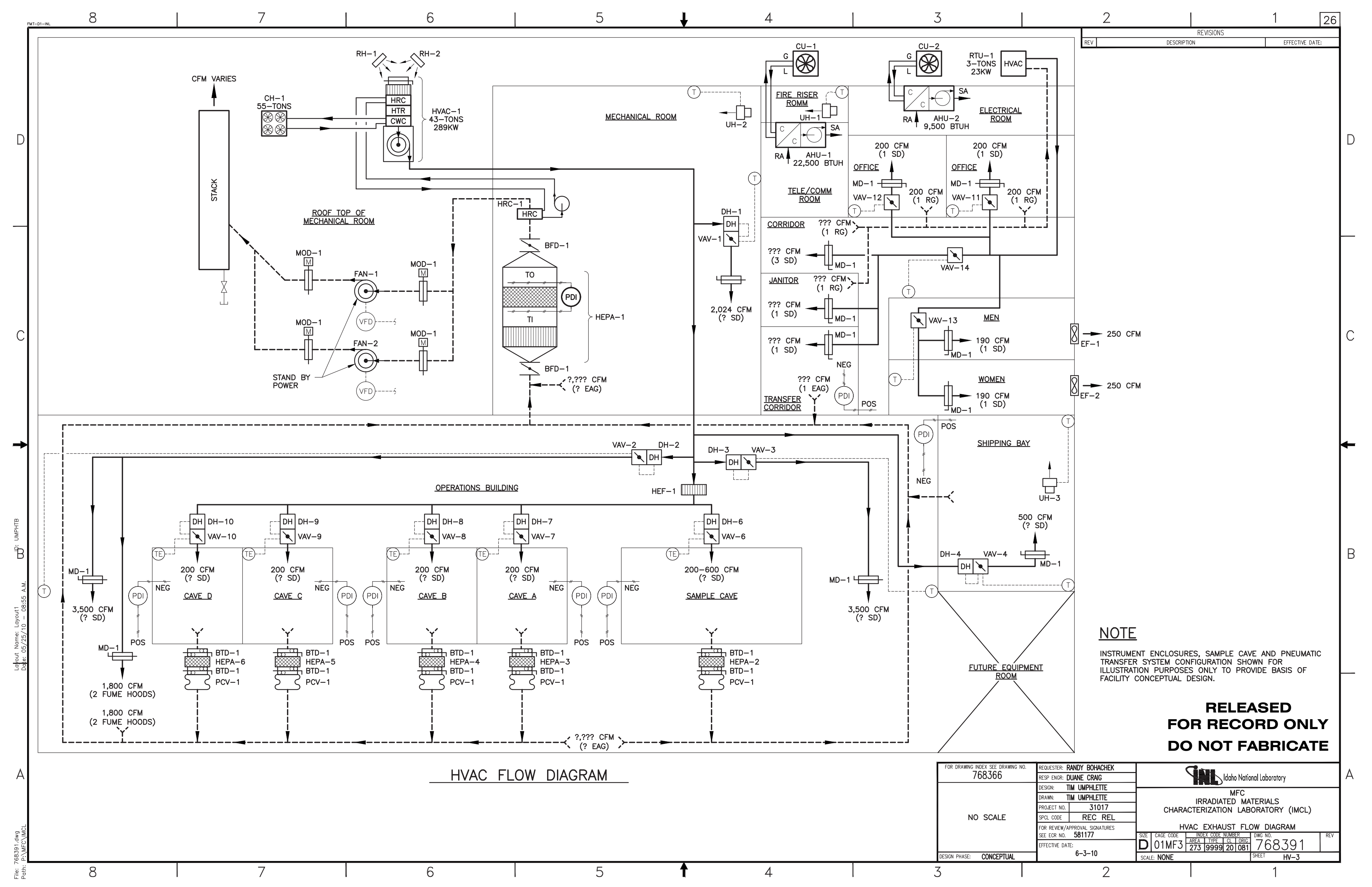




\begin{tabular}{|c|c|}
\hline & ELECTRICAL SYMBOL LEGEND \\
\hline SMBOL & DESCRPTION \\
\hline & CONTINUATION LINE \\
\hline$\frown-$ & CIRCUII BREAKER \\
\hline$m_{n}$ & TRANSFORMER \\
\hline 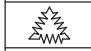 & HEATER \\
\hline op & AUTOMATIC TRANSFER SWITCH \\
\hline (1) & GENERATOR \\
\hline & 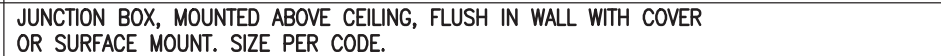 \\
\hline $\mathrm{s}$ & SINGLE POLE TOGGLE SWTCH, 20A, 120/277 VOLT \\
\hline$S_{\Phi}$ & OVERLAAD PROTECTION SWTCH \\
\hline$S_{3}$ & THREE-WAY TOGGLE SWTCH, 20A, 120/277 VOLT \\
\hline$S_{4}$ & FOUR-WAY TOGGLE SWTCH, 20A, 120/277 VOLT \\
\hline$S_{M}$ & $\begin{array}{l}\text { OCCUPANCY SENSOR (MOTION) WTH MANUAL OVER-RIDE SWTCH } \\
\text { 20A, 120/27TN FLORESCENT LGHTING COMPATBBEE }\end{array}$ \\
\hline - & PANELBOARD FLUSH OR SURFACE MOUNTED AS INOCACAED, REEER TO PANELBOARD SCHEDULES \\
\hline$\stackrel{\perp}{\equiv}$ & EQUPPMENT GROUND PER NEC SECTION 250 \\
\hline & RACEWAY INSTALLED CONCEALED IN WALLS AND/OR ABOVE CELLNG \\
\hline$\cdots$ & RACEWAY INSTALED CONCEALD IN/OR BELOW FLOOR SLAB OR BELOW GRADE \\
\hline & 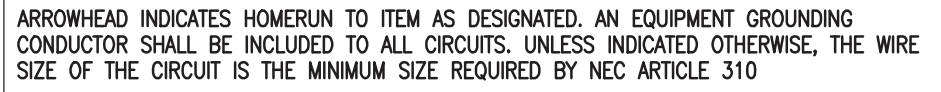 \\
\hline$\%$ & CONOUT TURNING UP/OR DOWN \\
\hline o & MOTOR CONNECTION \\
\hline$\square$ & 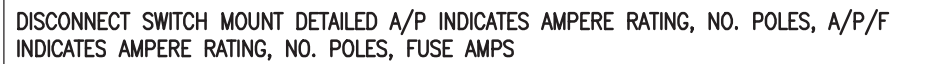 \\
\hline (4) & RECEPTACLE, 30A, 250V \\
\hline$\ominus$ & $\begin{array}{l}\text { RECEPAACLE, 20A, } 125 \text {, NEMA 5-20R GFI=GROUND FAULT CIRCUIT INTERRUPTER, } \\
\text { WPP=WEATHERPROOF WHLE IN USE COVER }\end{array}$ \\
\hline & 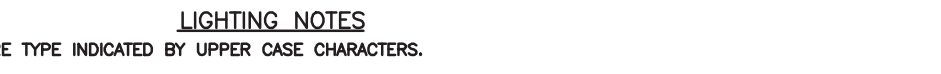 \\
\hline 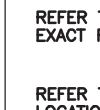 & 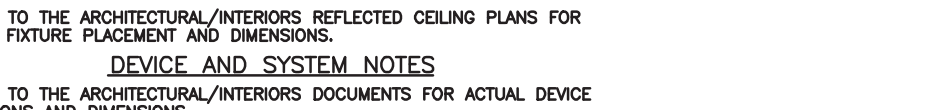 \\
\hline & 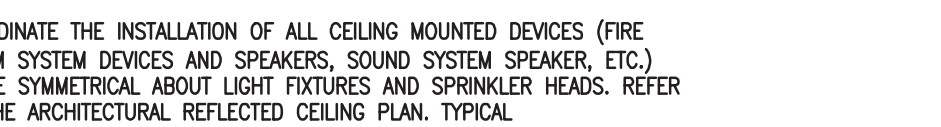 \\
\hline
\end{tabular}

ABBREVIATIONS

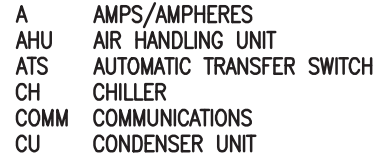

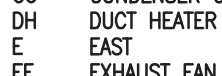

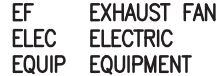

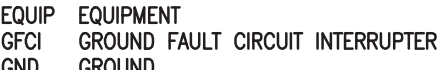

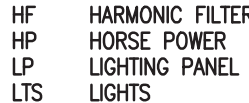

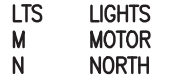

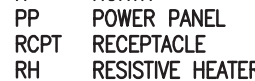

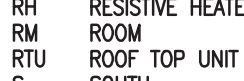

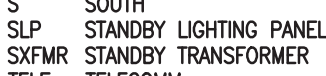

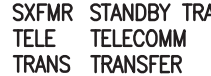

UP

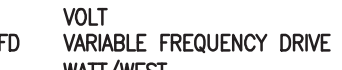

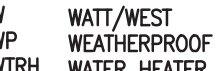

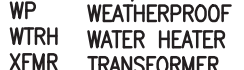

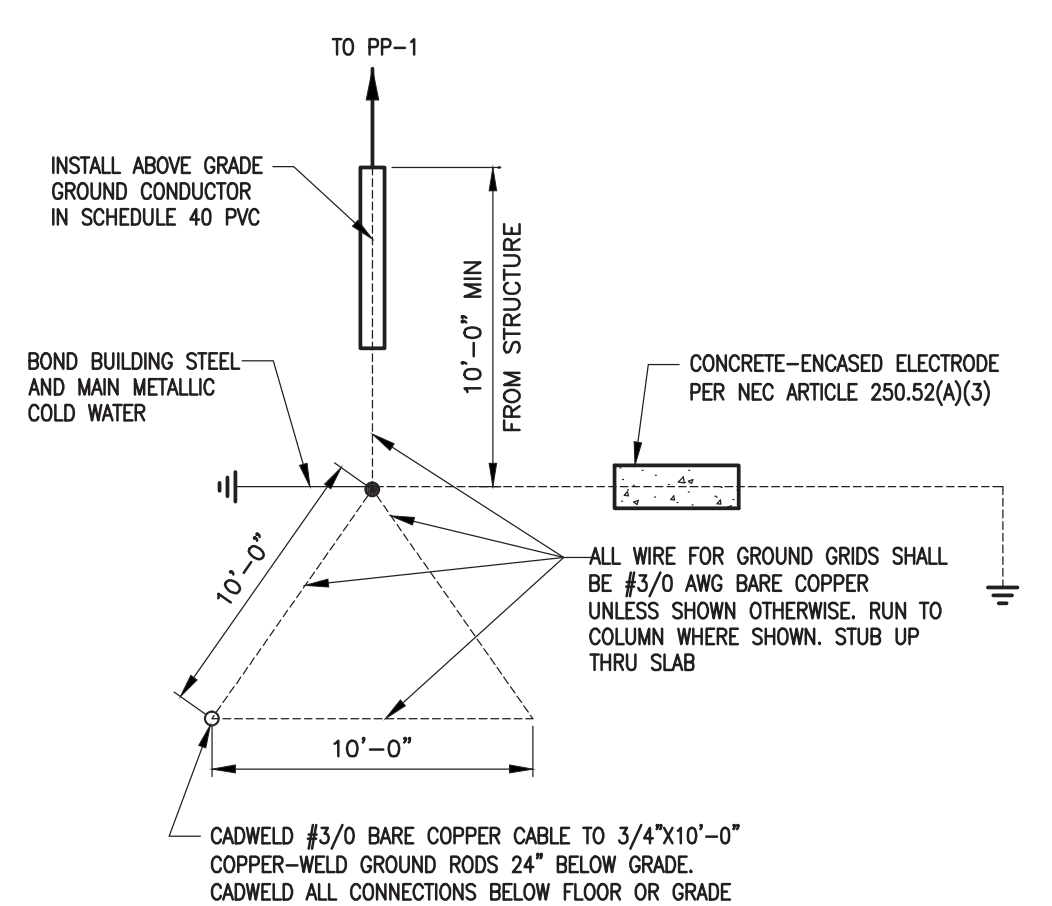

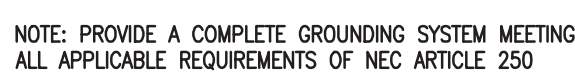

$\frac{\text { GROUND ROD GRID DETALIL }}{\text { SCALE: NONE }}$

\section{NOTE}

INSTRUMENT ENCLOSURES, SAMPLE CAVE AND PNEUMATIC

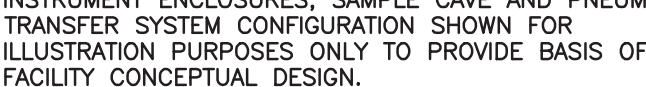

RELEASED FOR RECORD ONLY DO NOT FABRICATE

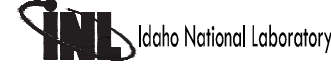

\begin{tabular}{|c|c|c|}
\hline 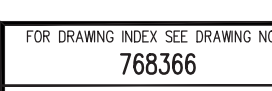 & 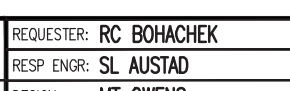 & 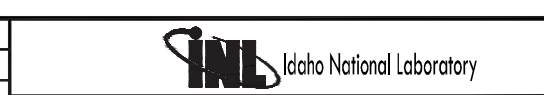 \\
\hline NO SCALE & 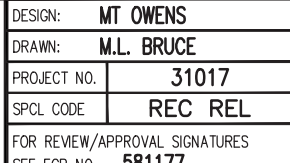 & 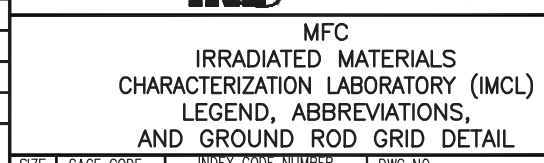 \\
\hline & 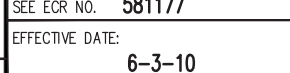 & 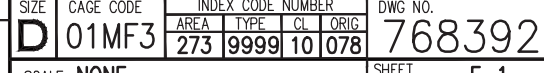 \\
\hline
\end{tabular}


败

2 


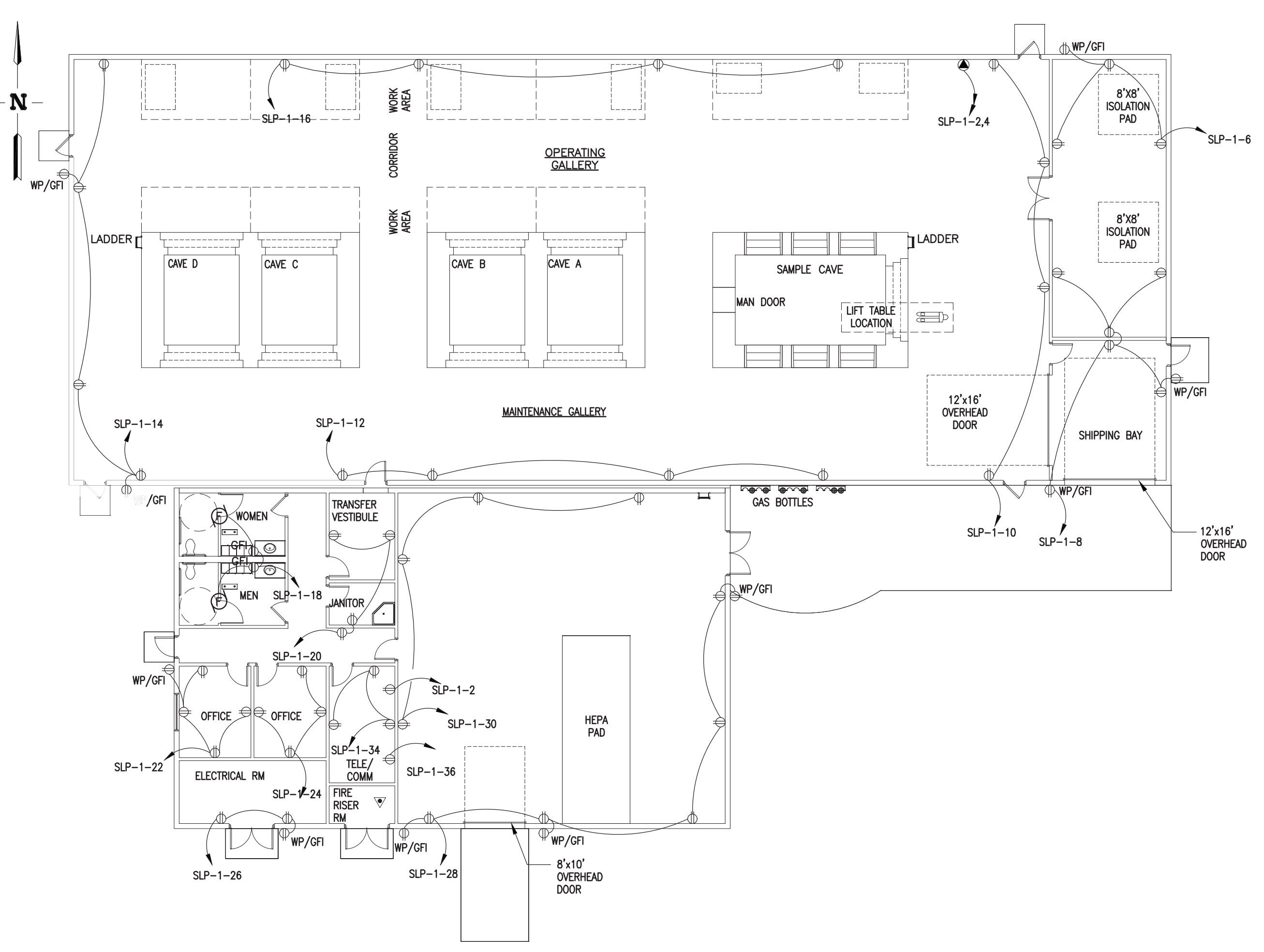

NOTE

INSTRUMENT ENCLOSURES, SAMPLE CAVE AND PNEUMATIC

INSTRUMENT ENCLOSURES, SAMPLE CAVE AND PNEUMATC
TRANSER SSSTEM CONEFGRATION SHOWN FOR
ILUSTRATION PUROOSOSE ONLY TO PROVIDE BASIS OF ILLUSTRATION PURPOSES ONYY
FACILIT CONCEPTUAL DESIGN.

LEGEND

$\theta \quad$ DUPLEX RECEPTACLE

$\ominus$ WEATHERPROOF, GFCI

RECEPTACLE PLAN

RELEASED FOR RECORD ONLY SCALE: $1 / 8^{\prime \prime}=1^{\prime}-0^{\prime \prime}$ DO NOT FABRICATE 


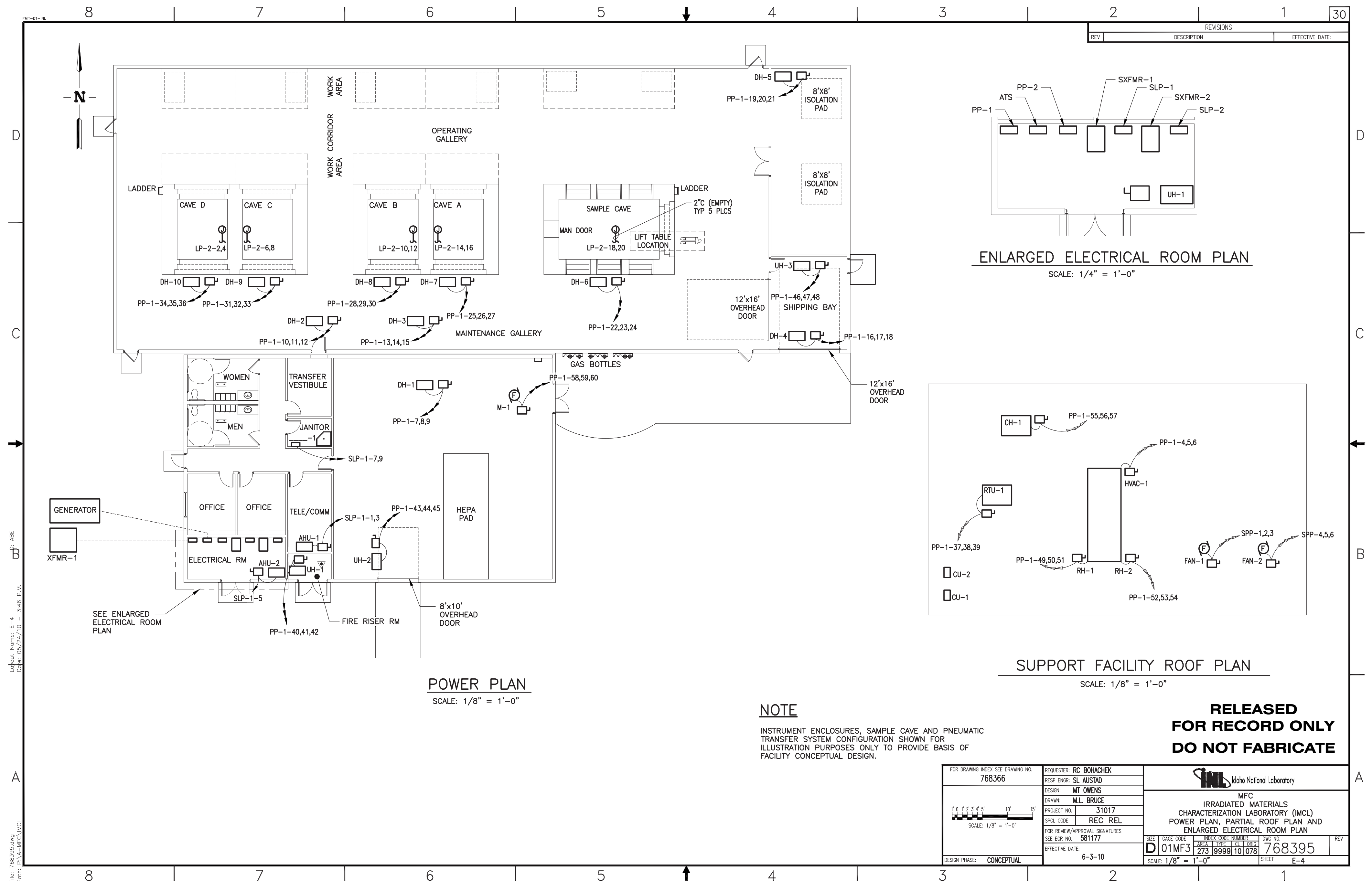




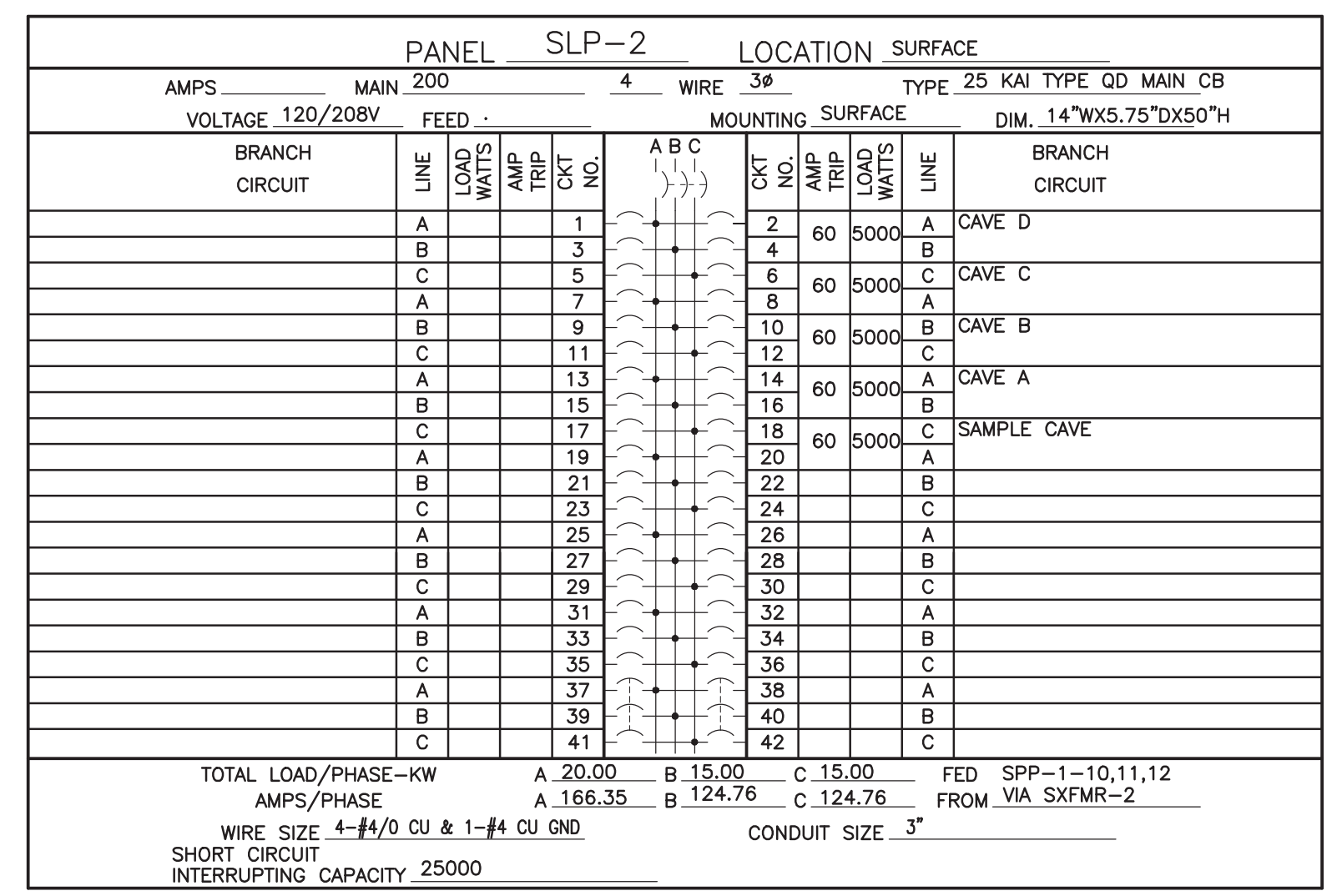

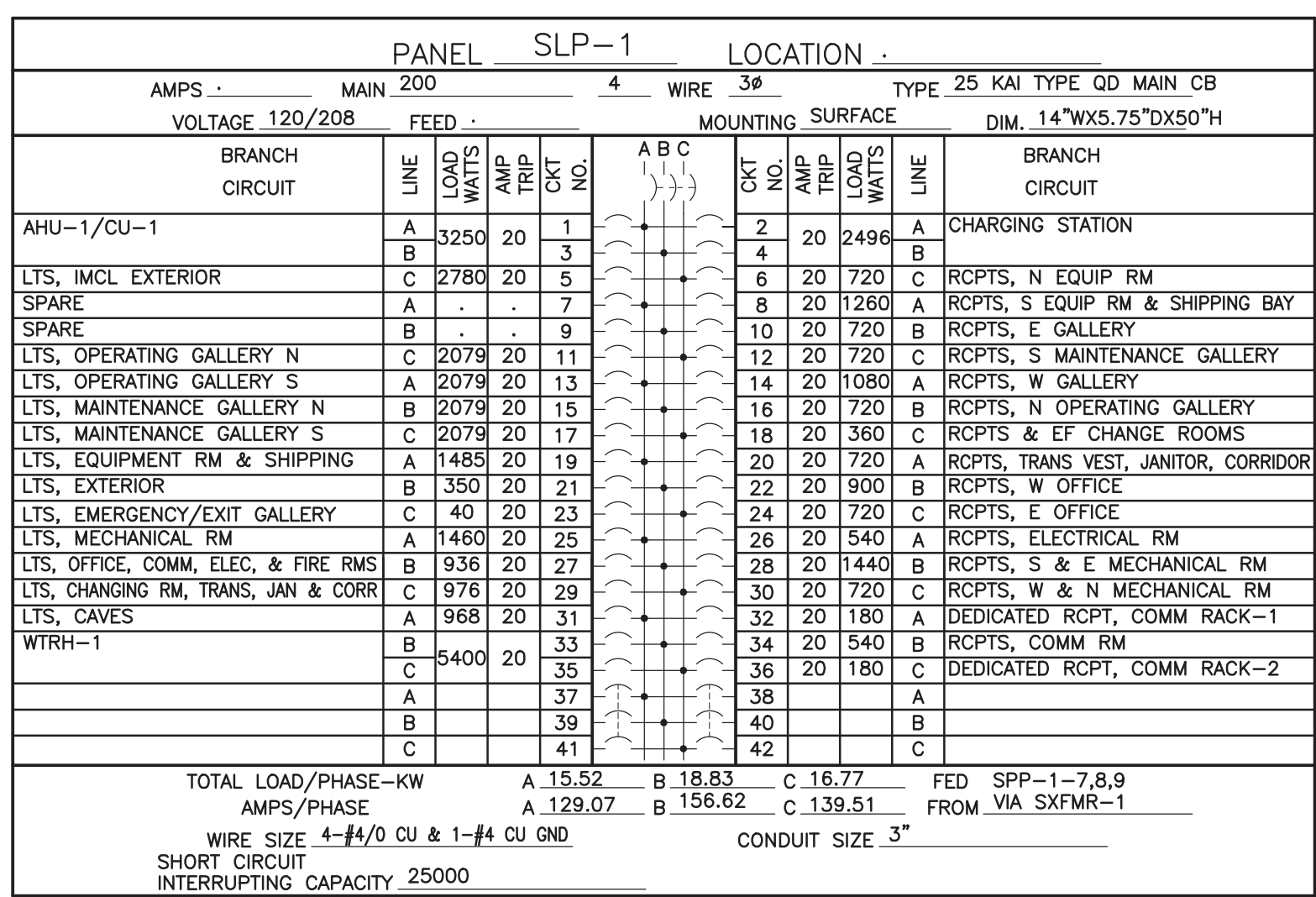

\begin{tabular}{|c|c|c|c|c|c|c|}
\hline \multicolumn{7}{|c|}{ LIGHTING FIXTURE SCHEDULE } \\
\hline TYPE] & MANUFACTURER & CATALOG PART \# & LAMPS & MOUNTING & DESCRIPTION & REMARKS \\
\hline A & LITHONIA & SB432 & (4)32WT8 & SURFACE & SQUARE-BACKET WRAP & 110W INCLUDING BALLAST \\
\hline$B$ & \begin{tabular}{l|l|l} 
LTHONIA \\
\end{tabular} & LB332 & (3)32WT8 & $\begin{array}{l}\text { SURFACE } \\
\end{array}$ & $\begin{array}{l}\text { LOW-PROFILE WRAPAROUND } \\
\end{array}$ & 88W INCLUDING BALLAST \\
\hline $\mathrm{c}$ & LITHONIA & CB232 & (2)32W18 & SURFACE & CORRIDOR, WRAPAROUND & 58W INCLUDING BALLAST \\
\hline D & LITHONIA & TWP70M & $70 \mathrm{M}$ & $\begin{array}{l}\text { WALL } \\
\end{array}$ & EXTERIOR, CAST, BULLDING MOUNTED, WALL-PAKS & 7OW METAL HALIDE WTH LAMP \& PHOTOELECTRIC CONTROL KIT \\
\hline E & LITHONIA & LQMSW2R120ELNSD & LED & WALL/CEILING & EXIT LIGHT & $\begin{array}{l}\text { DEDICATED CIRCUIT IN GALERE AND WIRED TO UN-SWTTCHED HOT } \\
\text { OF NEAREST LIGHTING CIRCUIT IN SUPPORT FACLITT. } 0.71 \mathrm{w} \\
\end{array}$ \\
\hline $\mathrm{F}$ & LITHONIA & EU2M6 & DC T5 & WALL & EGRESS LIGHT & $10.8 \mathrm{~W}$ \\
\hline$G$ & LITHONIA & TV 1000M GP2 TB SCWA & $1000 \mathrm{M}$ & CROSSARM & GALLERY HIGH BAY LIGHT & 1100W INCLUDING BALLAST \\
\hline
\end{tabular}

NOTE

CIRCUIT ALL EGRESS/EXIT LIGHTS IN SUPPORT FACLITT TO UN-SWITCHED HOT OF THE NEAREST LIGHTING CIRCUIT. EGRESS/EXIT
UGHTS IN GALLRY ARE ON A DEDICATED CIRCUIT. 1100W INCLUDING BALLAST

INSTRUMENT ENCLOSURES, SAMPLE CAVE AND PNEUMATIC

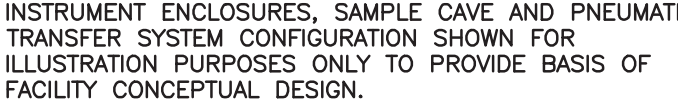

RELEASED

FOR RECORD ONLY DO NOT FABRICATE

STID Idaho National laboratory

IRRADIATED MATERIALS
CHARACERIATION LABORATORY (IMCL)

LIGHTNG PLAN

\begin{tabular}{|c|c|c|}
\hline 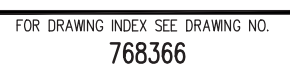 & 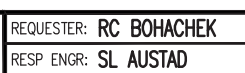 & GII ldath National laboctory \\
\hline \multirow{4}{*}{ 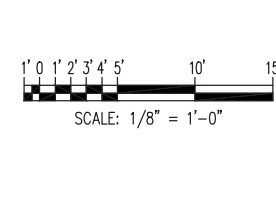 } & 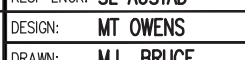 & \\
\hline & 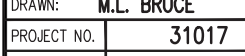 & $\begin{array}{l}\text { IRRRDATED MATERALLS } \\
\text { CHARACERIATION LABORTTRY (IMCL) }\end{array}$ \\
\hline & 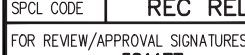 & LGHTING PLAN \\
\hline & & 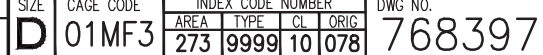 \\
\hline IN PHASE & $6-3-10$ & SCAE: $1 / 8^{\prime \prime}=1^{1}-0$ \\
\hline
\end{tabular}

